\title{
Mechanical Properties and Deformation Behavior of Additively Manufactured 316L Stainless Steel - FY 2020
}

Approved for public release. Distribution is unlimited.
T. S. Byun

M. N. Gussev

T. G. Lach

M. Li

X. Zhang

M. R. McAlister

J. J. Simpson

B. E. Garrison

Y. Yamamoto

C. B. Joslin

J. K. Carver

F. A. List

R. R. Dehoff

K.A. Terrani

June 30, 2020

M2TC-20OR0403014 
DOCUMENT AVAILABILITY

Reports produced after January 1, 1996, are generally available free via US Department of Energy (DOE) SciTech Connect.

Website www.osti.gov

Reports produced before January 1, 1996, may be purchased by members of the public from the following source:

National Technical Information Service

5285 Port Royal Road

Springfield, VA 22161

Telephone 703-605-6000 (1-800-553-6847)

TDD 703-487-4639

Fax 703-605-6900

E-mail info@ntis.gov

Website http://classic.ntis.gov/

Reports are available to DOE employees, DOE contractors, Energy Technology Data Exchange representatives, and International Nuclear Information System representatives from the following source:

Office of Scientific and Technical Information

PO Box 62

Oak Ridge, TN 37831

Telephone 865-576-8401

Fax 865-576-5728

E-mail reports@osti.gov

Website http://www.osti.gov/contact.html

\begin{tabular}{l}
\hline This report was prepared as an account of work sponsored by an \\
agency of the United States Government. Neither the United States \\
Government nor any agency thereof, nor any of their employees, \\
makes any warranty, express or implied, or assumes any legal liability \\
or responsibility for the accuracy, completeness, or usefulness of any \\
information, apparatus, product, or process disclosed, or represents \\
that its use would not infringe privately owned rights. Reference herein \\
to any specific commercial product, process, or service by trade name, \\
trademark, manufacturer, or otherwise, does not necessarily constitute \\
or imply its endorsement, recommendation, or favoring by the United \\
States Government or any agency thereof. The views and opinions of \\
authors expressed herein do not necessarily state or reflect those of \\
the United States Government or any agency thereof.
\end{tabular}


Transformational Challenge Reactor

\title{
Mechanical properties and Deformation Behavior of Additively Manufactured 316L Stainless Steel - FY 2020
}

T.S. Byun, M. N. Gussev, T. G. Lach, M. R. McAlister, J. J. Simpson, B. E. Garrison, Y. Yamamoto, C. B. Joslin, J. K. Carver, F. A. List, R. R. Dehoff, K. A. Terrani

Oak Ridge National Laboratory

M. Li, X. Zhang

Argonne National Laboratory

Date Published: June 30, 2019

M2TC-20OR0403014

\author{
Prepared by \\ OAK RIDGE NATIONAL LABORATORY \\ Oak Ridge, TN 37831-6283 \\ managed by \\ UT-BATTELLE, LLC \\ for the \\ US DEPARTMENT OF ENERGY \\ under contract DE-AC05-00OR22725
}





\section{CONTENTS}

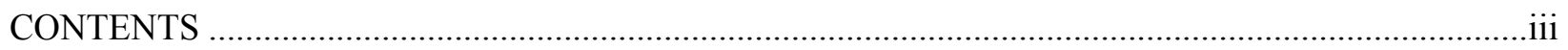

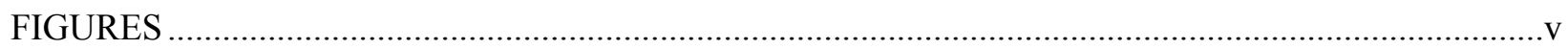

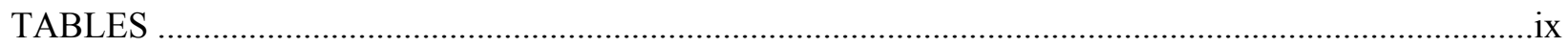

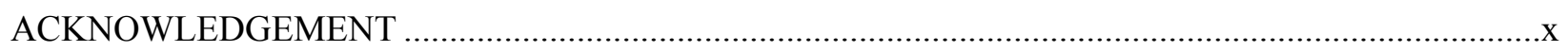

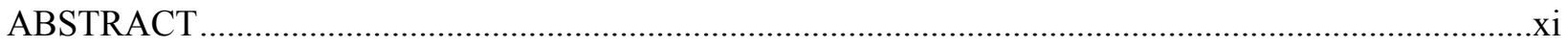

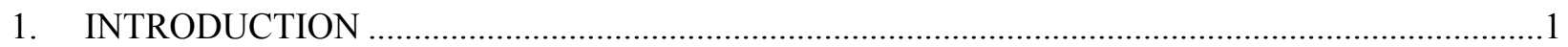

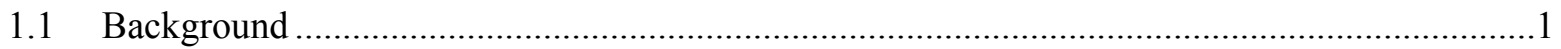

1.2 Document Purpose and Applications ..............................................................................2

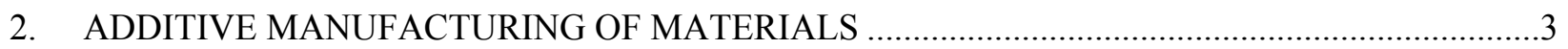

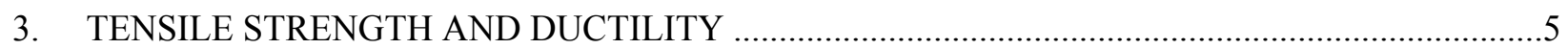

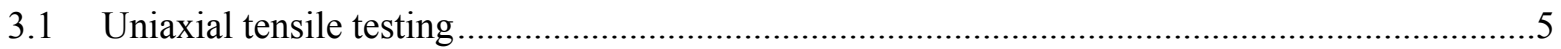

3.2 Temperature Dependence of Strength.............................................................................

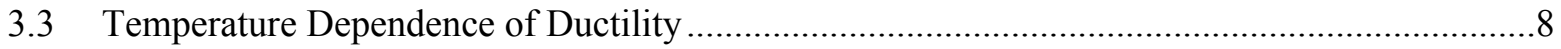

3.4 Statistics of Room Temperature Tensile Properties.................................................................10

3.5 Effect of Post-Build Processing on Tensile Properties .............................................................11

4. CREEP PROPERTIES and DEFORMATION BEHAVIOR .......................................................13

4.1 Creep Testing of AM 316L with and without Post-Build Heat Treatment...............................13

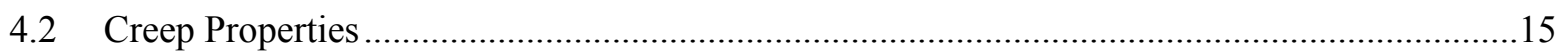

4.3 Microstructures of AM 316L before and after Creep Deformation ........................................20

4.4 Tensile Properties of AM 316L at a Creep Test Temperature ................................................26

4.5 In-Situ High-Energy X-Ray Analysis of Plastic Deformation in AM 316L............................29

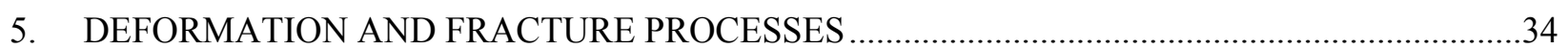

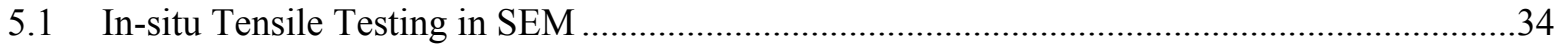

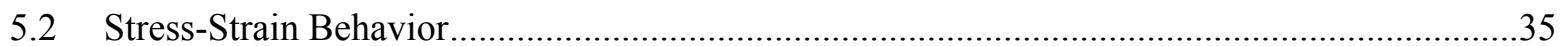

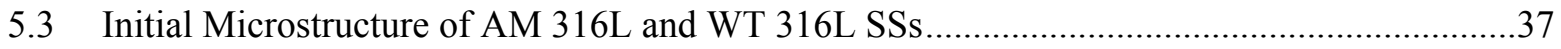

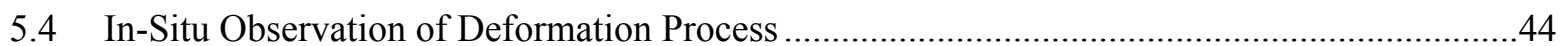

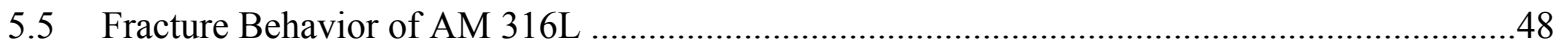

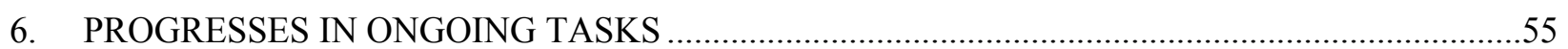

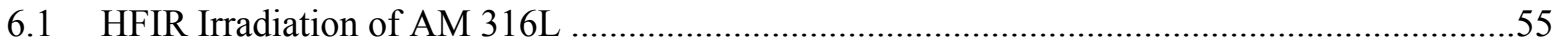

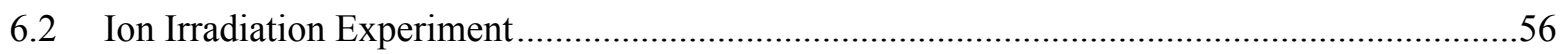

6.3 Small Ball Punch Testing of 316L and IN718 Alloys ........................................................56

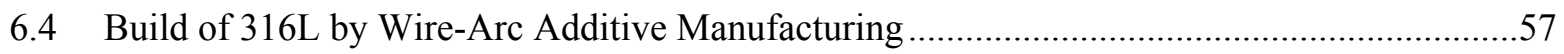

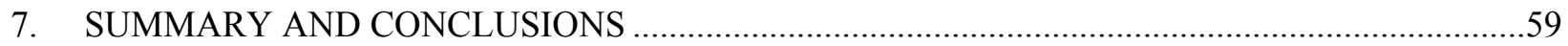

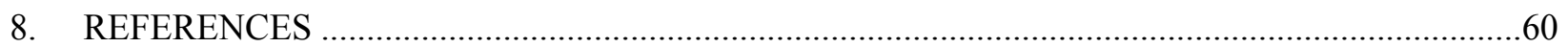




\section{FIGURES}

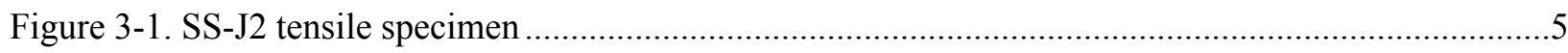

Figure 3-2. Comparison of the engineering stress-strain curves of AM 316L (as-built) and

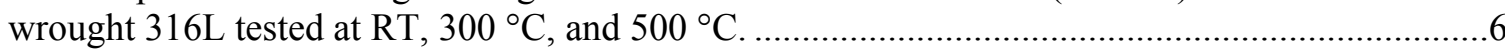

Figure 3-3. Temperature dependence of YS in 316L stainless steels after four different processing

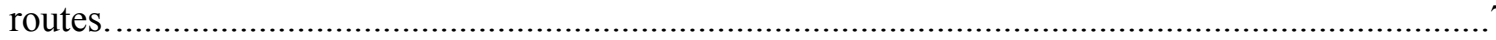

Figure 3-4. Temperature dependence of UTS in 316L stainless steels after four different

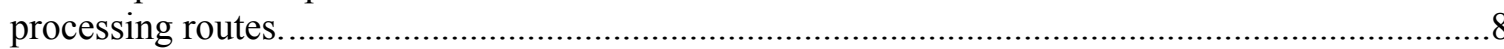

Figure 3-5. Temperature dependence of UE in 316L stainless steels after four different processing routes.

Figure 3-6. Temperature dependence of TE in 316L stainless steels after four different processing

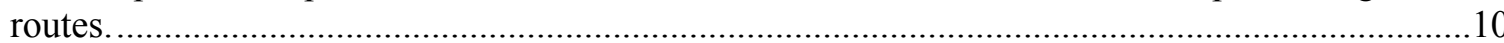

Figure 4-1. Schematic of the ASTM round bar creep specimen (unit: in).............................................13

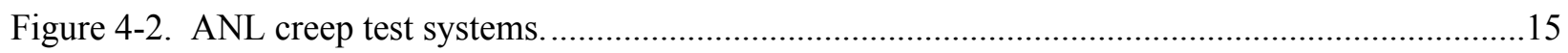

Figure 4-3. Creep strain as a function of time for AM 316L SS tested at $550{ }^{\circ} \mathrm{C}$ and $275 \mathrm{MPa}$...............16

Figure 4-4. Creep rupture data for AM 316L SS tested at $550{ }^{\circ} \mathrm{C}$ and $275 \mathrm{MPa}$..................................16

Figure 4-5. Minimum creep strain rates for AM 316L SS tested at $550{ }^{\circ} \mathrm{C}$ and $275 \mathrm{MPa}$.....................17

Figure 4-6. Photographs of the AM 316L SS creep-ruptured specimens. ..............................................17

Figure 4-7. Creep rupture data for AM 316L SS tested at 550 and $650{ }^{\circ} \mathrm{C}$ and comparison with

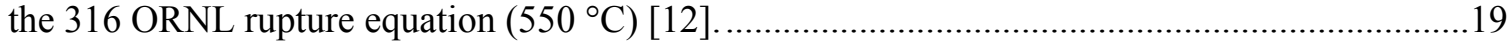

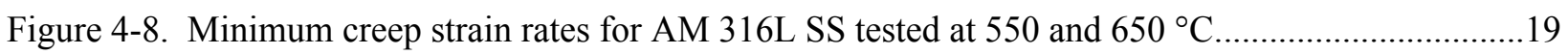

Figure 4-9. TEM micrographs showing the microstructure of the as-built AM 316 L SS (Laser 1 Build 20190308)

Figure 4-10. High-angle annular dark field (HAADF) micrograph and EDS elemental maps of the as-built AM $316 \mathrm{~L}$

Figure 4-11. TEM micrographs showing the microstructure of the AM 316L steel heat treated at $1,050{ }^{\circ} \mathrm{C} / 1 \mathrm{~h}$. The TEM specimen was taken from the grip section of specimen L205.

Figure 4-12. HAADF micrograph and EDS elemental maps of the AM 316L heat treated at 1,050

${ }^{\circ} \mathrm{C} / 1 \mathrm{~h}$. The TEM specimen was taken from the grip section of specimen L205.

Figure 4-13. Particle size distributions in the as-built condition (mean size $=25 \mathrm{~nm}$ ) (top) and in the $1,050{ }^{\circ} \mathrm{C} / 1 \mathrm{~h}$ heat treated condition (mean size $=87 \mathrm{~nm}$ ) (bottom).

Figure 4-14. TEM micrographs showing the microstructure of the as-built AM 316L after creep test at $550{ }^{\circ} \mathrm{C} / 275 \mathrm{MPa}$. TEM specimen was taken from the gauge section of specimen L204.

Figure 4-15. TEM images showing the microstructures of the $650^{\circ} \mathrm{C} / 1 \mathrm{~h}$ heat-treated AM $316 \mathrm{~L}$ after testing at $550{ }^{\circ} \mathrm{C} / 275 \mathrm{MPa}$. The under-focus, over-focus, and in-focus images show voids or precipitates inside a grain. Sample was taken from the gauge section of specimen L206.

Figure 4-16. TEM images showing the microstructures of the $1,050^{\circ} \mathrm{C} / 1 \mathrm{~h}$ heat-treated $\mathrm{AM} 316 \mathrm{~L}$ after creep test at $550{ }^{\circ} \mathrm{C} / 275 \mathrm{MPa}$. Sample was taken from the gauge section of specimen L205. 
Figure 4-17. Specimen fabrication drawings showing the orientation and location of each specimen (top); an SS-3 sheet-type specimen design for the top section of the printed rod (bottom); specimens for the middle and bottom sections were designed to be slightly shorter (1.15 and 1.12 in., respectively) for good traceability (unit: in.).

Figure 4-18. Engineering stress-strain curves at $550{ }^{\circ} \mathrm{C}$ for specimens taken from the top and bottom sections of rod L1-8.

Figure 4-19. Illustration of location-dependent UE and TE values in the printed rod L1-8. Tensile tests were conducted at $550{ }^{\circ} \mathrm{C}$.

Figure 4-20. (a) In-situ x-ray experiment setup, and (b) RT stress-strain curves of the conventional $316 \mathrm{H}$ and the AM 316L.

Figure 4-21. The lattice strain (a) and the FWHM (b) as a function of true strain for peaks 3-8 of the AM 316L sample.

Figure 4-22. X-ray radiographs of the gage area of AM 316L showing the internal porosity at different deformation levels.

Figure 5-1. TESCAN MIRA3 SEM (top): the inset (top) shows an Oxford EBSD detector in working position; K\&W tensile stage installed in the SEM chamber (bottom left) and master grip set for SS-J tensile specimen (bottom right).

Figure 5-2. Tensile curves for the ex-situ (thin, smooth lines) and in-situ (thick red line with relaxation segments) tests. The step S00 or reference step corresponds to zero stress and strain; the steps S01-S13 indicate deformation steps in the experiment.

Figure 5-3. Engineering stress-strain curves for the AM 316L specimens in as-built, stressrelieved, and solution-annealed conditions, compared with that of the reference material (wrought $316 \mathrm{~L}$ steel).

Figure 5-4. A representative grain structure in the as-built AM 316L steel shown in EBSD IPF, IQ, GROD, and KAM maps. This area is also an ROI for tracking during the in-situ test.

Figure 5-5. The microstructures (EBSD IPF maps) of AM-316L in different conditions. The building direction $(Z)$ is horizontal. The EBSD IPF maps are colored relative to the building (horizontal) direction.

Figure 5-6. Grains extracted from the IPF map EBSD dataset for the as-built AM 316L steel (in Figure 5-4). To highlight grain shape only, one uniform in-grain color is used instead of a standard IPF color key.

Figure 5-7. Detailed maps of a grain extracted from the EBSD dataset shown in Figure 5-4. The in-grain IPF color variations and the KAM and GROD maps suggest multiple in-grain low-angle boundaries $\left(\sim 1\right.$ to $\left.\sim 3^{\circ}\right)$ as a feature of concentrated dislocations.

Figure 5-8. Grain boundary network in AM 316L in as-built condition. Black indicates RHABs, and green indicates random low-angle boundaries (RLABs). The red lines indicate twin $(\Sigma 3)$ grain boundaries. Other grain boundary types (e.g., $\Sigma 9$ or $\Sigma 27$ ) are considered as RHAB for simplicity. Blue lines starting from the top of the image illustrate the RHAB walking exercise. An inset at the right bottom shows the GB structure in wrought steel with the same color coding but at a different scale.

Figure 5-9. Cr segregation to dislocation cell structure walls in both (a) as-built and (b) stressrelieved conditions; solution annealing at $1,050{ }^{\circ} \mathrm{C}$ (not shown) removes cellular structure. 
Figure 5-10. STEM-EDS maps showing nanoscale oxide inclusions in all conditions. In the (a) as-built and (b) stress-relieved conditions, Si/Mn-rich oxides decorate cell boundaries. (c) After solution annealing at $1,050{ }^{\circ} \mathrm{C}$, the oxides transform from Si-rich to $\mathrm{Cr}$-rich.

Figure 5-11. TKD analysis found grains of body-centered cubic ferrite in the as-built structure, but not in either of the annealed structures.

Figure 5-12. EBSD IPF maps recorded at different steps of the in-situ SEM-EBSD tests for the as-built AM 316L steel. The zero step (S00) corresponds to the structure shown in Figure 5-4, and the tensile curve for the test is given in Figure 5-2...

Figure 5-13. Evolution of in-grain structure during plastic deformation (grain shown here is

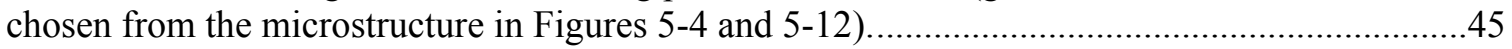

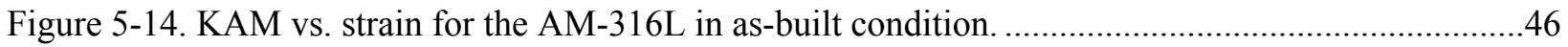

Figure 5-15. Fine needle-like twins in the as-built AM 316L steel (step 4). The inverse pole figure at the right shows the orientation of the parent grain with respect to the tensile axis.

Figure 5-16. STEM BF, LAADF, and HAADF imaging of the structure of (a) as-built, (b) stressrelieved, and (c) solution-annealed AM 316L SSs.

Figure 5-17. Fracture surfaces for the AM 316L specimens in different conditions. White arrows point to mesoscale defects $(\sim 20-40 \mu \mathrm{m})$, and black arrows point macroscale defects $(>$ $\sim 0.1 \mathrm{~mm})$.

Figure 5-18. A fracture surface of as-built AM 316L steel in which two mesoscale pores (see also Figure 5-17) are overlapped with EDS maps (oxygen, aluminum, and silicon).

Figure 5-19. Mesoscale defects (pores and delaminations) at the surface of the as-printed AM 316L steel after deformation. A cracked non-metallic inclusion is visible in the bottom right image.

Figure 5-20. Evolution of a mesoscale pre-existing defect in AM-316L (stress-relieved at 650 ${ }^{\circ} \mathrm{C}$ ). The defect grows via a cracking mechanism of ductile tearing into surrounding material.

Figure 5-21. The appearance of a macro-defect, Dm (size $\sim 0.12-0.15 \mathrm{~mm}$ ) at the specimen surface during the in-situ testing of AM 316L steel annealed at $650{ }^{\circ} \mathrm{C}$.

Figure 5-22. Fracture surfaces of 316L SSs at a high magnification. Only ductile dimples are observed for all conditions tested, but with different sizes and morphologies.

Figure 5-23. High magnification SEM images showing the presence of small, round-shaped particles (indicated by black arrows) inside the dimples. The reference steel has mostly clear, particle-free dimples, with only one fine object visible.

Figure 6-1. A thin AM 316L sheet $(0.5 \times 45 \times 120 \mathrm{~mm})$ before (top) and after (bottom) small ball punch testing.

Figure 6-2. A trial L-shape block made of 316L SS. Black lines indicates printing paths, and the red line contains the locations for metallographic characterization.

Figure 6-3. Color contour maps showing 2D hardness distribution in the cross sections of the asprinted 316L SS block with printing conditions of (a) block 265 and (b) the Rapid X block. 


\section{TABLES}

Table 2-1. Summary of metallic materials used for testing and evaluation..............................................

Table 2-2. Chemical composition of Praxair 316L powder used for AM (in wt \%) ....................................

Table 2-3. Chemical composition of the reference (wrought) 316L SS (in wt \%) ......................................4

Table 2-4. Composition of IN 718 powder used for AM (in wt\%) .......................................................

Table 3-1. Summary of RT tensile property data from SS-J2 tensile specimens: mean values and

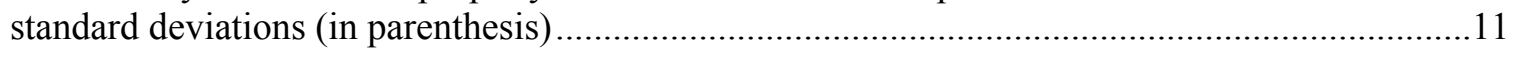

Table 3-2. Post-build heat treatments for AM 316L SSs .......................................................................11

Table 3-3. Summary of RT tensile property data from standard sized specimens: mean values and

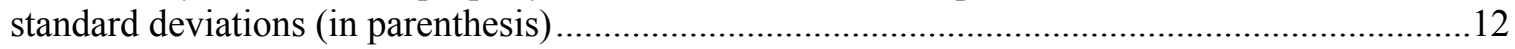

Table 4-1. List of ASTM-standard round bar creep specimens with test conditions..................................14

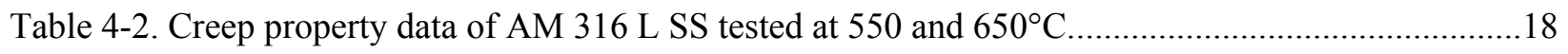

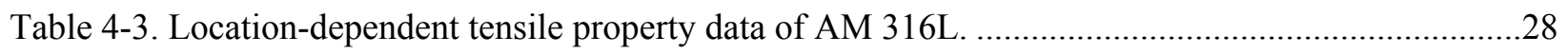

Table 4-4. Tensile properties obtained from the in-situ x-ray experiment ...............................................30

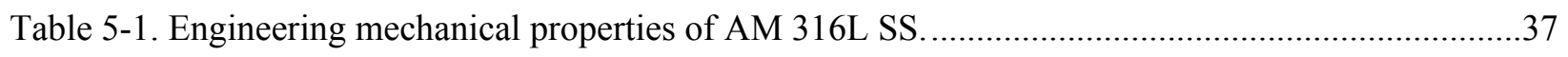

Table 6-1. SS-J2 tensile specimens being irradiated in ongoing irradiation experiment...........................55

Table 6-2. RT tensile properties of as-printed 316L SS with Rapid X ................................................58 


\section{ACKNOWLEDGEMENT}

This research was supported by the Transformational Challenge Reactor program supported by the US Department of Energy, Office of Nuclear Energy. The report was authored by UT-Battelle under Contract No. DE-AC05-00OR22725 with the DOE. 


\title{
Mechanical Properties and Deformation Behavior of Additively Manufactured 316L Stainless Steel - FY 2020
}

\begin{abstract}
The Transformational Challenge Reactor (TCR) program plans to build most of the TCR core components through additive manufacturing (AM) processes. These processes include laser powder bed fusion (LPBF) for the metallic (316L) components and the newly developed combined process of binderjet printing and chemical vapor infiltration (CVI) for the $\mathrm{SiC}$ fuel matrix. Mechanical testing and characterization tasks have been carried out since the beginning of the TCR program to (1) build a property database for the AM materials that will be used in TCR core and (2) to assess the materials' performance in TCR-relevant conditions. This document reports the outcome of the testing and characterization efforts for the fiscal year with a focus on the mechanical performance data of AM 316L stainless steel (SS). Baseline tensile testing over a wide temperature range of room temperature- $600{ }^{\circ} \mathrm{C}$ was completed for the AM 316L alloy in as-built, stress-relieved, and solution-annealed conditions. The as-built 316L showed the highest strength, and the alloy after the post-build treatments showed reduced strengths in the low-strain range. However, the strength differences among the AM materials became insignificant in the later part of deformation. Furthermore, regardless of post-build processing, the AM 316L SS showed higher strength and comparable ductility when compared with wrought 316L SS. Thermal creep testing and microstructural evolution during creep deformation were also performed under selected conditions. It was found that the AM $316 \mathrm{~L}$ steel showed the best creep resistance in the stressrelieved condition. In-situ tensile tests were performed using scanning electron microscopy and 1-ID beamline at the Advanced Photon Source to elucidate the deformation and fracture behavior of AM 316L and the evolution of crystalline stress, dislocations, and pore distribution. Using these in-situ testing data, an in-depth analysis of the roles of microstructural features in deformation and fracture processes is presented herein. The final section of the document introduces ongoing and future activities for materials testing and characterization, including irradiation effect studies and ball punch testing on AM 316L and AM IN718 alloys.
\end{abstract}




\section{INTRODUCTION}

\subsection{Background}

A key purpose of the Transformational Challenge Reactor (TCR) program is to build most reactor core components using additive manufacturing (AM) technologies. The main metallic components that constitute the TCR core structures will be the $316 \mathrm{~L} \mathrm{SS}$ parts printed using the laser powder bed fusion (LPBF) process [1]. The structural integrity of these components is of high importance for the reactor core, as they transfer the coolant medium and support the main core components, including the fuel and moderator assembly.

There are many opportunities and challenges in using AM technologies to build a nuclear reactor core. AM technologies provide enormous flexibility in building and designing components that could not be produced previously or that would have been cost prohibitive to build. Materials properties can be tailored based on AM processing parameters such as scan speed, laser power, powder feedstock purity, and powder layer thickness [2,3]. However, there are also many unknowns regarding the microstructural and chemical stability of AM materials in high temperature, corrosion, and irradiation environments. This document provides baseline mechanical properties and microstructural characterization data obtained after building, annealing, and/or deformation of AM 316L SSs in preparation for post-irradiation testing and examination.

Austenitic SSs like grade 316L SS processed using conventional metallurgical techniques are widely used in nuclear power plants because they provide a good combination of strength, ductility, and corrosion resistance. Additive manufacturing of such alloys has also been studied extensively in recent years for application to nuclear reactor components; it has been observed to have increased room temperature (RT) yield strength but less work hardening due to a characteristic microstructure of fine grains and dislocation cells formed during the localized rapid solidification [4-7]. On the other hand, the fracture toughness of AM 316L SS could be negatively affected by the increased porosity from the build process, structural anisotropy relative to the build direction, and inclusions from impurities in the feedstock powder [2,8]. These factors could also be significantly impacted by neutron or ion irradiation [9,10]. Since AM processes allow the microstructure to be tailored by changing processing parameters, the size and orientation of cell structures can be controlled [11]. The extensive knowledge of conventionally manufactured 316L SS combined with a well-established AM processing route makes the 316L alloy an ideal structural material for the TCR program's fast turnaround effort.

This document builds on the first version of the handbook of properties and microstructural characterization for the AM 316L SS [1]. During this fiscal year, the ex-situ tensile testing and creep testing were the main activities performed to determine tensile and creep properties. This report includes the mechanical testing results of the AM 316L SS in the as-built condition, in the stress-relieved condition (annealed at $650{ }^{\circ} \mathrm{C}$ for 1 hour), and in the solution-annealed condition (annealed at $1,050^{\circ} \mathrm{C}$ for 1 hour) at room and elevated temperatures. Additionally, the effects of other treatments, such as the anneals at $1,100{ }^{\circ} \mathrm{C}$ with pressure (i.e., hot isostatic pressing [HIP]) or without pressure, were also investigated, and the results are summarized herein. In-situ mechanical testing of the as-built and annealed AM 316 SSs was performed in a high-energy source x-ray scattering beamline at the Advanced Photon Source (APS) at Argonne National Laboratory (ANL) and in a scanning electron microscope (SEM), along with scanning transmission electron microscopy (STEM). These tests were conducted to analyze deformation and fracture mechanisms 
as a function of grain size, texture, and porosity. All of these outcomes will be used for baseline comparisons with the properties and behavior after neutron irradiation that has recently finished low dose cycles in the High Flux Isotope Reactor (HFIR) at Oak Ridge National Laboratory (ORNL).

\subsection{Document Purpose and Applications}

The purpose of this document is to quantify and summarize the mechanical property and microstructural characterization data of AM 316L SS in various conditions. Along with 3D-printed $\mathrm{SiC}$, the AM 316L SS components will be one of the most important core structural materials in the TCR. This document is intended for use by the core component manufacturers, modelers, and reactor designers in the TCR program and other researchers.

This document is primarily intended to inform the TCR design community on the material performance of candidate materials and manufacturing processes, but it can also be used for future reactor designs or applications for which the materials and manufacturing processes presented here are of interest. 


\section{ADDITIVE MANUFACTURING OF MATERIALS}

The AM metallic materials used for testing and evaluation in this fiscal year and planned for later years of the TCR program are summarized in Table 2-1. For the remainder of the document, the Build IDs, which are based on printing dates, will be used as material identifiers connected to the mechanical property and characterization data in program records. Table 2-1 lists all builds of metallic materials from which samples have been taken for the testing and characterization tasks for the year and for continuing tasks. All of these builds were fabricated using the LPBF process in two AM systems.

The Concept Laser M2 system was used to print all 316L builds listed in Table 2-1. This two-laser system has the added benefit of using two identical laser systems on different sections of the powder bed to fabricate larger or multiple components. This also enables a direct one-to-one batch variability within a single build while holding all other variables constant. The $316 \mathrm{~L}$ builds listed in Table 2-1 used the same powder feedstock with the nominal composition specified in Table 2-2. In addition to the AM 316L materials, the wrought (WT) 316L SS was also tested to obtain reference datasets for comparison. The chemical composition of the WT 316L is given in Table 23. The Concept Laser X Line 2000R system was used for manufacturing 0.5-10 mm thick IN718 plates. The chemical composition of IN718 powder is given in Table 2-4. For these builds, the vendor-recommended processing parameters were used and were held constant across the manufacturing of all parts.

Table 2-1. Summary of metallic materials used for testing and evaluation

\begin{tabular}{|c|c|c|c|c|c|}
\hline Build ID & $\begin{array}{c}\text { AM tech } \\
\text { Model }\end{array}$ & $\begin{array}{l}\text { Alloy/ } \\
\text { powder } \\
\text { supplier }\end{array}$ & Post-processing & Geometry & Purpose \\
\hline \multirow[t]{2}{*}{20190308} & LPBF & \multirow[t]{2}{*}{ 316L/Praxair } & \multirow{2}{*}{$\begin{array}{l}\text { - As-built, } \\
\text { - Stress-relieved } \\
\text { - Solution-annealed }\end{array}$} & \multirow{2}{*}{$\begin{array}{l}\text { Round bar, } \\
\text { thick plate, } \\
\text { others }\end{array}$} & \multirow{2}{*}{$\begin{array}{l}\text { - Baseline materials } \\
\text { properties } \\
\text { - Radiation effects } \\
\text { - Creep properties }\end{array}$} \\
\hline & $\begin{array}{l}\text { Concept } \\
\text { Laser M2 }\end{array}$ & & & & \\
\hline \multirow[t]{2}{*}{20190315} & LPBF & \multirow[t]{2}{*}{ 316L/Praxair } & - As-built & \multirow{2}{*}{$\begin{array}{l}\text { Round bar, } \\
\text { thick plate, } \\
\text { others }\end{array}$} & \multirow{2}{*}{$\begin{array}{l}\text { - Mechanical } \\
\text { properties, } \\
\text { - Creep properties }\end{array}$} \\
\hline & $\begin{array}{l}\text { Concept } \\
\text { Laser M2 }\end{array}$ & & $\begin{array}{l}\text { - Stress-relieved } \\
\text {-Solution-annealed }\end{array}$ & & \\
\hline \multirow[t]{2}{*}{20191213} & LPBF & \multirow[t]{2}{*}{ 316L/Praxair } & \multirow{2}{*}{$\begin{array}{l}\text { - As-built } \\
\text {-(to be decided) }\end{array}$} & \multirow{2}{*}{$\begin{array}{l}\text { Thick plate, } \\
\text { thin plate }\end{array}$} & \multirow{2}{*}{$\begin{array}{l}\text { - Mechanical } \\
\text { properties, } \\
\text { - Radiation effects }\end{array}$} \\
\hline & $\begin{array}{l}\text { Concept } \\
\text { Laser M2 }\end{array}$ & & & & \\
\hline \multirow[t]{2}{*}{20200206} & LPBF & \multirow[t]{2}{*}{ IN718/Praxair } & \multirow{2}{*}{$\begin{array}{l}\text { - As-built } \\
\text { - Precipitation- } \\
\text { hardened }\end{array}$} & \multirow{2}{*}{$\begin{array}{l}\text { Thick plate, } \\
\text { thin plate }\end{array}$} & \multirow{2}{*}{$\begin{array}{l}\text { - Baseline materials } \\
\text { testing, } \\
\text { - Radiation effects }\end{array}$} \\
\hline & $\begin{array}{c}\text { Concept } \\
\text { Laser X } \\
\text { Line 2000R }\end{array}$ & & & & \\
\hline \multirow[t]{2}{*}{20190523} & LPBF & \multirow[t]{2}{*}{ 316L/Praxair } & - As-built & \multirow{2}{*}{$\begin{array}{l}\text { Round bar } \\
\text { for regular } \\
\text { tensile } \\
\text { specimens }\end{array}$} & \multirow{2}{*}{$\begin{array}{l}\text { - Effect of post- } \\
\text { build treatment }\end{array}$} \\
\hline & $\begin{array}{c}\text { Concept } \\
\text { Laser M2 }\end{array}$ & & $\begin{array}{l}\text { - Stress-relieved } \\
\text { - Solution-annealed } \\
\text { - HIP treated }\end{array}$ & & \\
\hline
\end{tabular}


Table 2-2. Chemical composition of Praxair 316L powder used for AM (in wt\%)

\begin{tabular}{cccccccccccc}
\hline $\mathrm{Fe}$ & $\mathrm{Cr}$ & $\mathrm{Ni}$ & $\mathrm{Mo}$ & $\mathrm{Mn}$ & $\mathrm{Si}$ & $\mathrm{N}$ & $\mathrm{Cu}$ & $\mathrm{Co}$ & $\mathrm{C}$ & $\mathrm{P}$ & $\mathrm{O}$ \\
\hline Bal. & 17.07 & 12.08 & 2.41 & 1.19 & 0.46 & 0.01 & 0.01 & 0.1 & 0.006 & $<0.005$ & 0.05 \\
\hline
\end{tabular}

Table 2-3. Chemical composition of the reference (wrought) 316L SS (in wt\%)

\begin{tabular}{ccccccccc}
\hline $\mathrm{Fe}$ & $\mathrm{Cr}$ & $\mathrm{Ni}$ & $\mathrm{Mo}$ & $\mathrm{Mn}$ & $\mathrm{Si}$ & $\mathrm{N}$ & $\mathrm{C}$ & $\mathrm{P}$ \\
$\mathrm{Bal}$. & 16.7 & 10.15 & 2.03 & 0.63 & 0.53 & 0.047 & 0.002 & 0.027 \\
\hline
\end{tabular}

Table 2-4. Composition of IN 718 powder used for AM (in wt\%)

\begin{tabular}{ccccccccccc}
\hline $\mathrm{Ni}$ & $\mathrm{Cr}$ & $\mathrm{Fe}$ & $\mathrm{Mo}$ & $\mathrm{Al}$ & $\mathrm{Co}$ & $\mathrm{Cu}$ & $\mathrm{Mn}$ & $\mathrm{C}$ & $\mathrm{B}$ & $\mathrm{Ni}$ \\
$\mathrm{Bal}$. & 18.84 & 17.92 & 3.04 & 0.47 & 0.15 & 0.03 & 0.04 & 0.03 & 0.001 & 0.009 \\
\hline
\end{tabular}

As indicated in the last column of Table 2-1, specimens in various geometries were taken from the parts of the builds and used for respective purposes. Tensile and creep test specimens were machined in different sizes for different testing tasks: SS-J2, SS-3, and ASTM regular round bar specimens. Some thin $(0.5 \mathrm{~mm})$ plates are being used in their as-printed shape in ball punch testing, and microscopy samples are usually taken from the tested specimens using focused ion beam (FIB) equipment. Detailed descriptions on specimens, including their dimensions, are given in the following sections where their results are described. 


\section{TENSILE STRENGTH AND DUCTILITY}

\subsection{Uniaxial tensile testing}

Uniaxial tensile testing using SS-J2 subsized specimens with a nominal gage section of $5 \times 1.2 \times$ $0.5 \mathrm{~mm}$ (Figure 3-1) was performed primarily to obtain the baseline mechanical properties of the AM 316L SSs following the testing procedure in ASTM E8/8M, "Standard test methods for tension testing of metallic materials." All SS-J2 specimens were machined from the two thick plates of Build 20190308, in which vertical bars and plates were printed together for machining regular-sized creep specimens and SS-J2 tensile specimens, respectively. The AM 316L SS was tested in three different conditions - as-built, stress-relieved $\left(650^{\circ} \mathrm{C} / 1 \mathrm{~h}\right)$, and solution-annealed $\left(1050{ }^{\circ} \mathrm{C} / 1 \mathrm{~h}\right.$ ) - along with the wrought $316 \mathrm{~L}$ (WT 316L) SS as a reference alloy for comparison. So far, 54 SS-J2 specimens in a nonirradiated condition have been tested in a temperature ranging from RT up to $600{ }^{\circ} \mathrm{C}$.

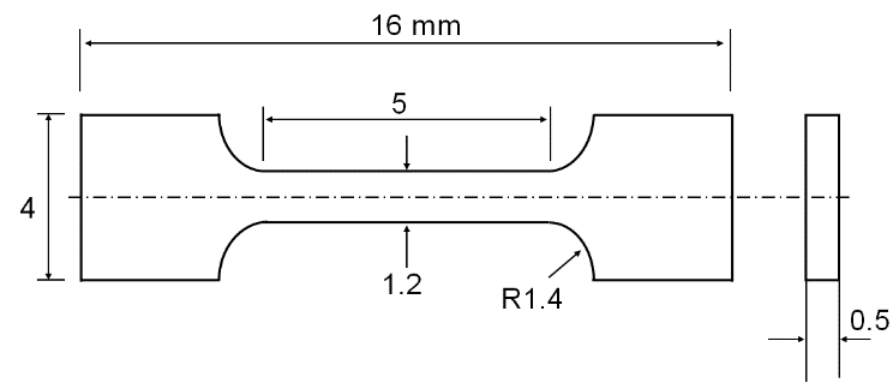

Figure 3-1. SS-J2 tensile specimen

A tabletop servohydraulic testing system (Model MTS-858) in the Low Activation Materials Design and Analysis Laboratory (LAMDA) facility was used for the tensile testing, in which all specimens were tested at a nominal strain rate of $5 \times 10^{-4} \mathrm{~s}^{-1}(0.15 \mathrm{~mm} / \mathrm{min})$ in the shoulder loading mode. Raw data or load-displacement data up to failure were recorded and used to determine the common engineering strength and ductility parameters, including yield strength (YS), ultimate tensile strength (UTS), uniform elongation (UE), and total elongation (TE).

A larger set of 216 SS-J2 specimens are being irradiated in six rabbit capsules at the High Flux Isotope Reactor (HFIR). Mechanical testing after neutron irradiation will be performed in the future under the TCR program [12], and the results will be compared with the baseline data reported in this document. The following sections present the results of uniaxial tensile testing for the AM 316L in three different conditions and the WT 316L in standard, solution-annealed condition.

\subsection{Temperature Dependence of Strength}

Since the rapid melting-cooling and remelting-cooling cycles occur during printing by the laser powder bed fusion, the as-printed 316L SS usually shows many unique microstructural features that are distinctly different from those observed in common annealed or cold-worked SSs [1]. The grains are much smaller when compared to annealed austenite, and in most cases, they have an elongated shape. Furthermore, each rapid heating-cooling cycle occurs in a small local volume of 
the material which can induce an intense thermal stress field. This can result in a high-density dislocation network, often with a well-developed cellular structure [4-7]. The as-built 316L SS, therefore, shows a unique mechanical behavior that differs from those of annealed austenitic SSs.

Figure 3-2 compares four engineering stress-strain curves that were obtained from the AM 316L and WT 316L specimens tested at RT, $300{ }^{\circ} \mathrm{C}$, and $500{ }^{\circ} \mathrm{C}$. The two most stark differences observed between these AM and WT 316L stainless steels are that (i) the strength of AM $316 \mathrm{~L}$ in the early deformation is much higher than that of the wrought material, and (ii) much higher workhardening rates are observed in WT 316L than in AM 316L. The combination of these two effects often results in closer stress-strain curve behaviors in the later part of plastic deformation.

One aspect that can explain these tensile behaviors is the characteristic deformation of lowstacking fault energy alloys such as the $316 \mathrm{~L} \mathrm{SSs.} \mathrm{In} \mathrm{these} \mathrm{alloys,} \mathrm{gliding} \mathrm{dislocations} \mathrm{tend} \mathrm{to} \mathrm{be}$ separated into partial dislocations under high stress, which would lead to more linear glides and thus to a higher, sustainable work hardening. Therefore, the significantly higher strength measured in early deformation of AM 316L alloy does not result in a reduced ductility at room temperature. This positive effect from the strength-enhanced linear glides tends to diminish at higher temperatures because the overall strength of the alloy is reduced and thus the dislocation glides become more random. In addition, both materials show serrated curves at $500{ }^{\circ} \mathrm{C}$ due to dynamic strain aging effect. This is a phenomenon observed when some alloy elements (most likely $\mathrm{Cr}$ ) move along with gliding dislocations, generating extra friction to the glides. These characteristic strength and temperature dependences are well represented in Figure 3-2.

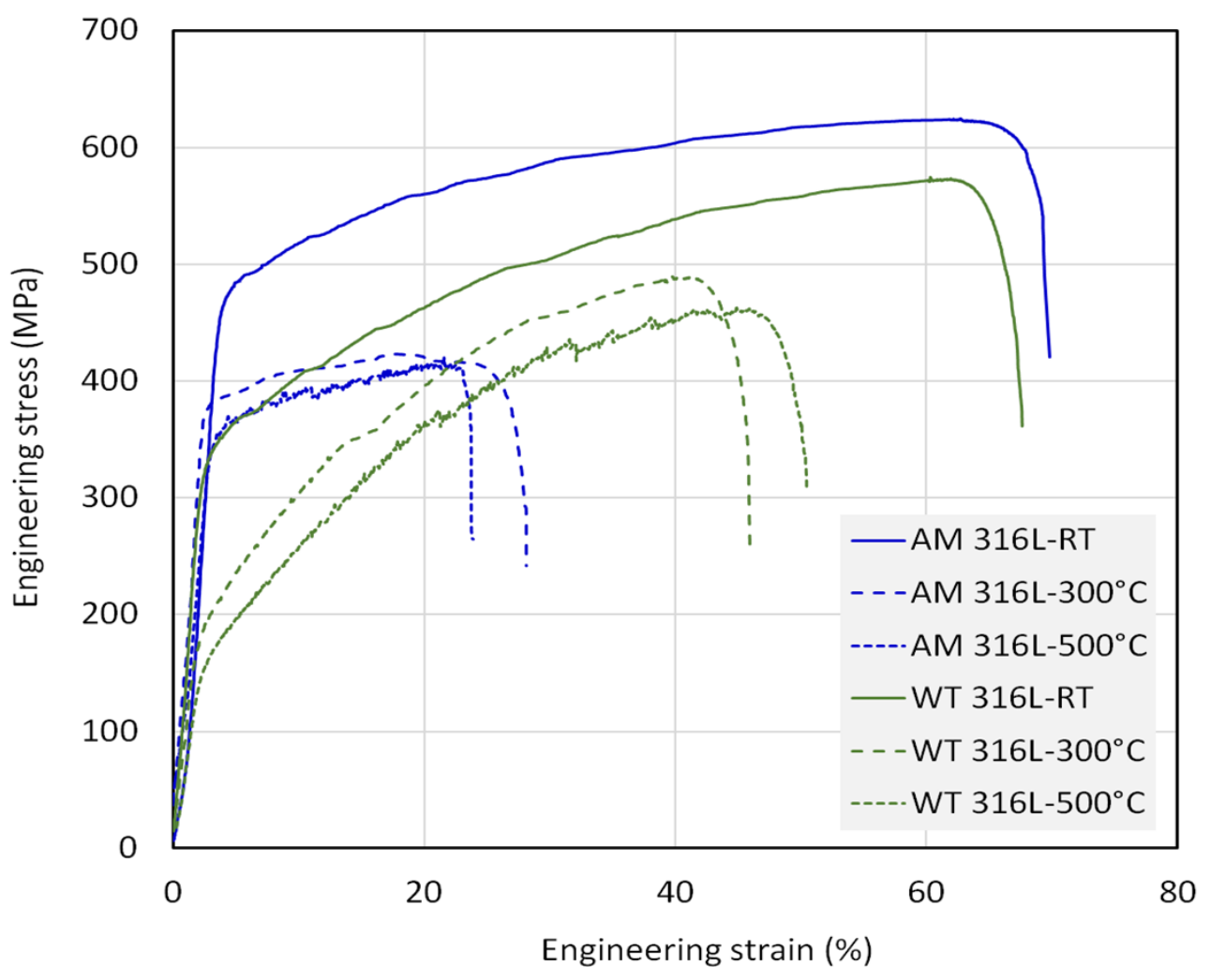

Figure 3-2. Comparison of the engineering stress-strain curves of $A M 316 \mathrm{~L}$ (as-built) and wrought $316 \mathrm{~L}$ tested at $\mathrm{RT}, 300{ }^{\circ} \mathrm{C}$, and $500{ }^{\circ} \mathrm{C}$. 
Engineering strength and ductility data were determined from the load-displacement curves obtained from 54 SS-J2 specimens and are presented in Figure 3-3 through Figure 3-6. Note that the RT data presented in these graphs are average values from multiple specimens. The results of statistical analysis of these RT data are discussed later in this section. In Figure 3-3, the YS data from the four different processing routes are compared. It is observed that YS decreases monotonically with the test temperature over the range of RT- $-600^{\circ} \mathrm{C}$, and all four $316 \mathrm{~L}$ conditions show similar temperature dependences. The wrought $316 \mathrm{~L}$ alloy, which is in a hotrolled, fully annealed condition, shows the lowest YS among the four materials, while the asprinted 316L (AM 316L) demonstrates the highest strength at all test temperatures. Application of a stress-relieving treatment at $650{ }^{\circ} \mathrm{C}$ for 1 hour reduced the strength of $\mathrm{AM} 316 \mathrm{~L}$ at all test temperatures, and the solution annealing at $1,050{ }^{\circ} \mathrm{C}$ for 1 hour further decreased the YS to about $2 / 3$ level of the YS in the as-built condition.

It is also noted that the AM 316L alloy can still retain high YS, even after solution annealing; its YS is higher than that of the wrought $316 \mathrm{~L}$ alloy over the entire test temperature range. This might be because the solution treatment has removed much of the built-up dislocations and residual stresses, but it has not induced a significant grain growth: the strengthening effect from the characteristically fine microstructure of AM materials still contributes to the strengthening of the material even after high temperature $\left(1,050^{\circ} \mathrm{C}\right)$ annealing.

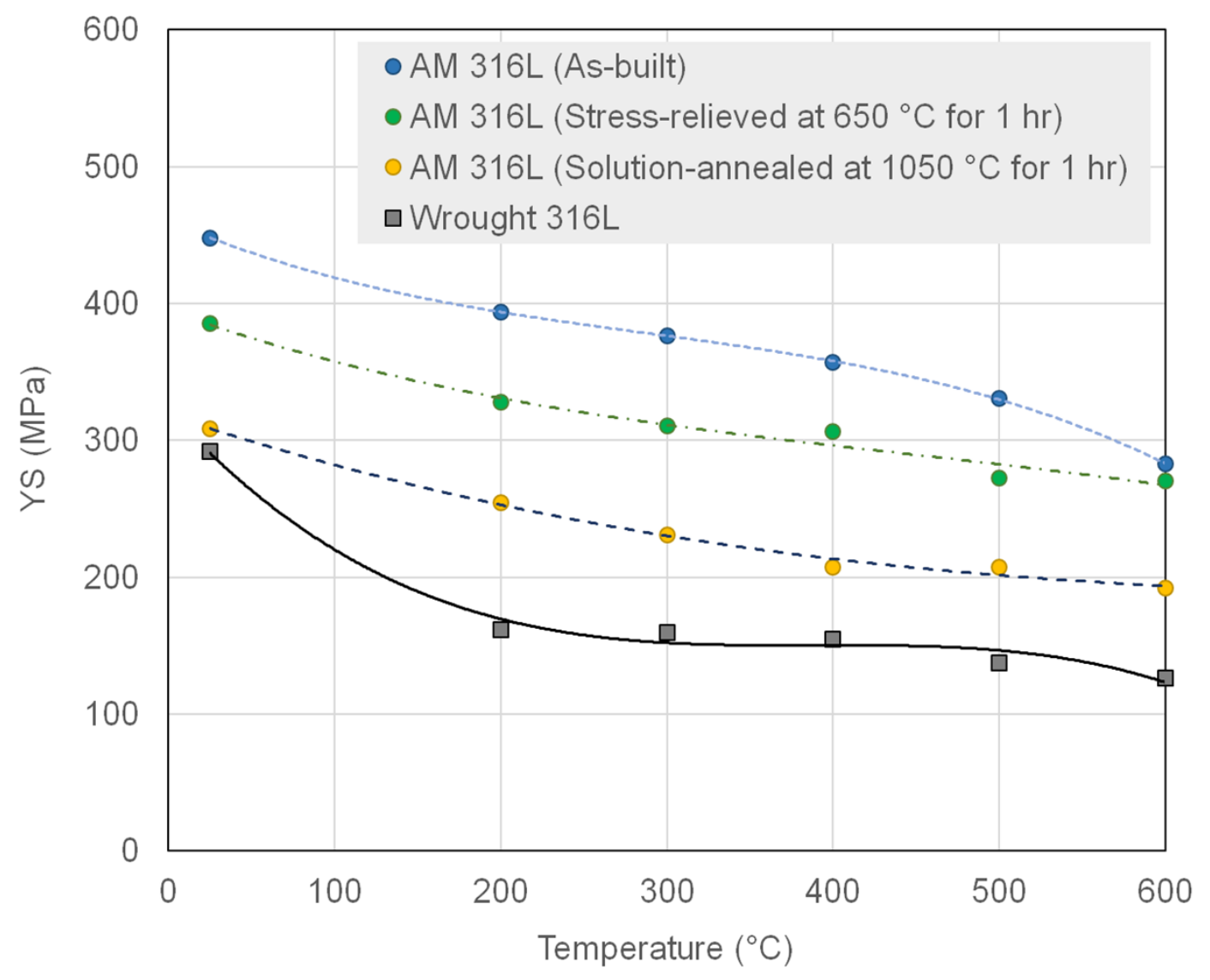

Figure 3-3. Temperature dependence of YS in 316L stainless steels after four different processing routes. 
Figure 3-4 compares the ultimate tensile strength (UTS) data of the AM 316L SS in three different conditions and reference $316 \mathrm{~L}$ alloy in a fully annealed condition. Overall, high UTS values ( $>550 \mathrm{MPa}$ ) were measured for all 316L variants at RT, and it decreases with test temperature, except for the WT 316L SS. It is observed that the differences in UTS values among the four different processing routes are much smaller than those in the YS data. This is because UTS is determined at the maximum load in each load-displacement record and is an engineering parameter measured at a relatively large strain or in a later part of tensile deformation, where the stress-strain curves of AM 316L and WT 316L become closer. It is also observed that the dependence of strength in three AM 316 materials is monotonic, while that for the WT 316L alloy shows a local minimum in strength around $200^{\circ} \mathrm{C}$.

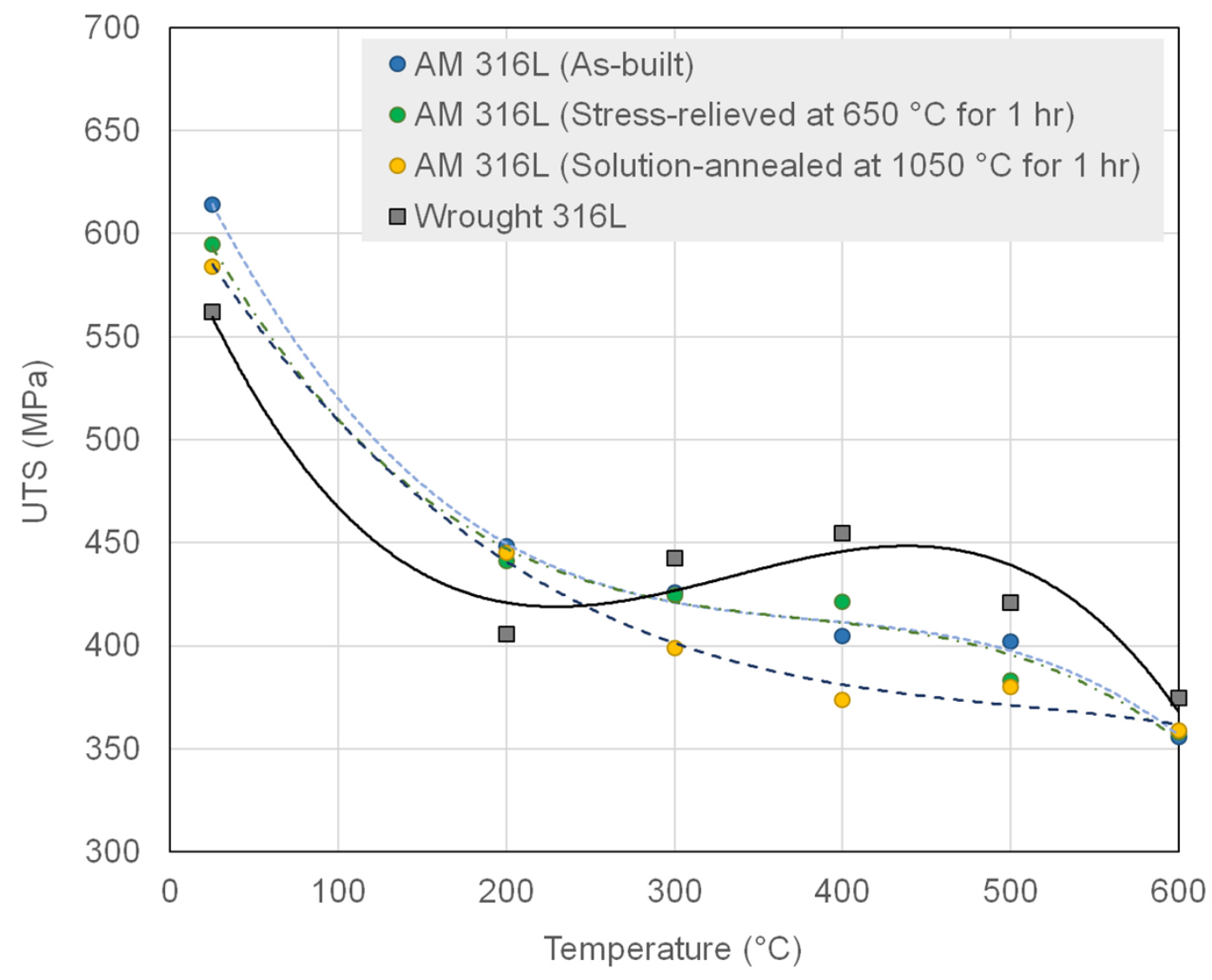

Figure 3-4. Temperature dependence of UTS in 316L stainless steels after four different processing routes.

\subsection{Temperature Dependence of Ductility}

The ductility data for the AM 316L and WT 316L SSs are displayed in Figures 3-5 and 3-6. It is commonly found in these datasets that the UE and TE rapidly decrease with test temperature in the range of $\mathrm{RT}-200{ }^{\circ} \mathrm{C}$, and their temperature dependence becomes much less significant in the higher temperature range $\left(200-600^{\circ} \mathrm{C}\right)$. Over this elevated-to-high temperature range, the 
temperature dependences of ductility parameters are similar to that of UTS rather than to that of YS, although they are relatively small and more varied.

In general, the stronger 316L materials showed lower ductility, as observed in most of the metallic materials. That is, relatively lower ductilities are measured from the AM 316L materials. For example, the lowest uniform ductility measured is $\sim 15 \%$, which was measured at $300{ }^{\circ} \mathrm{C}$ from the as-built 316L. It is noted that only small differences between UE and TE, 4-10\%, are measured as their limited necking deformation. It is also observed that a local ductility minimum exists in the temperature range of $200-500{ }^{\circ} \mathrm{C}$ before the parameters increase with temperature.

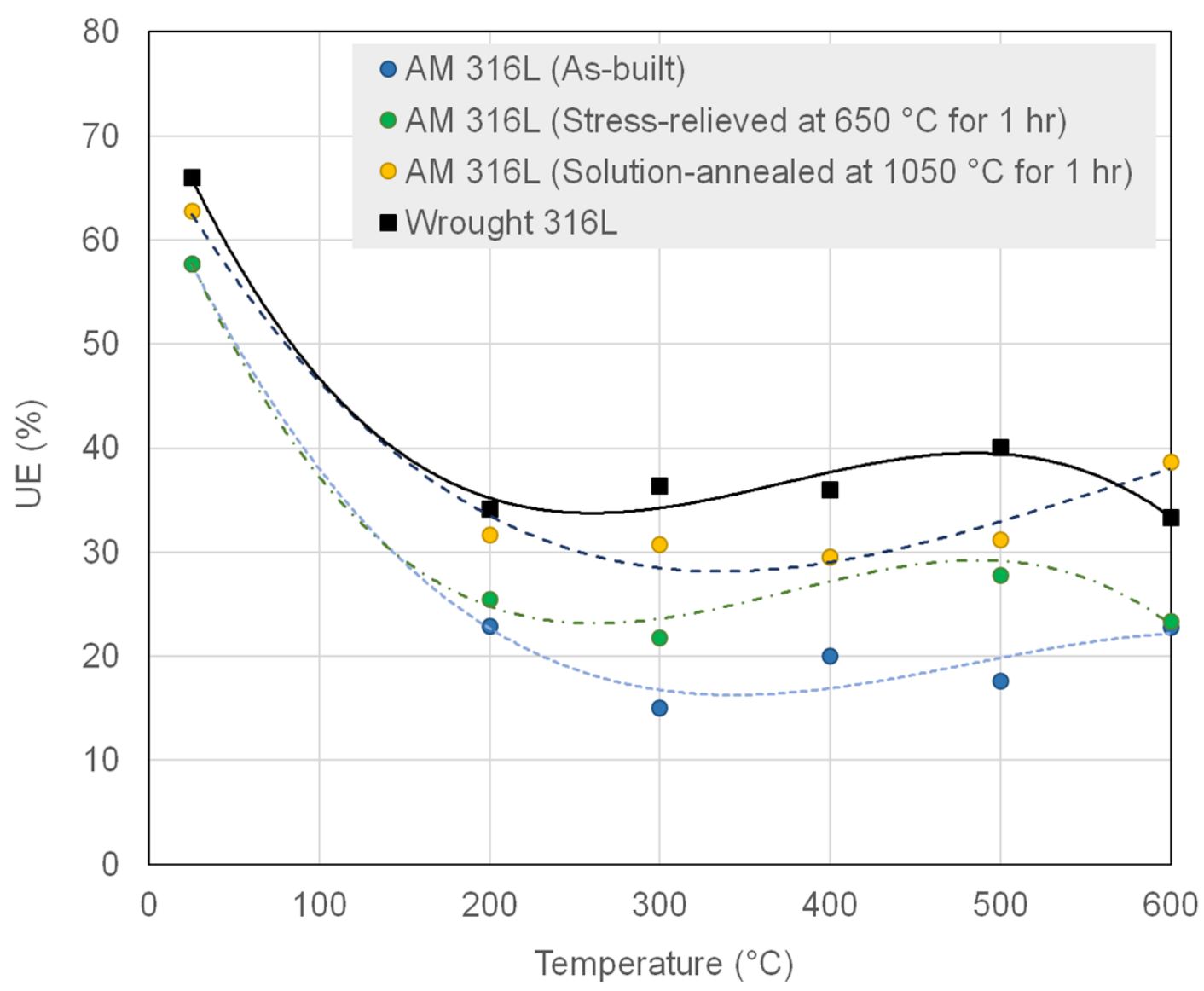

Figure 3-5. Temperature dependence of $\mathrm{UE}$ in 316L stainless steels after four different processing routes. 


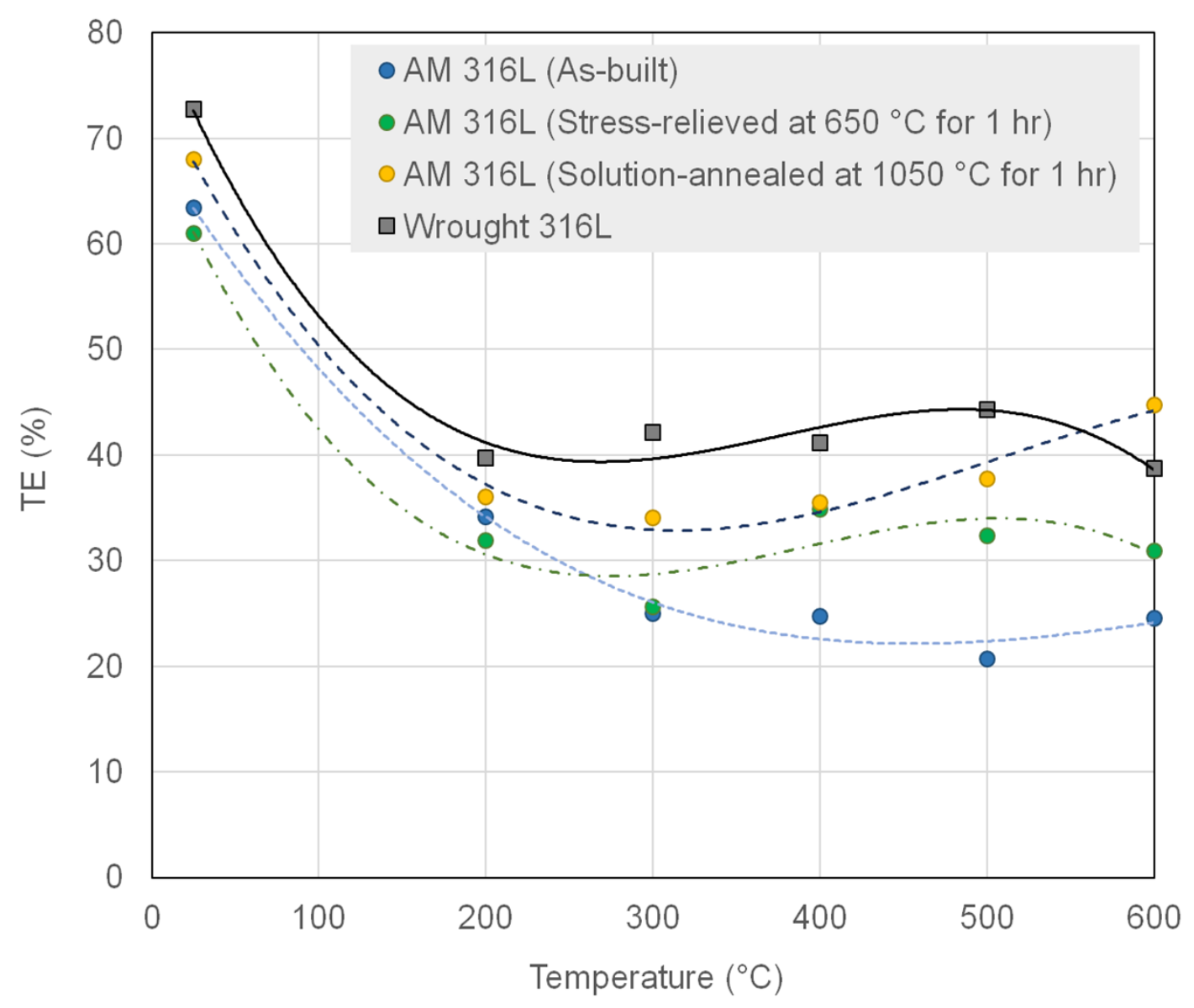

Figure 3-6. Temperature dependence of TE in 316L stainless steels after four different processing routes.

\subsection{Statistics of Room Temperature Tensile Properties}

Multiple tensile tests (7-10 per material) have been performed at RT to evaluate nonuniformity in the tensile properties of individual materials and to compare variations within their datasets. The results of statistical treatment are summarized in Table 3-1. For the strength datasets, relatively larger standard deviations were calculated for the WT 316L SS and the AM 316L in the stressrelieved condition, while the AM 316L steel in the solution-annealed condition demonstrates the lowest deviation in both of its strength datasets. For the ductility datasets, the lowest standard deviations, $2.1 \%$ for UE and 3.3\% for TE, were measured for the AM 316L in the as-built condition. With the varied printing conditions and complex microstructures, higher variations in the tensile properties of the AM materials were expected. Contrary to this expectation, the asprinted 316L alloy did not show any evidence of higher variation in its tensile property data. A high variation in a property data might be caused by a nonuniform microstructure, and therefore, the fine microstructure of AM 316L are not considered as a highly heterogeneous microstructure. 
Table 3-1. Summary of RT tensile property data from SS-J2 tensile specimens: mean values and standard deviations (in parenthesis)

\begin{tabular}{lccccc}
\hline Materials & $\begin{array}{c}\text { \# of } \\
\text { Tests }\end{array}$ & YS (MPa) & UTS (MPa) & UE (\%) & TE (\%) \\
\hline AM 316L (As-built) & 10 & $448.0(11.9)$ & $614.1(15.3)$ & $57.7(2.1)$ & $63.5(3.3)$ \\
$\begin{array}{l}\text { AM 316L (stress-relieved at } \\
\text { 650 }{ }^{\circ} \mathrm{C} \text { for 1 h) }\end{array}$ & 7 & $385.1(17.2)$ & $594.7(23.4)$ & $57.7(5.0)$ & $61.0(5.4)$ \\
$\begin{array}{l}\text { AM 316L (solution- } \\
\text { annealed at 1050 }{ }^{\circ} \mathrm{C} \text { for 1 h) }\end{array}$ & 9 & $308.2(4.9)$ & $584.1(9.4)$ & $62.8(6.7)$ & $68.0(9.6)$ \\
\begin{tabular}{l} 
Wrought 316L \\
\hline
\end{tabular} & 8 & $261.1(14.3)$ & $562.2(32.5)$ & $66.0(8.4)$ & $72.8(9.0)$ \\
\hline
\end{tabular}

\subsection{Effect of Post-Build Processing on Tensile Properties}

Various post-build treatments were applied to the AM 316L SS to find an optimized material condition. This task used a large standard sized specimen since it was independent of the irradiation effect studies in which specimen size is limited. The $316 \mathrm{~L}$ alloy powder was additively fabricated into cylinders that were $13 \mathrm{~mm}$ in diameter and $65 \mathrm{~mm}$ long, oriented in the $\mathrm{Z}$ axis in a single build with a Concept Laser M2 system, and the ASTM E8 standard round specimens with the gage section of $\varnothing 6 \times 30 \mathrm{~mm}$ were machined from the printed cylinders. In printing, the same laser parameters of $370 \mathrm{~W}$ power, $1,350 \mathrm{~mm} / \mathrm{s}$ velocity, $130 \mu \mathrm{m}$ spot size, $90 \mu \mathrm{m}$ hatch spacing, 10 $\mathrm{mm}$ stripe width, $67^{\circ}$ inter-layer rotation, and $50 \mu \mathrm{m}$ layer thickness with a snaking strategy were used for all specimens. The argon gas atomized 316L powder from Praxair (TruForm 316-3) with a median diameter of $31 \mu \mathrm{m}$ was used for this fabrication.

Five different post-build treatments at $650{ }^{\circ} \mathrm{C}$ and $1,100{ }^{\circ} \mathrm{C}$ were applied to the specimens, as summarized in Table 3-2. The Group 1 specimens were treated and rapidly quenched within a HIP furnace (Quintus Technologies model QIH), and all other quenched groups were cooled by placing specimens on a large steel heat sink and air cooling. Samples for all groups other than the Group 1 were sealed in quartz tubes with a partial pressure $(0.25 \mathrm{~atm})$ of high purity argon $(99.999 \%)$ and heat treated in the same furnace (CM Furnaces model 1730-20HT). In these processes all samples were heated to target temperatures at $10^{\circ} \mathrm{C} / \mathrm{min}$. Specimen surfaces were electrochemically polished before testing. The heat-treatment groups were duplicated for the specimens printed by the laser 1 and laser 2 of the Concept Laser M2 system.

Table 3-2. Post-build heat treatments for AM 316L SSs

\begin{tabular}{lccccc}
\hline $\begin{array}{l}\text { Treatment } \\
\text { condition }\end{array}$ & $\begin{array}{c}\text { Group 1 } \\
\text { (HIP) }\end{array}$ & Group 2 & Group 3 & Group 4 & Group 5 \\
\hline Temperature $\left({ }^{\circ} \mathrm{C}\right)$ & 1,100 & 1,100 & 1,100 & 650 & 650 \\
Time $(\mathrm{min})$ & 60 & 60 & 60 & 60 & 60 \\
Pressure $(\mathrm{MPa})$ & 100 & 0 & 0 & 0 & 0 \\
Cooling & Quench & Quench & $\begin{array}{c}\text { Furnace cool } \\
\left(10^{\circ} \mathrm{C} / \mathrm{min}\right)\end{array}$ & $\begin{array}{c}\text { Quench } \\
\text { Furnace cool }\end{array}$ & $\begin{array}{c}\text { Furn } \\
\left(10^{\circ} \mathrm{C} / \mathrm{min}\right)\end{array}$ \\
\hline
\end{tabular}


For each specimen group, four specimens were prepared and tensile-tested, and the engineering tensile data in each group from three to four successful tests were statistically treated. The mean values for the respective data groups and corresponding standard deviations are summarized in Table 3-3. The last column of this table lists the 2D optical porosity measurements obtained for a single specimen from each group/laser combination.

If compared with the other $1,100{ }^{\circ} \mathrm{C}$-annealed sample groups ( 2 and 3 ), the $1,100{ }^{\circ} \mathrm{C}$-hipped specimens (Group 1) demonstrate only insignificant effect of the high pressure of $100 \mathrm{MPa}$. The YS after HIPing is 8-12 MPa lower than those after other $1,100{ }^{\circ} \mathrm{C}$ annealing treatments but other strength and ductility parameters show little differences. It is obvious that the HIPing treatment with high pressure has closed or reduced pores, as compared in the last column, and might have eliminated most of dislocation networks and associated residual stresses; however, the effects of these thermomechanical phenomena on mechanical properties are limited.

Thermal annealing effect was commonly significant for all $1,100{ }^{\circ} \mathrm{C}$ treatments with or without pressure, and therefore the strengths after these treatments are lower than those of the as-built and $650{ }^{\circ} \mathrm{C}$ annealed 316L SSs. As aforementioned, the YS data show more significant difference than the UTS data between the two annealing temperatures. As discussed in the earlier section, the ductility parameters UE and TE show less significant changes due to the different treatments. Overall, the annealing temperature was found to have substantial influence on the mechanical properties, while the gas pressure, lasers, and different cooling methods were found to have insignificant effects. That is, the temperature of a post-build treatment is the primary explanatory variable of tensile properties as a higher temperature annealing might result in dislocation annihilation, stress relieving, and/or grain growth.

Table 3-3. Summary of RT tensile property data from standard sized specimens: mean values and standard deviations (in parenthesis)

\begin{tabular}{|c|c|c|c|c|c|c|}
\hline & Group & YS (MPa) & UTS (MPa) & UE (\%) & TE (\%) & $\begin{array}{c}\text { 2D optical } \\
\text { porosity (\%) }\end{array}$ \\
\hline \multirow{5}{*}{ 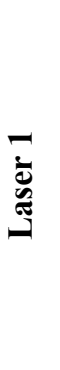 } & Group 1 & $309.42(1.80)$ & $586.80(3.49)$ & $60.08(0.52)$ & $75.76(2.00)$ & 0.022 \\
\hline & Group 2 & $317.09(2.63)$ & $589.46(0.98)$ & $59.62(1.17)$ & $75.19(3.46)$ & 0.135 \\
\hline & Group 3 & 320.84 (1.96) & $590.92(2.24)$ & $59.05(0.53)$ & $75.44(1.60)$ & 0.158 \\
\hline & Group 4 & $382.06(1.76)$ & $609.97(0.95)$ & $52.48(0.60)$ & $69.95(3.94)$ & 0.142 \\
\hline & Group 5 & $387.37(5.44)$ & $611.52(3.12)$ & $52.37(0.37)$ & $67.77(1.53)$ & 0.117 \\
\hline \multirow{5}{*}{ 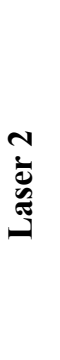 } & Group 1 & $311.16(2.89)$ & $588.16(1.62)$ & $59.89(1.16)$ & $76.49(3.61)$ & 0.012 \\
\hline & Group 2 & $319.76(0.71)$ & $589.73(1.06)$ & $56.96(2.11)$ & $70.36(3.40)$ & 0.119 \\
\hline & Group 3 & $318.33(1.87)$ & $590.13(1.96)$ & $57.60(0.64)$ & $74.33(2.81)$ & 0.149 \\
\hline & Group 4 & $383.48(2.44)$ & $611.22(2.43)$ & $52.35(0.21)$ & $69.95(2.34)$ & 0.139 \\
\hline & Group 5 & $380.04(0.63)$ & $610.13(1.15)$ & $52.36(0.28)$ & $69.01(1.69)$ & 0.126 \\
\hline
\end{tabular}




\section{CREEP PROPERTIES AND DEFORMATION BEHAVIOR}

This section describes ANL's FY 2020 progress in materials research to investigate the creep and fatigue properties of AM materials. The discussion focuses on the results of creep tests at $550{ }^{\circ} \mathrm{C}$ and microstructural characterization to assess the effects of post-build heat treatment on the creep behavior of AM 316L SS. Some preliminary results from in-situ x-ray analysis during tensile deformation are also discussed.

\subsection{Creep Testing of AM 316L with and without Post-Build Heat Treatment}

In FY 2019, ANL conducted six creep tests at $650{ }^{\circ} \mathrm{C}$ using ASTM standard round bar specimens (Figure 4-1) of AM 316L provided by ORNL [1]. The specimens were fabricated from Build 20190308 printed by a LPBF process using a Concept Laser M2 printer [1]. Three of the specimens were fabricated from rods printed in laser 1 mode (specimen IDs, L101, L102, L103), and the other three from rods printed in laser 2 mode (specimen ID, L201, L202, L203). The three specimens from laser 1 mode were creep tested at $650^{\circ} \mathrm{C}$ at 175,200 , and $225 \mathrm{MPa}$, respectively, and the three specimens from laser 2 mode were tested at the same temperature and stress conditions to evaluate batch variability.

Six additional round bar specimens were provided by ORNL in November 2019 (FY 2020) for evaluation of the influence of post-build heat treatment on the creep property of AM 316L SS. These specimens were also fabricated from the Build 20190308 rods, with three of them printed in laser 1 mode (specimen IDs, L104, L105, L106), and the other three in laser 2 mode (specimen ID, L204, L205, L206). A post-build solution annealing at $1,050{ }^{\circ} \mathrm{C}$ for one hour followed by rapid cooling was conducted for specimens L105 and L205, and a stress relieving treatment at $650{ }^{\circ} \mathrm{C}$ for one hour followed by furnace cooling was conducted for the specimens L106 and L206. Each specimen was individually encapsulated in a quartz tube under vacuum and heat treated in an air furnace. Specimens L104 and L204 were in the as-built condition before the creep tests. All specimens were creep tested under the same conditions, namely, $550{ }^{\circ} \mathrm{C}$ and $275 \mathrm{MPa}$. Table 4-1 lists the ASTM creep specimen and testing conditions for AM $316 \mathrm{~L}$.

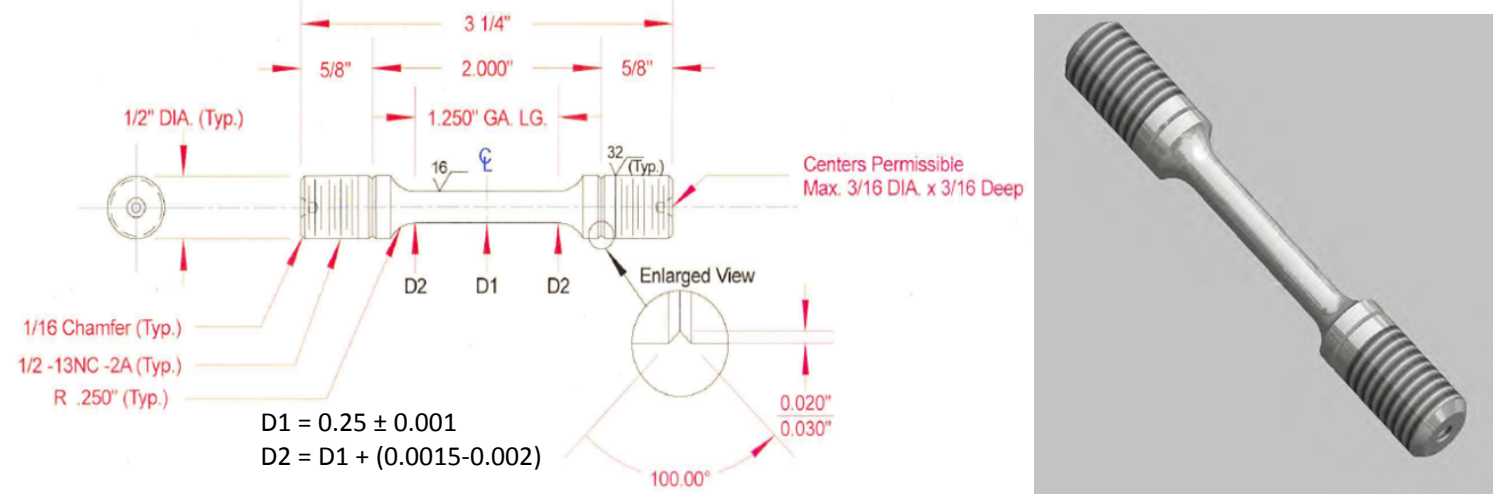

Figure 4-1. Schematic of the ASTM round bar creep specimen (unit: in). 
Table 4-1. List of ASTM-standard round bar creep specimens with test conditions.

\begin{tabular}{ccccccc}
\hline $\begin{array}{c}\text { Specimen } \\
\text { ID }\end{array}$ & Build ID & $\begin{array}{c}\text { Laser } \\
\text { mode }\end{array}$ & $\begin{array}{c}\text { Specimen } \\
\text { type }\end{array}$ & $\begin{array}{c}\text { Processing } \\
\text { condition } * *\end{array}$ & $\begin{array}{c}\text { Test temp. } \\
\left({ }^{\circ} \mathbf{C}\right)\end{array}$ & $\begin{array}{c}\text { Stress } \\
(\text { MPa })\end{array}$ \\
\hline L101 & 20190308 & Laser 1 & ASTM & As-built & 650 & 225 \\
L102 & 20190308 & Laser 1 & ASTM & As-built & 650 & 200 \\
L103 & 20190308 & Laser 1 & ASTM & As-built & 650 & 175 \\
L104 & 20190308 & Laser 1 & ASTM & As-built & 550 & 275 \\
L105 & 20190308 & Laser 1 & ASTM & $1050^{\circ} \mathrm{C} / 1 \mathrm{~h}$ & 550 & $*$ \\
L106 & 20190308 & Laser 1 & ASTM & $650^{\circ} \mathrm{C} / 1 \mathrm{~h}$ & 550 & 275 \\
L201 & 20190308 & Laser 2 & ASTM & As-built & 650 & 225 \\
L202 & 20190308 & Laser 2 & ASTM & As-built & 650 & 200 \\
L203 & 20190308 & Laser 2 & ASTM & As-built & 650 & 175 \\
L204 & 20190308 & Laser 2 & ASTM & As-built & 550 & 275 \\
L205 & 20190308 & Laser 2 & ASTM & $1050^{\circ} \mathrm{C} / 1 \mathrm{~h}$ & 550 & 275 \\
L206 & 20190308 & Laser 2 & ASTM & $650^{\circ} \mathrm{C} / 1 \mathrm{~h}$ & 550 & 275 \\
\hline
\end{tabular}

*L105 failed at $550^{\circ} \mathrm{C}$ during initial loading to $375 \mathrm{MPa}$. The applied creep stress was then reduced to $275 \mathrm{MPa}$ for other five specimens. ${ }^{* *} 1,050^{\circ} \mathrm{C} / 1 \mathrm{~h}$, solution-annealed; $650^{\circ} \mathrm{C} / 1 \mathrm{~h}$, stress-relieved.

Creep tests were conducted according to ASTM Standard E139-11, "Standard Test Methods for Conducting Creep, Creep-Rupture, and Stress-Rupture Tests on Metallic Materials." Tests were carried out on ATS Series 2300 Lever Arm Creep Testing Systems integrated with WinCCS II computer control and data acquisition software package (Figure 4-2). Each creep frame is equipped with a three-zone split-tube furnace capable of operating up to $1,100{ }^{\circ} \mathrm{C}$. An averaging extensometer frame was mounted on the specimen to measure the specimen displacement. 


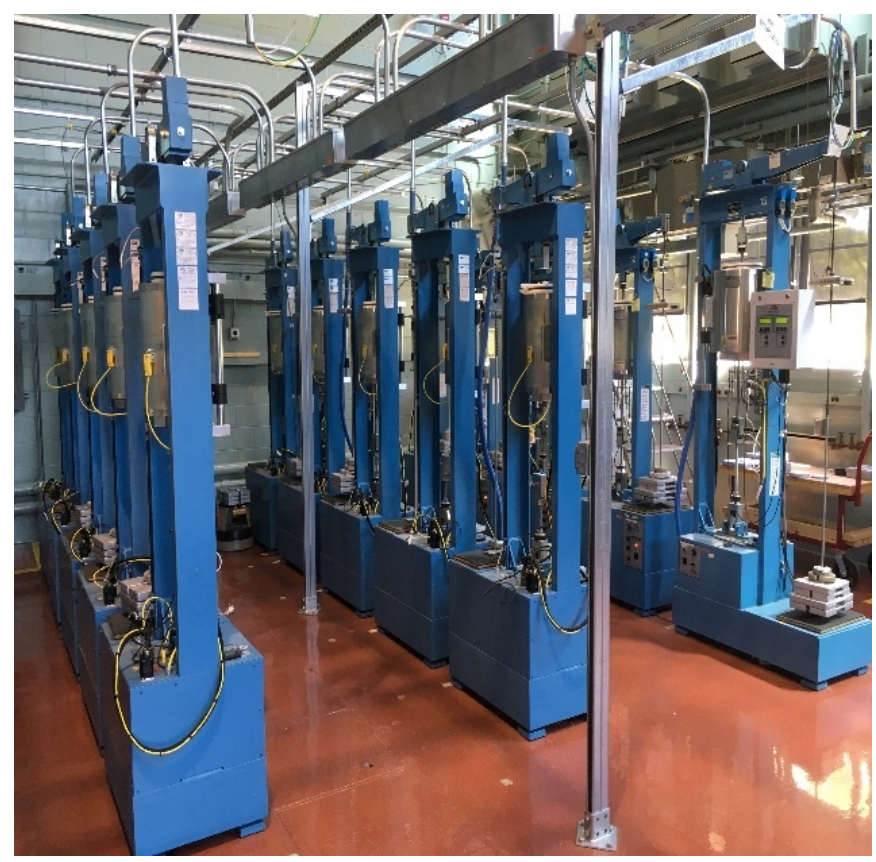

Figure 4-2. ANL creep test systems.

\subsection{Creep Properties}

The $650{ }^{\circ} \mathrm{C}$ creep data for AM $316 \mathrm{~L}$ is presented in a previous report [1]. In summary, specimens in laser 1 and laser 2 modes showed comparable creep behavior. AM 316L SS showed a very short steady-state creep, in contrast to a long steady-state creep in conventional Type $316 \mathrm{SS}$. The minimum creep rate was reached in the first few hours and was followed by a continuous increase in creep rate to the final failure. The minimum creep rate of AM 316L followed a power law relationship with the applied stress, $\dot{\varepsilon}=A \sigma^{n}$, with the power exponent of $\mathrm{n}=\sim 12$, which implies a low-temperature dislocation creep mechanism.

Figure 4-3 shows the creep strain as a function of time for the five creep specimens tested at 550 ${ }^{\circ} \mathrm{C}$ and $275 \mathrm{MPa}$ to evaluate the influence of the post-build heat treatment on creep properties. L105 failed at $550{ }^{\circ} \mathrm{C}$ during initial loading to $375 \mathrm{MPa}$. The applied stress was reduced for other five specimens, which were tested at $550^{\circ} \mathrm{C} / 275 \mathrm{MPa}$. The creep rupture data are given in Figure 4-4. The post-build heat treatment of $1,050{ }^{\circ} \mathrm{C} / 1 \mathrm{~h}$ significantly reduced the creep life, while the heat treatment of $650{ }^{\circ} \mathrm{C} / 1 \mathrm{~h}$ slightly increased the creep life compared with that of the as-built specimen. Specimens of laser 1 mode (L104 and L106) showed somewhat longer creep lives than specimens of laser 2 mode (L204 and L206). The as-built specimens and the $650{ }^{\circ} \mathrm{C} / 1 \mathrm{~h}$ heattreated specimens had a very short steady-state stage (a few percent of the total life), followed by an accelerated creep until the final failure, which is similar to the sequence observed for the $650^{\circ} \mathrm{C}$ creep tests. The $1,050{ }^{\circ} \mathrm{C} / 1 \mathrm{~h}$ heat-treated specimen had a much more pronounced steady-state creep, resembling the creep behavior of conventional 316 SSs. The minimum creep rate of the $1,050{ }^{\circ} \mathrm{C} / 1 \mathrm{~h}$ heat-treated specimen is about six times higher than the minimum creep rates of all other specimens, as shown in Figure 4-5. The minimum creep rates of the $650{ }^{\circ} \mathrm{C} / 1 \mathrm{~h}$ heat-treated specimens are smaller than those of the as-built specimens. Specimens of laser 1 mode have 
somewhat lower creep rates than specimens of laser 2 mode. Figure 4-6 shows that all the specimens exhibited slant fracture.

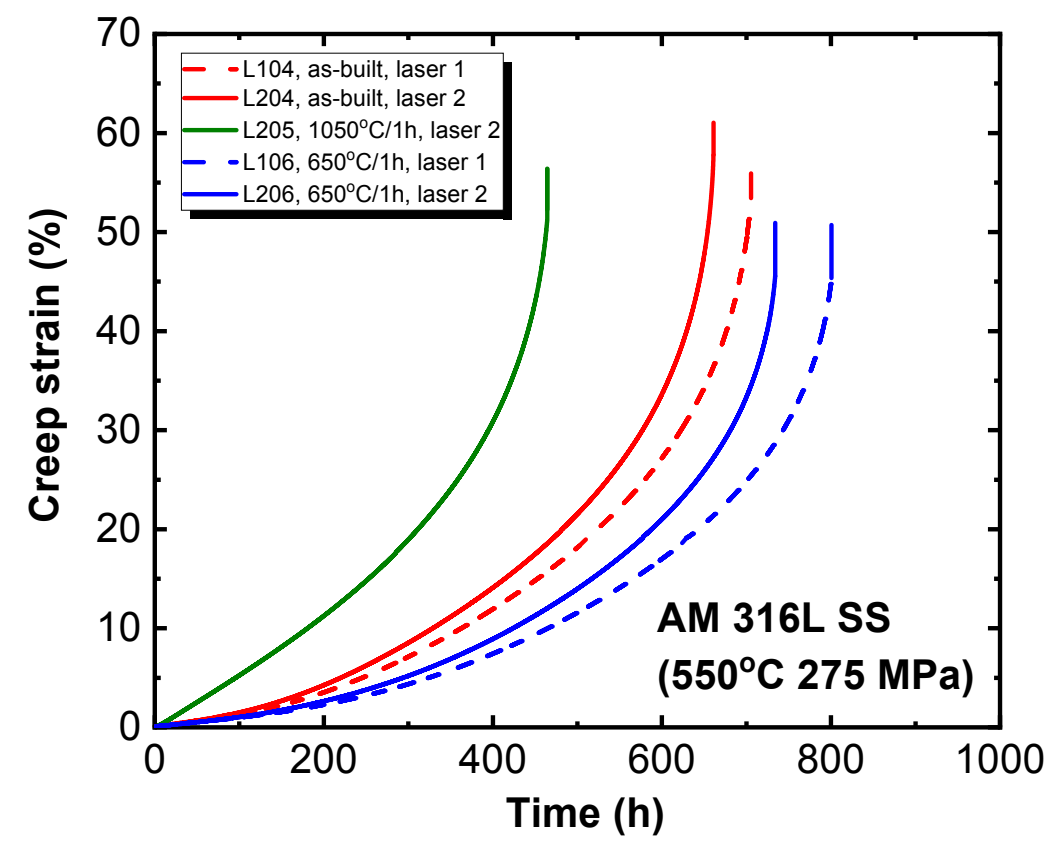

Figure 4-3. Creep strain as a function of time for AM $316 \mathrm{~L} \mathrm{SS}$ tested at $550{ }^{\circ} \mathrm{C}$ and $275 \mathrm{MPa}$.

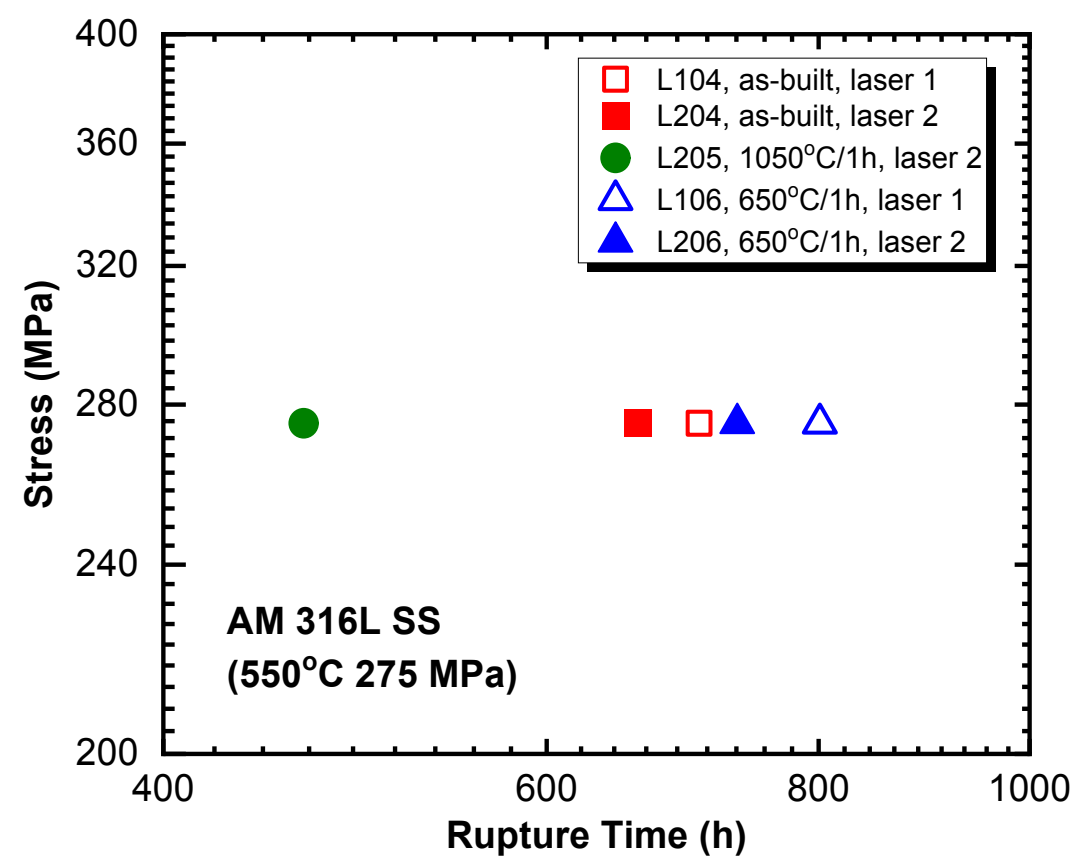

Figure 4-4. Creep rupture data for AM 316L SS tested at $550{ }^{\circ} \mathrm{C}$ and $275 \mathrm{MPa}$. 


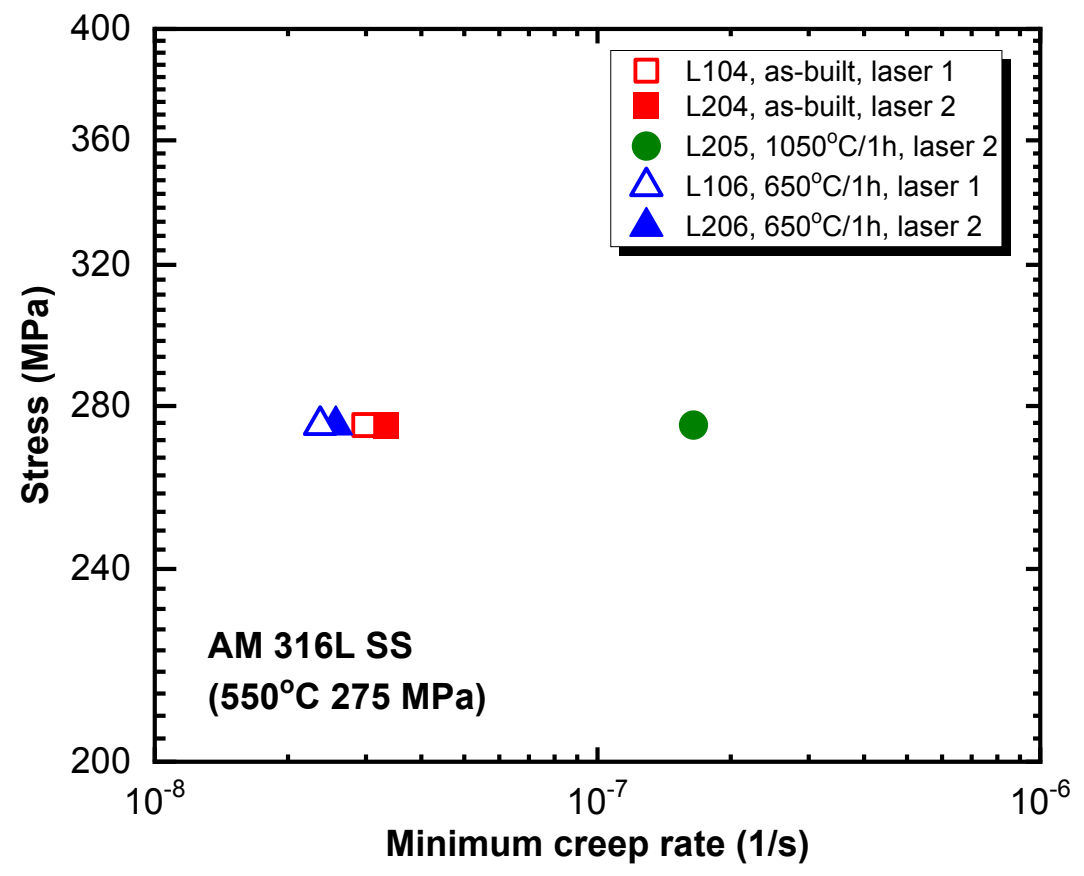

Figure 4-5. Minimum creep strain rates for AM 316L SS tested at $550^{\circ} \mathrm{C}$ and $275 \mathrm{MPa}$.
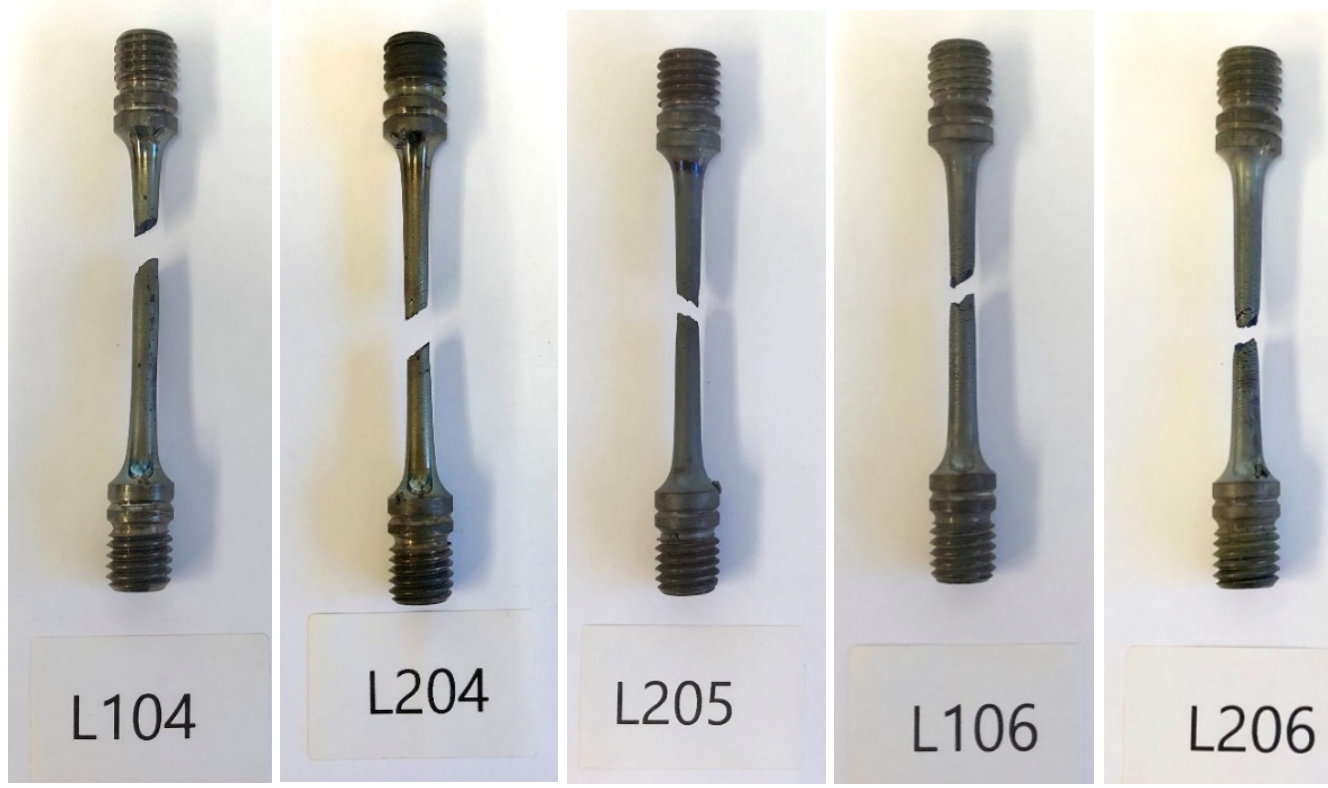

Figure 4-6. Photographs of the AM 316L SS creep-ruptured specimens.

The creep property data of AM $316 \mathrm{~L}$ at 550 and $650{ }^{\circ} \mathrm{C}$ are summarized in Table 4-2. Figure 4-7 shows the creep rupture data of AM $316 \mathrm{~L} \mathrm{SS}$ at 550 and $650{ }^{\circ} \mathrm{C}$ and compares the $550{ }^{\circ} \mathrm{C}$ data 
with the creep rupture equation at $550{ }^{\circ} \mathrm{C}$ for conventional $316 \mathrm{SS}$ developed by ORNL [12]. It is shown that the AM $316 \mathrm{~L} \mathrm{SSs} \mathrm{have} \mathrm{a} \mathrm{shorter} \mathrm{creep} \mathrm{life} \mathrm{than} \mathrm{the} \mathrm{wrought} 316 \mathrm{SS}$, regardless of different AM specimen conditions. The post-build heat treatment of $650{ }^{\circ} \mathrm{C} / 1 \mathrm{~h}$ improved the creep rupture life of AM 316L, which is still below that for the conventional $316 \mathrm{SS}$. It is also observed that the post-build solution annealing treatment of $1,050^{\circ} \mathrm{C} / 1 \mathrm{~h}$ significantly shortened the creep life. Figure 4-8 summarizes the minimum creep rate data for AM $316 \mathrm{~L}$ at 550 and $650{ }^{\circ} \mathrm{C}$. Creep data obtained to date show that the batch variability between laser 1 and laser 2 modes is insignificant.

Table 4-2. Creep property data of AM $316 \mathrm{~L} \mathrm{SS} \mathrm{tested} \mathrm{at} 550$ and $650^{\circ} \mathrm{C}$.

\begin{tabular}{ccccccccc}
\hline $\begin{array}{c}\text { Specimen } \\
\text { ID }\end{array}$ & $\begin{array}{c}\text { Laser } \\
\text { mode }\end{array}$ & $\begin{array}{c}\text { Processing } \\
\text { condition }\end{array}$ & $\begin{array}{c}\text { Test temp. } \\
\left({ }^{\circ} \mathbf{C}\right)\end{array}$ & $\begin{array}{c}\text { Stress } \\
(\mathbf{M P a})\end{array}$ & $\begin{array}{c}\text { Rupture } \\
\text { time (h) }\end{array}$ & $\begin{array}{c}\text { Minimum } \\
\text { creep rate (1/s) }\end{array}$ & $\begin{array}{c}\text { Creep rupture } \\
\text { strain (\%) }\end{array}$ & $\begin{array}{c}\text { R.A. } \\
(\%)\end{array}$ \\
\hline L101 & Laser 1 & As-built & 650 & 225 & 13.8 & $1.22 \times 10^{-6}$ & 46.9 & 45.1 \\
L102 & Laser 1 & As-built & 650 & 200 & 41.6 & $2.59 \times 10^{-7}$ & 40.7 & 43.0 \\
L103 & Laser 1 & As-built & 650 & 175 & 150.3 & $6.41 \times 10^{-8}$ & 45.8 & 44.2 \\
L104 & Laser 1 & As-built & 550 & 275 & 705.4 & $2.97 \times 10^{-8}$ & 55.9 & 53.5 \\
L106 & Laser 1 & $650^{\circ} \mathrm{C} / 1 \mathrm{~h}$ & 550 & 275 & 800.6 & $2.36 \times 10^{-8}$ & 50.7 & 53.4 \\
L201 & Laser 2 & As-built & 650 & 225 & 13.0 & $1.39 \times 10^{-6}$ & 47.5 & 46.0 \\
L202 & Laser 2 & As-built & 650 & 200 & 43.9 & $2.53 \times 10^{-7}$ & 53.5 & 46.9 \\
L203 & Laser 2 & As-built & 650 & 175 & 144.5 & $6.61 \times 10^{-8}$ & 43.2 & 44.2 \\
L204 & Laser 2 & As-built & 550 & 275 & 661.0 & $3.33 \times 10^{-8}$ & 61.0 & 58.1 \\
L205 & Laser 2 & $1050^{\circ} \mathrm{C} / 1 \mathrm{~h}$ & 550 & 275 & 464.4 & $1.65 \times 10^{-7}$ & 56.4 & 54.7 \\
L206 & Laser 2 & $650^{\circ} \mathrm{C} / 1 \mathrm{~h}$ & 550 & 275 & 734.0 & $2.56 \times 10^{-8}$ & 50.9 & 57.7 \\
\hline
\end{tabular}




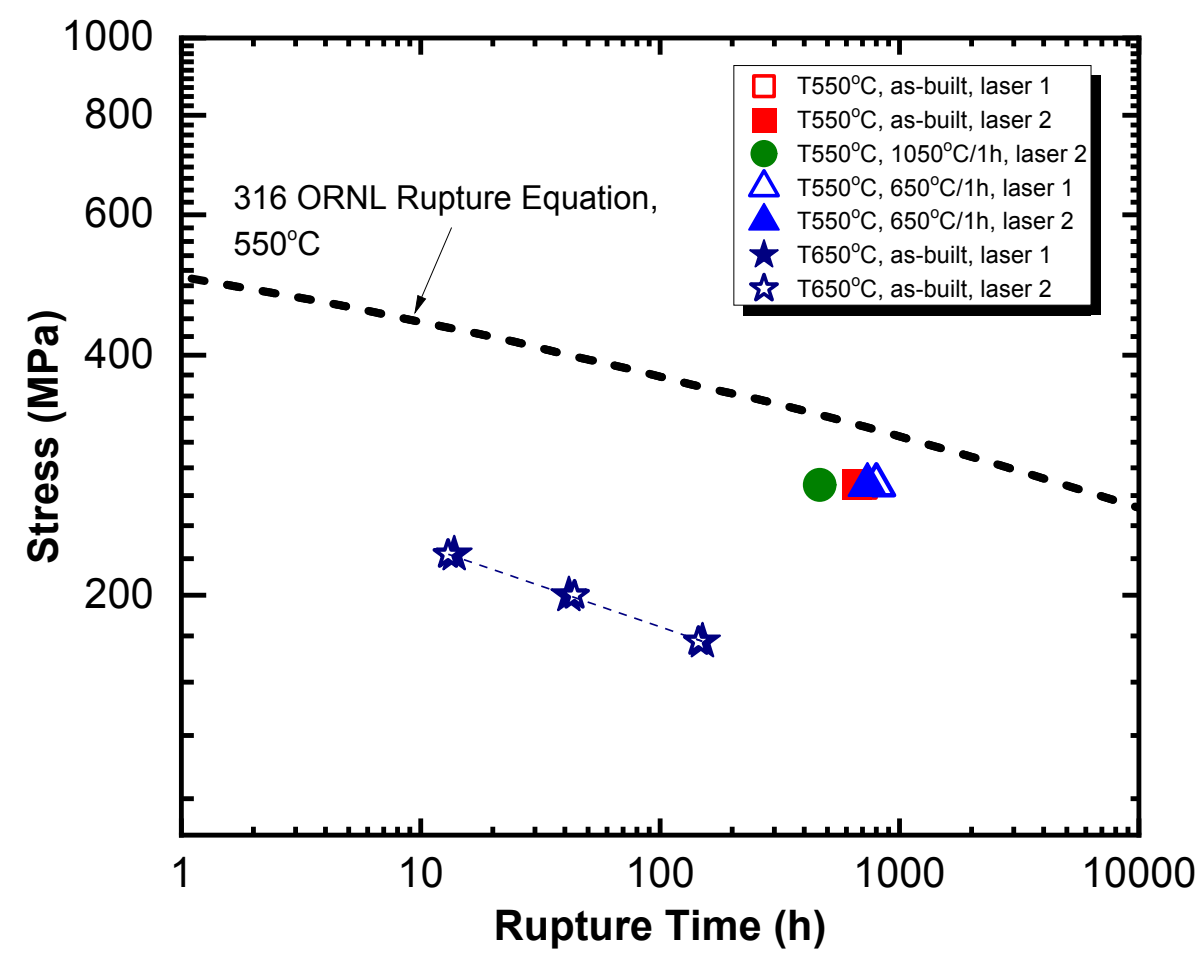

Figure 4-7. Creep rupture data for AM 316L SS tested at 550 and $650{ }^{\circ} \mathrm{C}$ and comparison with the 316 ORNL rupture equation $\left(550{ }^{\circ} \mathrm{C}\right)$ [12].

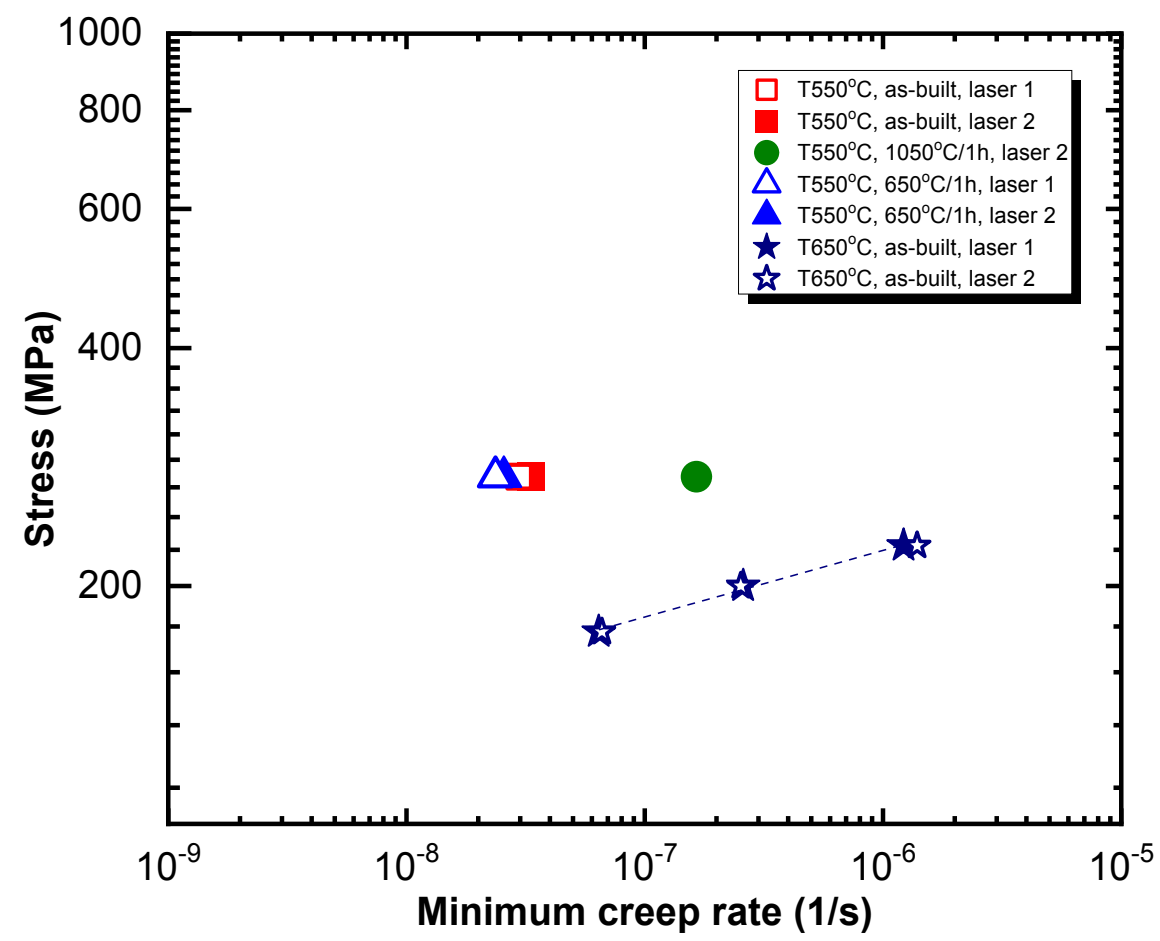

Figure 4-8. Minimum creep strain rates for AM 316L SS tested at 550 and $650{ }^{\circ} \mathrm{C}$. 


\subsection{Microstructures of AM 316L before and after Creep Deformation}

To examine the microstructure of the as-built AM 316L, a thin sheet ( $\sim 0.25 \mathrm{~mm}$ thick) was sectioned from a rod (laser 1 mode, 20190308 build) approximately 0.7 inches away from one end of the rod. Disk specimens $3 \mathrm{~mm}$ in diameter were made from the thin sheet for transmission electron microscopy (TEM) analysis. TEM disk specimens were electropolished to perforation using an electrolyte of $5 \%$ methanol and $95 \%$ perchloric acid at about $-40{ }^{\circ} \mathrm{C}$. Electropolished thin foil specimens were further ion milled to obtain appreciable thin areas for TEM observation.

In Figure 4-9, the TEM images at various magnifications reveal well-organized dislocation cells in the as-built AM 316L, in which the cell size is $\sim 500 \mathrm{~nm}$. The dislocation density is very low inside the cells. Both cell boundaries and grain boundaries are decorated with precipitate particles. Energy dispersive spectroscopy (EDS) elemental mapping shows that the particles are oxides enriched in $\mathrm{Si}$ and $\mathrm{Mn}$; elemental segregation was observed at the cell boundaries which are enriched in $\mathrm{Cr}$ and Mo and depleted of Fe, as shown in Figure 4-10. The observations are consistent with the findings reported in the literature [13].

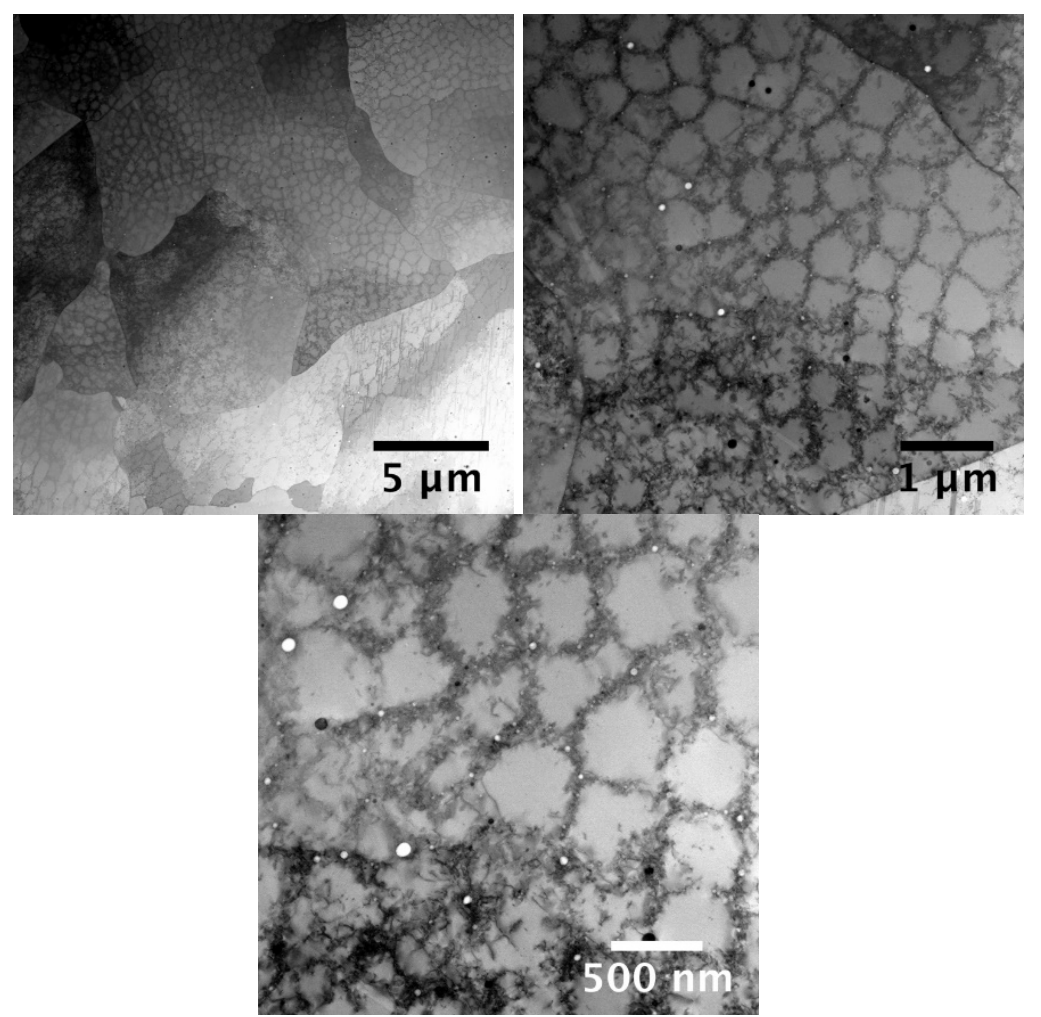

Figure 4-9. TEM micrographs showing the microstructure of the as-built AM $316 \mathrm{~L}$ SS (Laser 1 Build 20190308). 


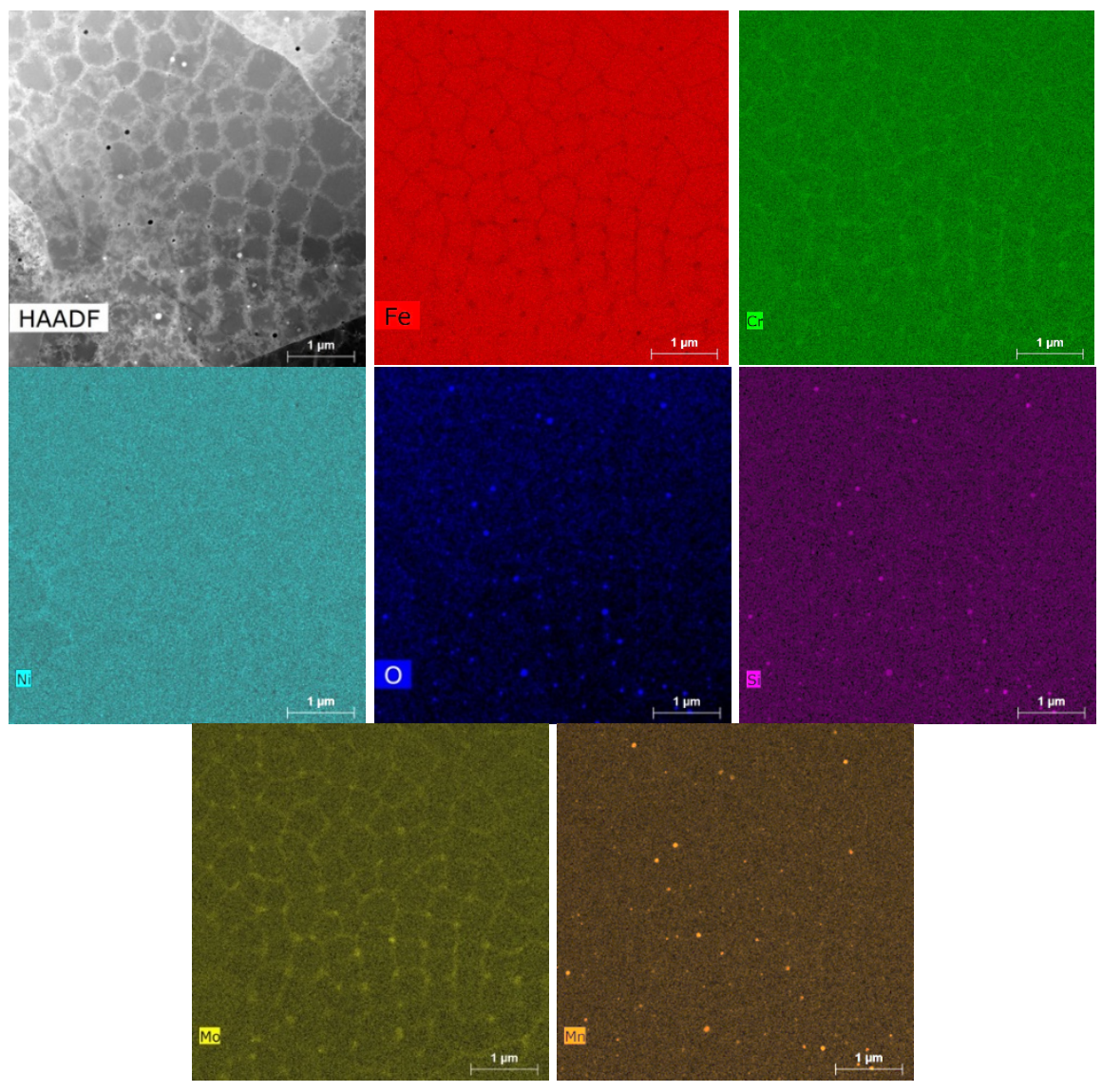

Figure 4-10. High-angle annular dark field (HAADF) micrograph and EDS elemental maps of the as-built AM $316 \mathrm{~L}$.

The solution-anneal treatment at $1,050{ }^{\circ} \mathrm{C}$ for $1 \mathrm{~h}$ effectively removed the dislocation cell structure and elemental segregation at cell boundaries observed in the as-built condition, as shown in Figures 4-11 and 4-12. Note that the TEM disks were taken from the grip section of specimen L205, which underwent an additional thermal exposure of $550{ }^{\circ} \mathrm{C}$ for $464 \mathrm{~h}$ during the creep test. This thermal exposure is expected to have an insignificant effect on the TEM-visible microstructure. Unlike the conventional solution-annealed $316 \mathrm{SS}$, dislocation lines and precipitates were observed within equiaxed grains after the heat treatment of $1,050{ }^{\circ} \mathrm{C} / 1 \mathrm{~h}$ in $\mathrm{AM}$ 316L SS. EDS elemental mapping (Figure 4-12) shows oxide particles enriched in $\mathrm{Cr}$ and $\mathrm{Mn}$, which have different chemistries from those observed in the as-built condition (Figure 4-10). The particle size in the $1,050^{\circ} \mathrm{C} / 1 \mathrm{~h}$ heat-treated specimen is significantly larger, with a mean size of 87 $\mathrm{nm}$ relative to the particle mean size of $25 \mathrm{~nm}$ in the as-built specimen (Figure 4-13). It is also noted that the particles in the as-built specimen appear to have a bimodal size distribution. 

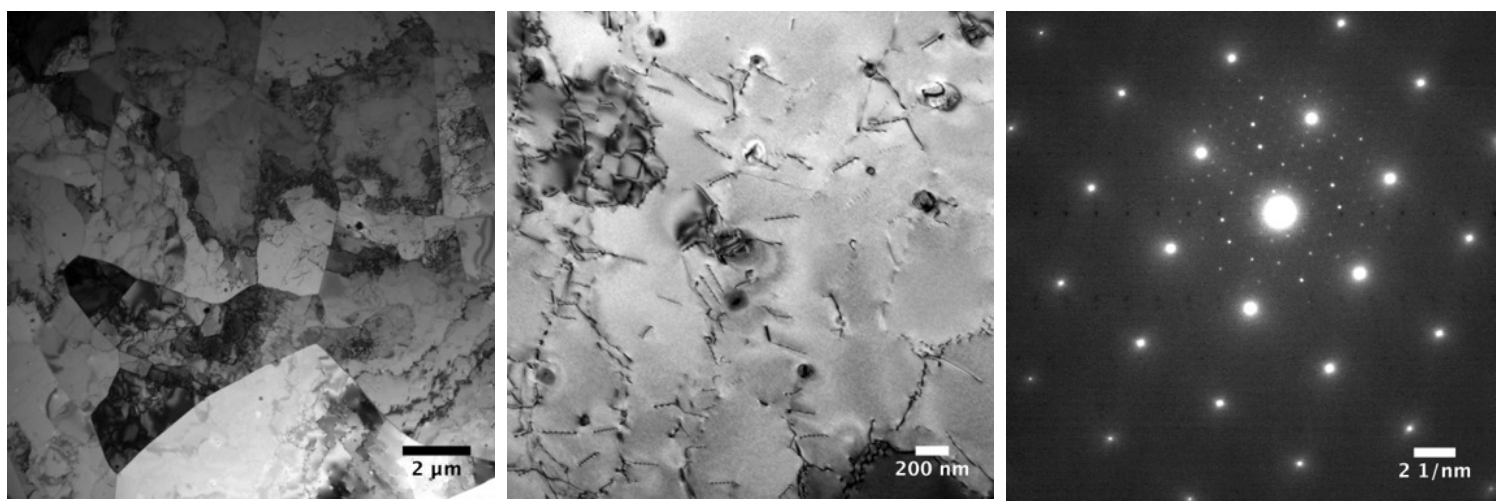

Figure 4-11. TEM micrographs showing the microstructure of the AM 316L steel heat treated at $1,050{ }^{\circ} \mathrm{C} / 1 \mathrm{~h}$. The TEM specimen was taken from the grip section of specimen $\mathrm{L} 205$.

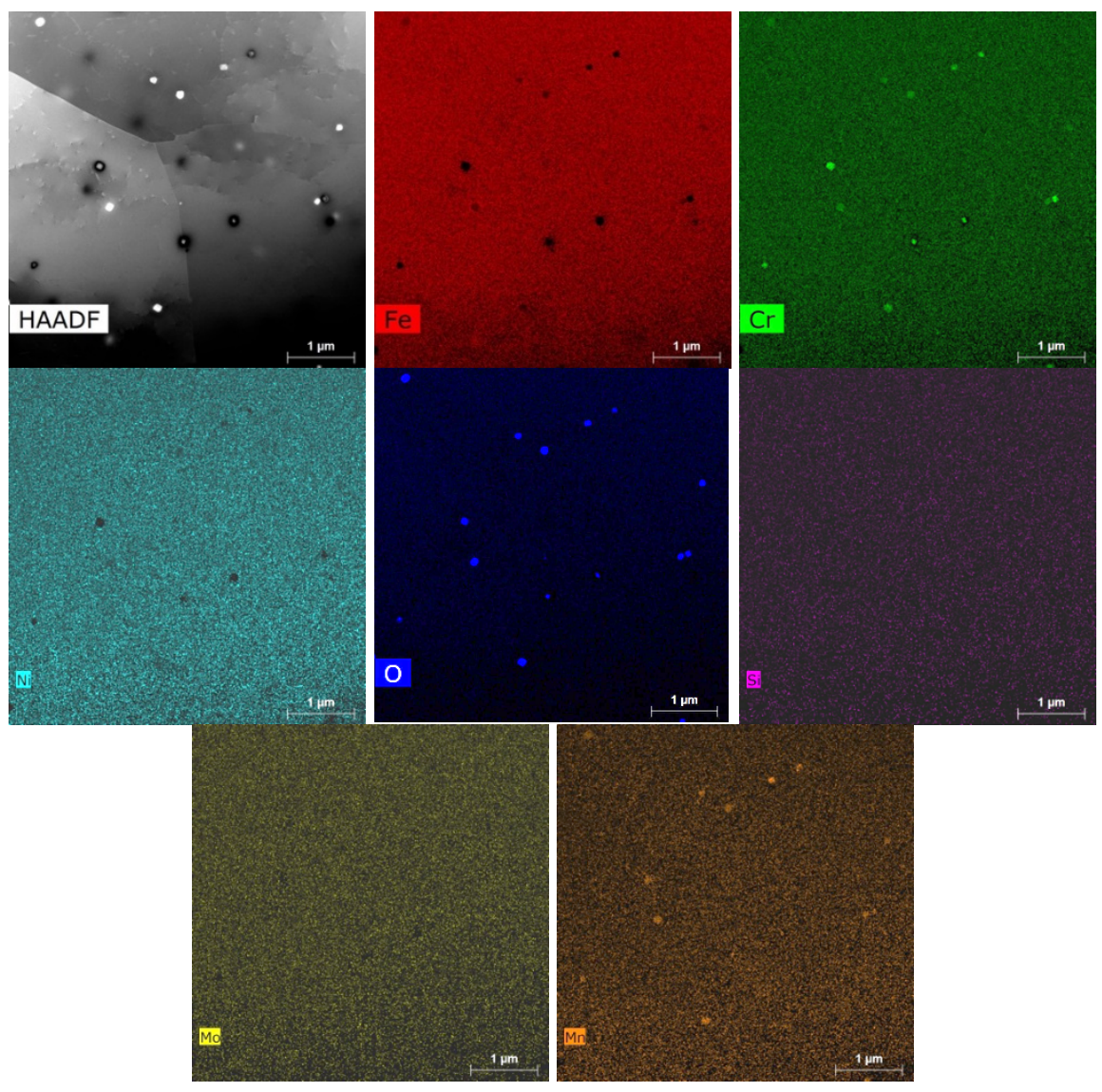

Figure 4-12. HAADF micrograph and EDS elemental maps of the AM 316L heat treated at $1,050{ }^{\circ} \mathrm{C} / 1 \mathrm{~h}$. The TEM specimen was taken from the grip section of specimen $\mathrm{L} 205$. 


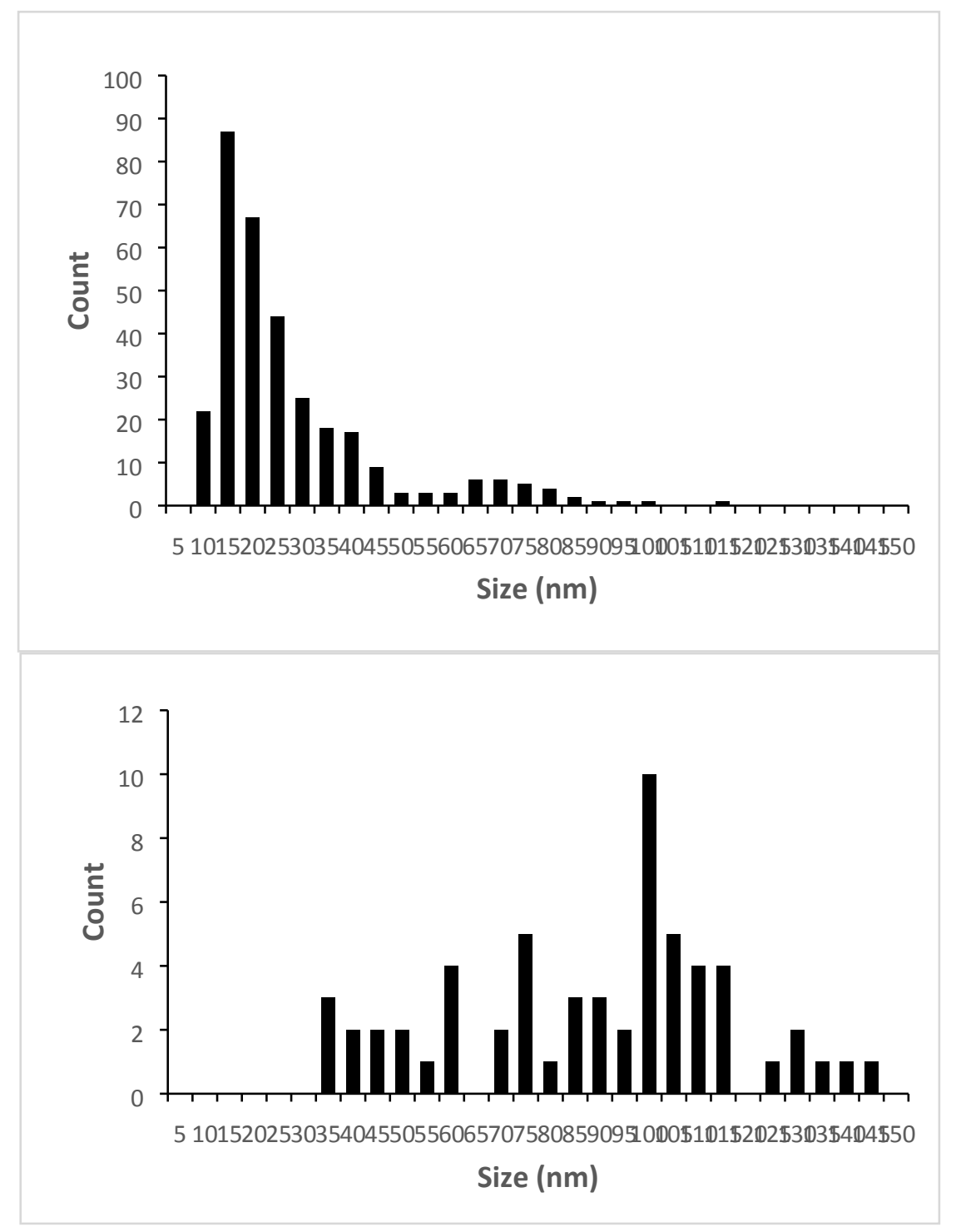

Figure 4-13. Particle size distributions in the as-built condition (mean size $=\mathbf{2 5} \mathbf{n m}$ ) (top) and in the $1,050{ }^{\circ} \mathrm{C} / 1 \mathrm{~h}$ heat treated condition (mean size $\left.=87 \mathrm{~nm}\right)($ bottom).

Figure 4-14 shows the microstructure of the as-built AM 316L after the creep test at $550{ }^{\circ} \mathrm{C}$ and $275 \mathrm{MPa}$. The specimen was taken from the gauge of specimen L204. It was found that the initial dislocation cells mostly evolved into dislocation tangles, with some cell structures still observable but less well defined. A similar observation was made in the $650{ }^{\circ} \mathrm{C} / 1 \mathrm{~h}$ heat-treated specimen after the creep test - heavy dislocation tangles, but the cell structure was less evident, as shown in Figure 4-15 (TEM specimen taken from the gauge section of specimen L206). The through-focus imaging reveal features with lower electron density features in some of the grains segregated along dislocation lines. These features may be voids or precipitates, but their exact nature is to be resolved. High density of dislocations was also observed in the $1,050{ }^{\circ} \mathrm{C} / 1 \mathrm{~h}$ heat-treated specimen after the creep test, as shown in Figure 4-16. It appears that the end microstructure after the creep test was similar, regardless of the initial state. 
Fast cooling rates during the LPBF process can produce microstructure with high non-equilibrium and high residual stress. A post-build heat treatment of $650{ }^{\circ} \mathrm{C} / 1 \mathrm{~h}$ can potentially reduce the residual stress in the as-built condition. The solution-annealing treatment at $1,050{ }^{\circ} \mathrm{C} / 1 \mathrm{~h}$ removed the dislocation cell structure and the elemental segregation at boundaries, resulting in an equilibrium structure and a homogeneous solute distribution. The oxide particles in the as-built condition, $(\mathrm{Mn}, \mathrm{Si}) \mathrm{O}$, were replaced with oxides, $(\mathrm{Mn}, \mathrm{Cr}) \mathrm{O}$, which is potentially more stable in equilibrium, and $\mathrm{Si}$ atoms dissolved in the solution. It is suggested that the dislocation cell structure in the as-built condition is largely responsible for the observed low minimum creep rate. However, this structure is unstable and can readily undergo dynamic recovery during creep, resulting in an accelerated creep. The oxide particles distributed along the cell boundaries may also play a role in reducing the creep rate and slowing the recrystallization process during the postbuild solution annealing treatment.
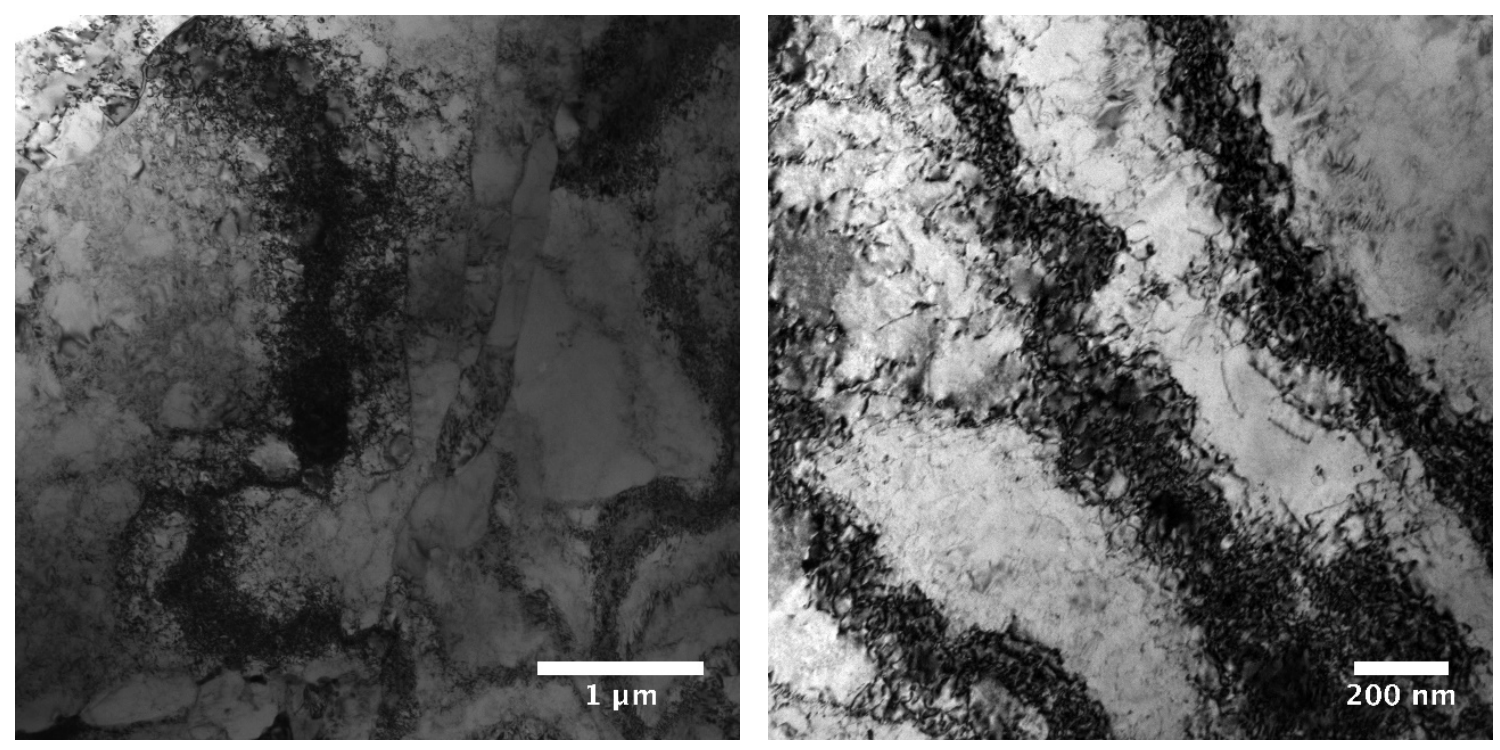

Figure 4-14. TEM micrographs showing the microstructure of the as-built $A M 316 \mathrm{~L}$ after creep test at $550{ }^{\circ} \mathrm{C} / 275 \mathrm{MPa}$. TEM specimen was taken from the gauge section of specimen $\mathrm{L} 204$. 


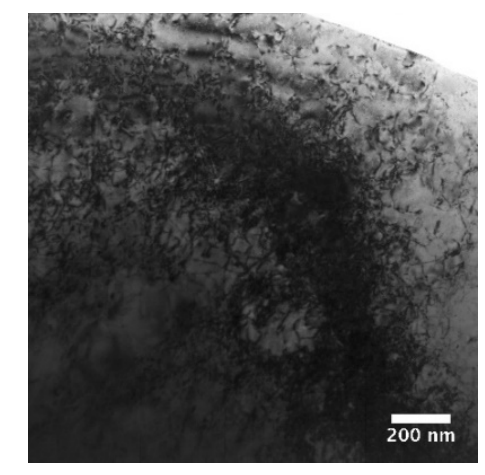

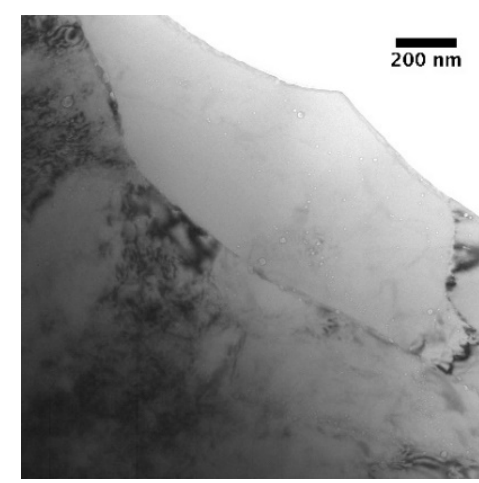

Under-focus

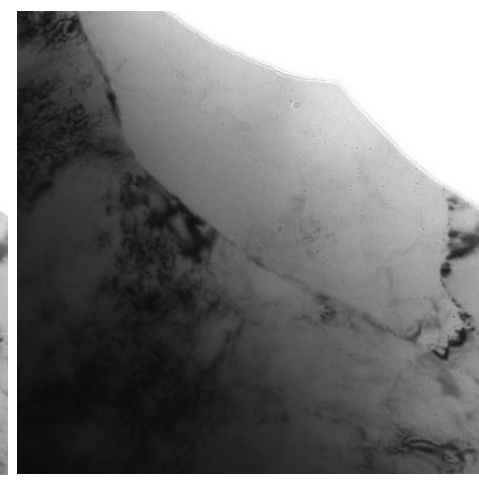

Over-focus

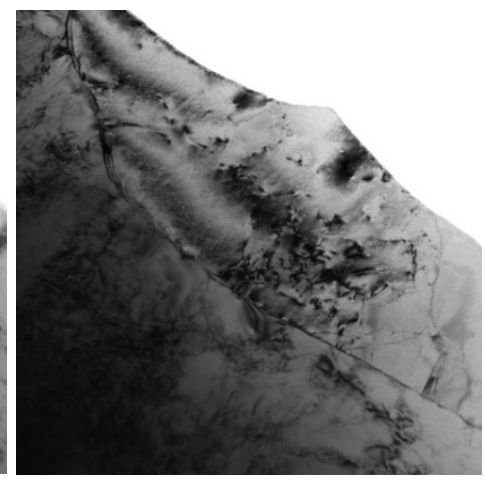

In-focus

Figure 4-15. TEM images showing the microstructures of the $650{ }^{\circ} \mathrm{C} / 1 \mathrm{~h}$ heat-treated $A M 316 \mathrm{~L}$ after testing at $550{ }^{\circ} \mathrm{C} / 275 \mathrm{MPa}$. The under-focus, over-focus, and in-focus images show voids or precipitates inside a grain. Sample was taken from the gauge section of specimen $\mathbf{L 2 0 6}$.
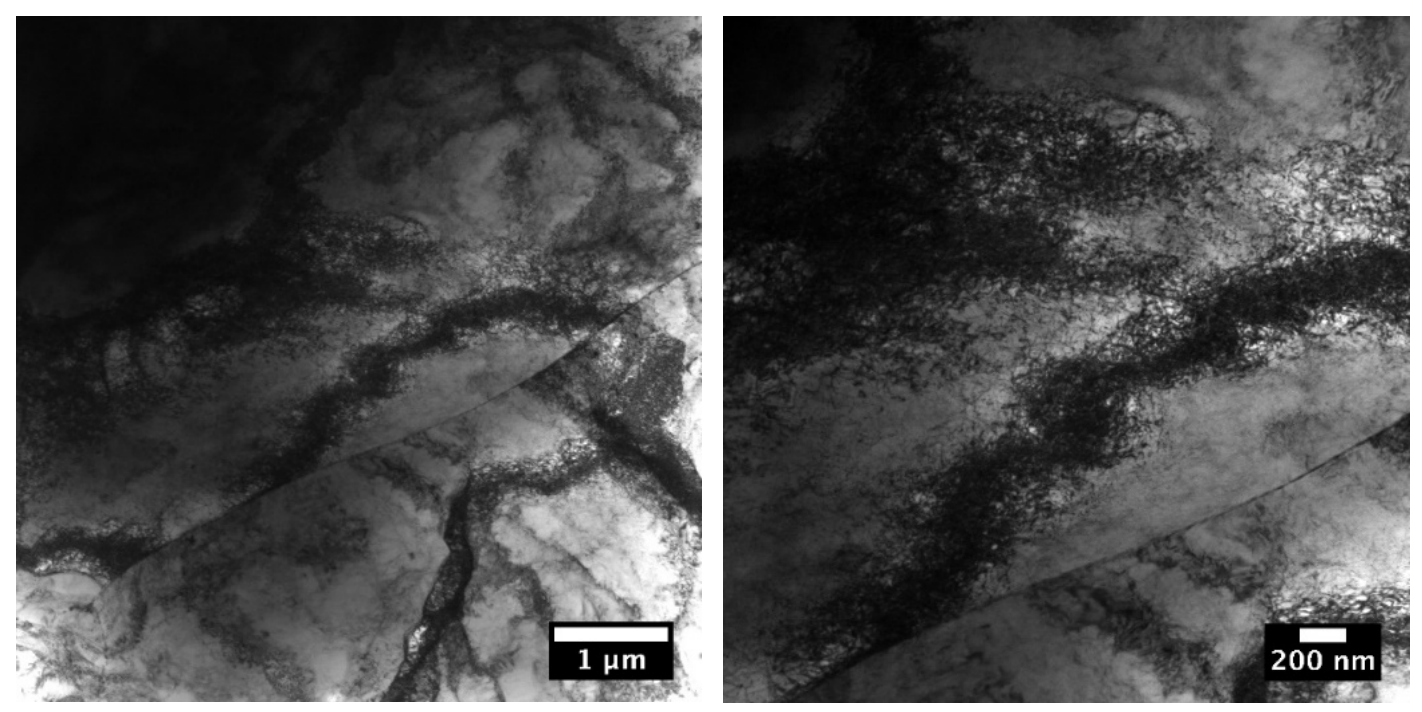

Figure 4-16. TEM images showing the microstructures of the $1,050{ }^{\circ} \mathrm{C} / 1 \mathrm{~h}$ heat-treated $A M 316 \mathrm{~L}$ after creep test at $550{ }^{\circ} \mathrm{C} / 275 \mathrm{MPa}$. Sample was taken from the gauge section of specimen $\mathrm{L} 205$. 


\subsection{Tensile Properties of AM 316L at a Creep Test Temperature}

To evaluate the effect of part geometry on tensile and creep properties and to provide locationspecific data to the TCR digital platform, 24 subsized SS-3 sheet-type specimens per rod underwent electrical discharge machining (EDM) from rods L1-8 and L2-8. Rod L1-8 was printed in laser 1 mode, and rod L2-8 printed in laser 2 mode, with the build ID of 20190315. The nominal diameters and lengths of the rods are $0.5 \mathrm{in}$. and $4 \mathrm{in}$., respectively, while the nominal gauge section of the SS-3 tensile specimen is $0.3 \times 0.06 \times 0.035 \mathrm{in}$. The gage length of each specimen was in parallel with the build direction, and three rows of specimens were machined along the build direction.

As shown in Figure 4-17, eight specimens were taken from each row, or four from each side. To track the location of each specimen, the length of the upper grip section of the specimen was increased by different amounts relative to the length of the lower grip section (instead of equal lengths as in a conventional specimen). Specifically, the upper grip is 0.09 inch longer than the lower grip in the top row specimens, 0.06 inch longer in the middle row specimens, and 0.03 inch longer in the bottom row specimens. The location of a specimen within a rod is also tracked by the specimen ID. For example, in ID "1T1," the first character "1" represents laser 1 mode, the second character " $T$ " represents the top section of the rod, and the final character " 1 " shows the location of the specimen in the cross section of the rod (see the cross section view in Figure 4-17).

Tensile tests were performed in an electromechanical testing system equipped with Instron Bluehill software. Tests were conducted at $550{ }^{\circ} \mathrm{C}$ at a nominal strain rate of $1 \times 10^{-3} / \mathrm{s}$ using a set of pin-loading grips. The applied load was recorded by a load cell; the specimen displacement was measured by the crosshead extension. Engineering tensile properties were determined from the analysis of the load and displacement data.

Figure 4-18 shows the engineering stress-strain curves of four specimens: two in the top section, and the other two in the bottom section of rod L1-8. These four specimens showed remarkably similar tensile behavior with comparable YS, working hardening rate, and UTS. However, their tensile ductility varied: specimen 1B4 has the lowest UE and TE, and specimen 1T4 has the highest elongations, both of which were machined from the central region of the rod. Specimens $1 \mathrm{~B} 2$ and 1T2, which were from the periphery of the rod, have similar elongation values that are between the elongation values of specimens 1B4 and 1T4. There appears to be a location dependence of tensile ductility, as illustrated in Figure 4-19. Specimens in the middle section of rod L1-8 will be tested to provide further information. The tensile properties-YS, UTS, UE, and TE-are summarized in Table 4-3.

It is observed that the $550{ }^{\circ} \mathrm{C}$ tensile test data in Table 4-3 are mostly very close to the tensile data of as-built 316L SS plotted in Figures 3-3 through 3-6, in which we need to interpolate the data between $500{ }^{\circ} \mathrm{C}$ and $600{ }^{\circ} \mathrm{C}$ for a direct comparison. Only noticeable difference is found in the TE data: the data from the SS-3 specimens are within 27-34\% (Table 4-3) and are slightly higher than the interpolated TE value in Figure 3-6 ( 23\%). This may be because the necking deformation after UE is slightly more stable in the larger SS-3 specimens than in the SS-J2 specimens. 


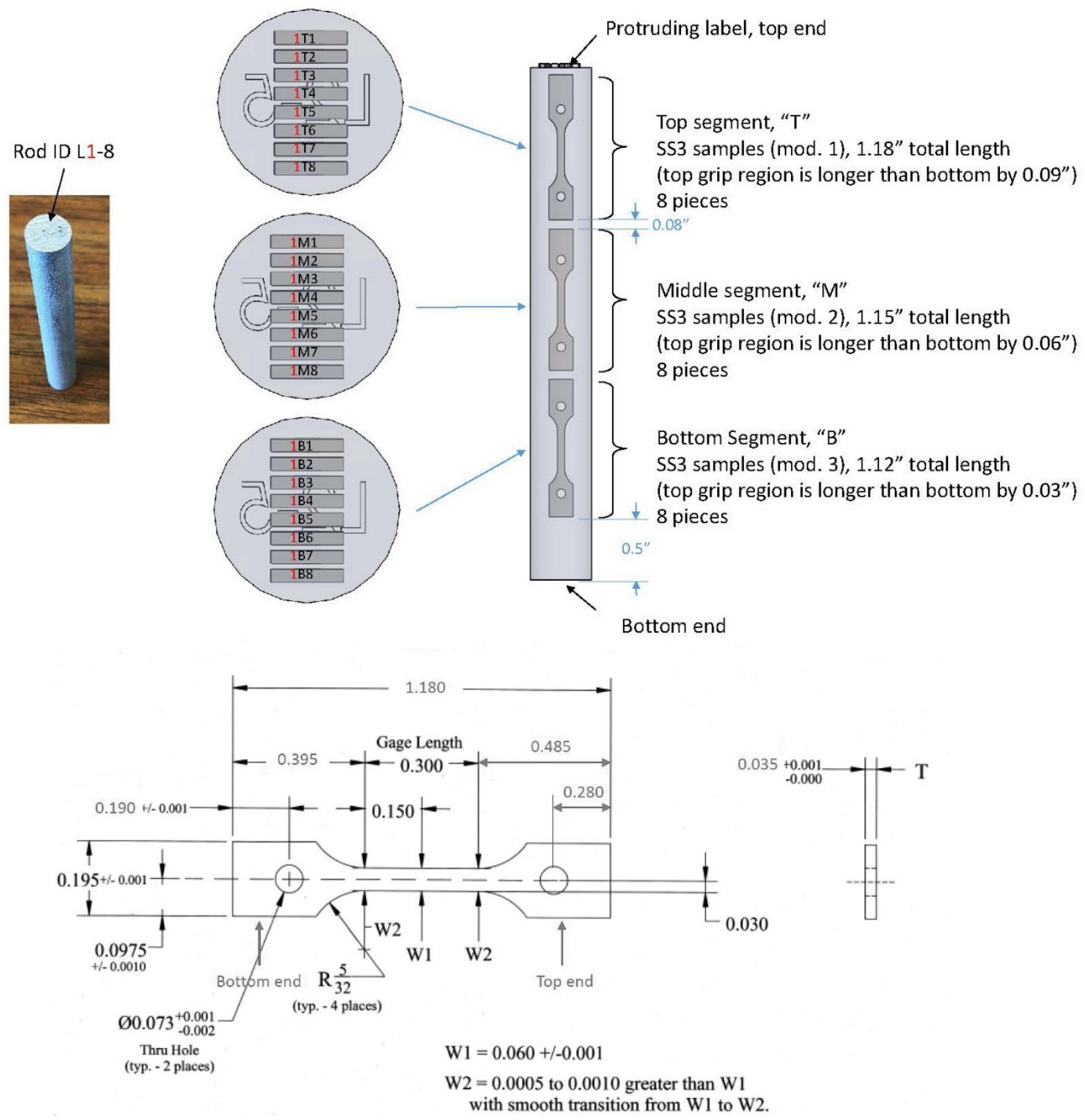

Figure 4-17. Specimen fabrication drawings showing the orientation and location of each specimen (top); an SS-3 sheet-type specimen design for the top section of the printed rod (bottom); specimens for the middle and bottom sections were designed to be slightly shorter (1.15 and 1.12 in., respectively) for good traceability (unit: in.). 


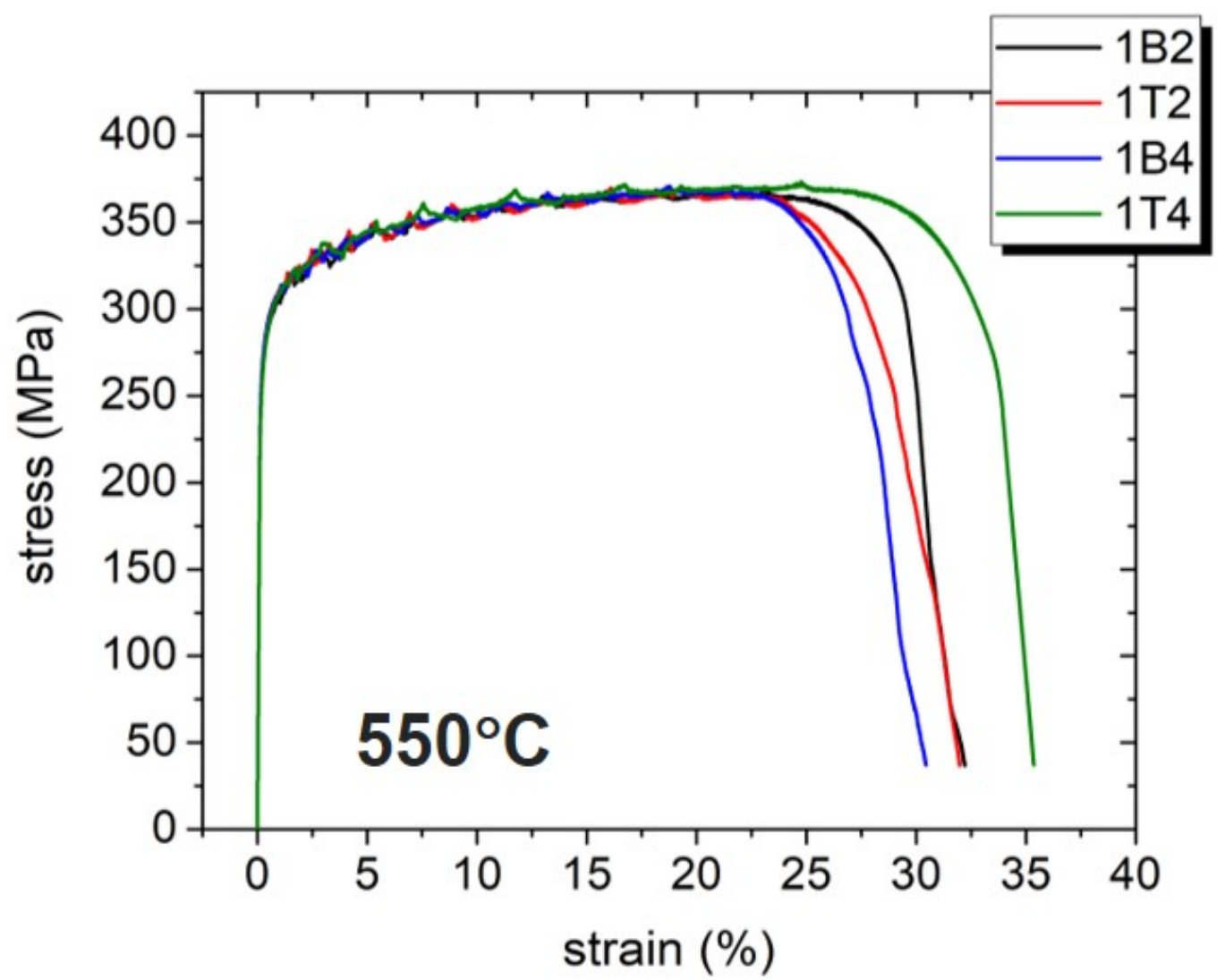

Figure 4-18. Engineering stress-strain curves at $550{ }^{\circ} \mathrm{C}$ for specimens taken from the top and bottom sections of $\operatorname{rod} \mathrm{L1-8}$.

Table 4-3. Location-dependent tensile property data of AM 316L.

\begin{tabular}{ccccccccc}
\hline $\begin{array}{c}\text { Specimen } \\
\text { ID }\end{array}$ & $\begin{array}{c}\text { Rod } \\
\text { ID }\end{array}$ & $\begin{array}{c}\text { Specimen } \\
\text { type }\end{array}$ & $\begin{array}{c}\text { Test temp. } \\
\left({ }^{\circ} \mathbf{C}\right)\end{array}$ & $\begin{array}{c}\text { Strain rate } \\
(\mathbf{1} / \mathbf{s})\end{array}$ & $\begin{array}{c}\text { YS } \\
(\mathbf{M P a})\end{array}$ & $\begin{array}{c}\text { UTS } \\
(\mathbf{M P a})\end{array}$ & $\begin{array}{c}\text { UE } \\
(\mathbf{\%})\end{array}$ & $\begin{array}{c}\text { TE } \\
(\mathbf{\%})\end{array}$ \\
\hline 1T2 & L1-8 & SS-3 & 550 & 0.001 & 281 & 370 & 22.9 & 29.0 \\
1T4 & L1-8 & SS-3 & 550 & 0.001 & 277 & 373 & 24.8 & 33.7 \\
1B2 & L1-8 & SS-3 & 550 & 0.001 & 277 & 368 & 23.2 & 29.6 \\
1B4 & L1-8 & SS-3 & 550 & 0.001 & 281 & 371 & 21.5 & 27.0 \\
\hline
\end{tabular}




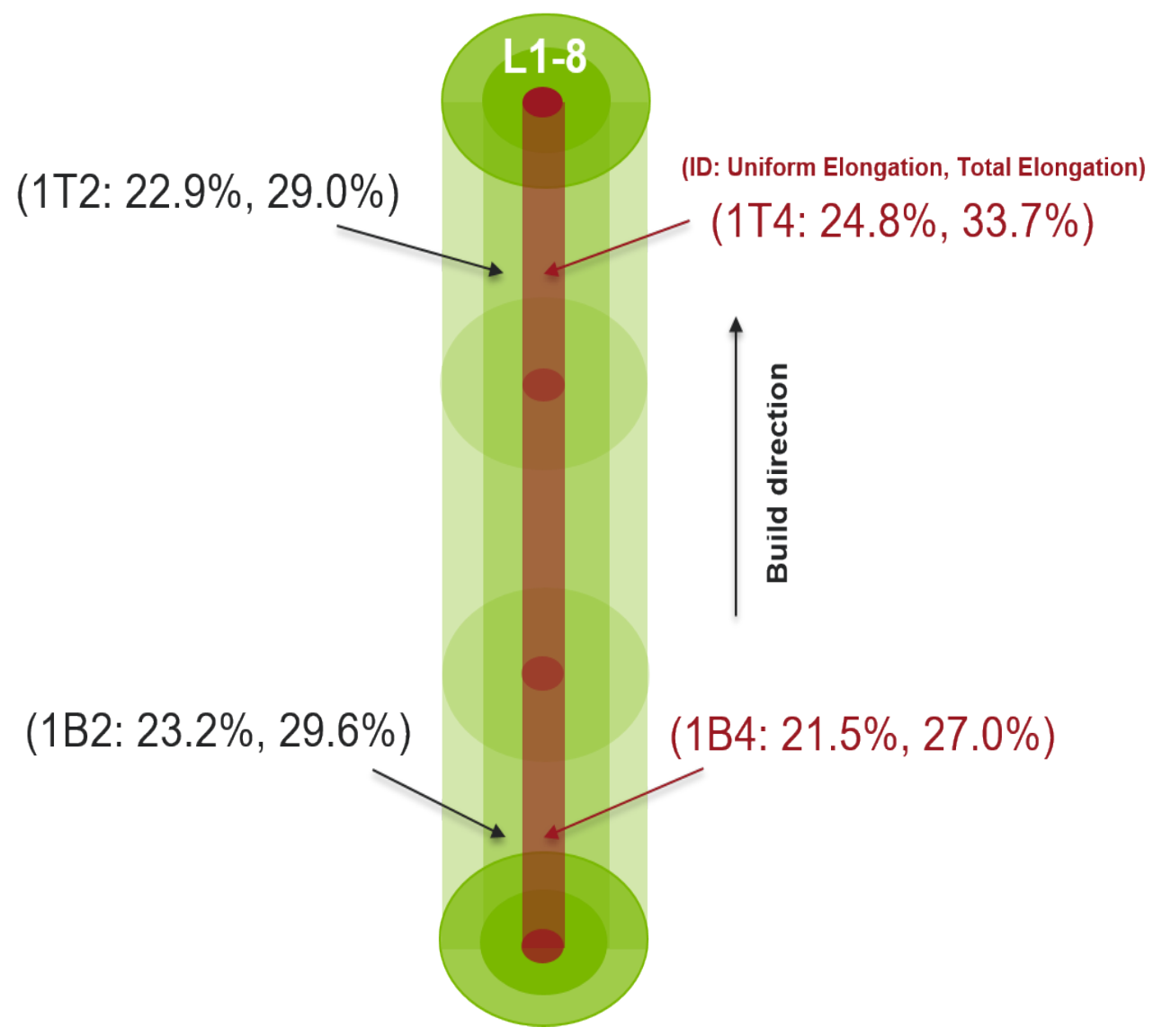

Figure 4-19. Illustration of location-dependent $U E$ and TE values in the printed rod L1-8. Tensile tests were conducted at $550{ }^{\circ} \mathrm{C}$.

\subsection{In-Situ High-Energy X-Ray Analysis of Plastic Deformation in AM 316L}

Previous sections show that the AM 316L possesses an outstanding balance of low temperature strength and ductility due to the unique hierarchical microstructure [14] or texture [15]. In this work, the RT tensile deformation of AM 316L was studied by in-situ high-energy x-ray diffraction and x-ray tomography/radiography techniques at ANL's Advanced Photon Source (APS). A conventional $316 \mathrm{H}$ specimen was also studied using in-situ x-ray diffraction for comparison. Lattice strain evolution, dislocation kinetics, and coherent domain size evolution during deformation process were monitored using the x-ray diffraction technique. The morphology of the pores in the AM 316L during deformation was also tracked.

The SS-J3 type tensile samples made of AM 316L were provided by ORNL under the TCR program. The conventional $316 \mathrm{H}$ sample was machined from a plate into the SS-J3 geometry. The in-situ tensile tests were performed at RT in air using a $\mu \mathrm{TS}$ load frame manufactured by Psylotech Inc. at the APS beamline 1-ID. In each test, the strain rate was set at $5 \times 10^{-5} / \mathrm{s}$ for the first few percent of strain and then was changed to $2 \times 10^{-4} / \mathrm{s}$ for the remainder of the test. No strain rate sensitivity was expected at RT within this strain rate range. 
During tensile testing, monochromatic x-ray beams were transmitted through the sample around the center of the gage, and the diffraction signal was received by a GE RT-41 area detector 881 mm down-stream from the sample. The x-ray energy was $80.725 \mathrm{keV}$, and the beam size was 30 $\mu \mathrm{m} \times 40 \mu \mathrm{m}$. For the AM 316L sample, tensile deformation and diffraction measurements were paused at 4 intermittent steps for x-ray tomography. Except for the final scan, which was taken around the necking center (the necking center was not at the gage center in this sample), the other 3 scans were all centered on the gage, providing direct observation of the changing morphology of a group of pores. The beam size for tomography was $2.0 \mathrm{~mm}(\mathrm{~W}) \times 1.0 \mathrm{~mm}(\mathrm{~L})$.

The x-ray diffraction data were processed by a MatLab package provided by the beamline. The area detector signals were first converted to 1-dimensional (1D) diffraction profiles in the loading direction by summing up the intensities of each Debye-Scherrer ring from $\pm 10^{\circ}$ around the loading direction, and the peaks were fitted for peak positions to obtain the lattice strain as a function of tensile strain in the loading direction. The entire area's detector signals were then processed and fitted to obtain the full-width at half-maximum (FWHM) using a method detailed in Zhang et al. [16]. The FWHM data were analyzed using the modified Williamson-Hall (W-H) method [17] to obtain the evolution of dislocations and the coherently scattering domain sizes with deformation,. Details of the FWHM data analysis method can also be found in Zhang et al. [16].

Figure 4-20(a) is a schematic of the test setup at the beamline. Figure 4-20(b) shows the stressstrain $(\sigma-\varepsilon)$ curves of the AM $316 \mathrm{~L}$ and the conventional $316 \mathrm{H}$ samples. The thicker lines are the engineering $\sigma-\varepsilon$ curves, and the thinner ones are the true $\sigma-\varepsilon$ curves. The tensile properties are listed in Table 4-4. Compared to the conventional $316 \mathrm{H}$, the AM 316L shows a significant increase in YS, from $223 \mathrm{MPa}$ to $431 \mathrm{MPa}$, while maintaining a high total elongation of $75.6 \%$. The green asterisk symbols on the AM $316 \mathrm{~L}$ curves indicate the tomography scanning points.

Table 4-4. Tensile properties obtained from the in-situ $x$-ray experiment

\begin{tabular}{lcccc}
\hline Sample I.D. & $\mathbf{0 . 2 \%}$ YS (MPa) & UTS (MPa) & UE (\%) & TE (\%) \\
\hline AM 316L & 431 & 590 & 60.4 & 75.6 \\
$316 \mathrm{H}$ & 223 & 566 & 76.2 & 82.5 \\
\hline
\end{tabular}


(a)
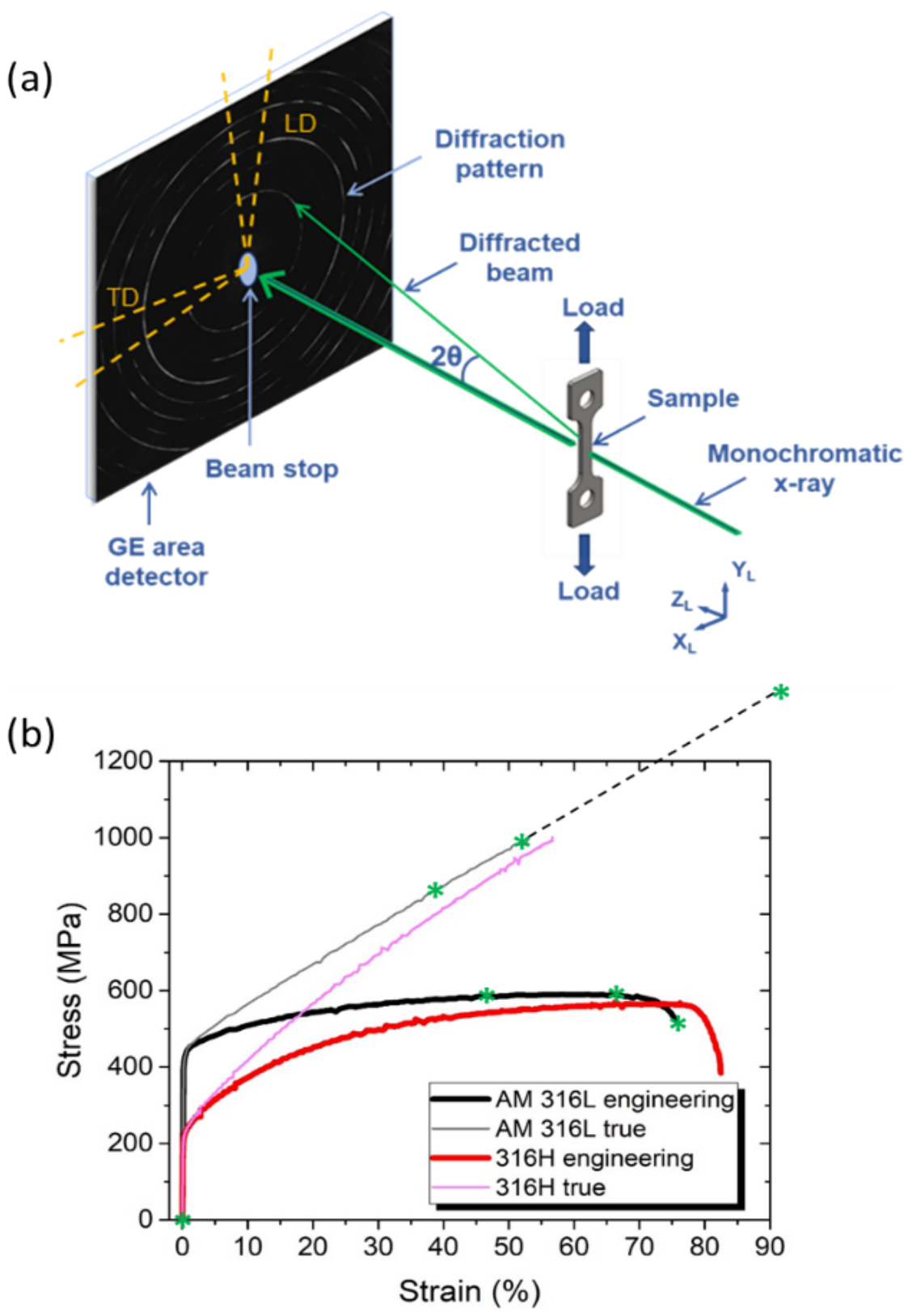

Figure 4-20. (a) In-situ x-ray experiment setup, and (b) RT stress-strain curves of the conventional $316 \mathrm{H}$ and the AM 316L.

Figure 4-21 shows the lattice strain (a) and the FWHM (b) as a function of true strain for peaks 38 of the face-centered cubic (FCC) AM 316L SS. All of these parameters increase monotonically with strain. The FWHM data were analyzed by the modified W-H method to gain insights into the dislocation dynamics, and the behavior of AM 316L will be compared with that of the conventional $316 \mathrm{~L}$ to understand the differences in their tensile behavior. 
(a)

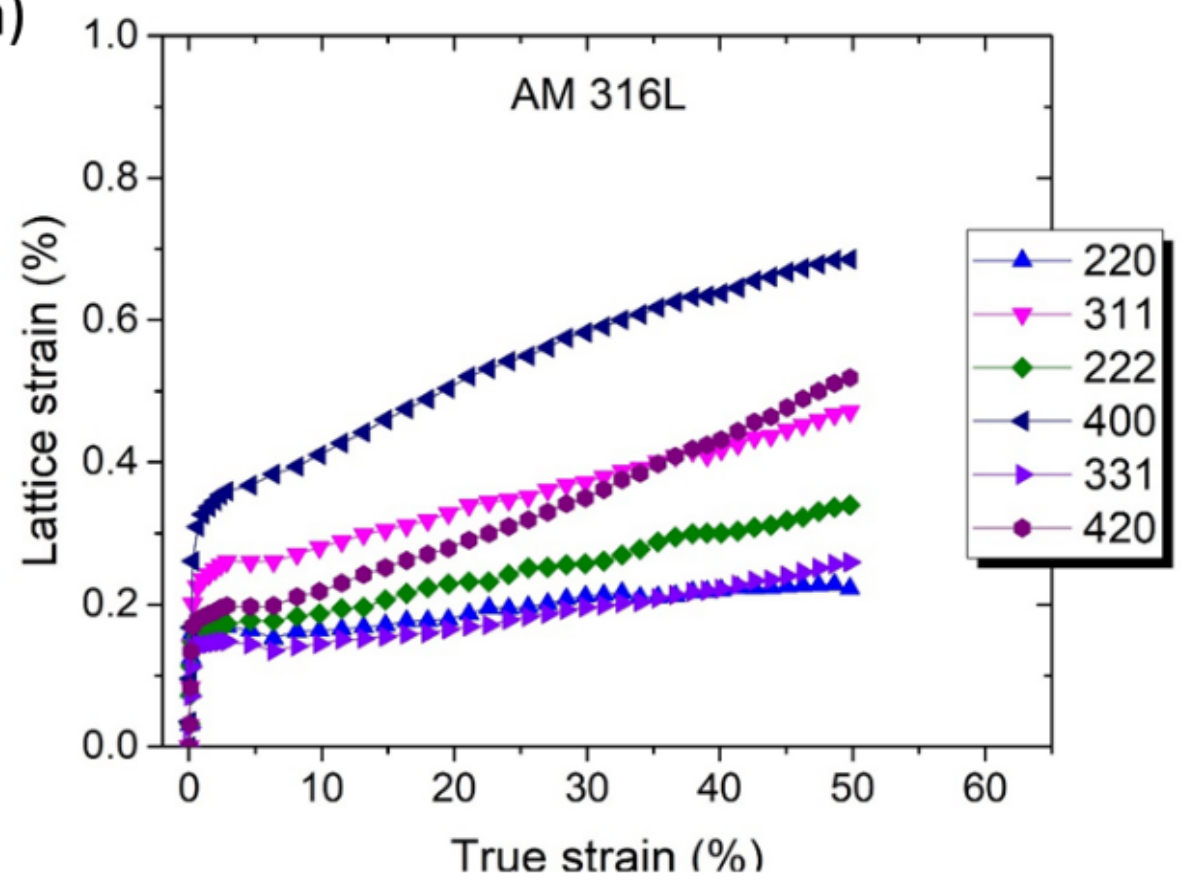

(b)

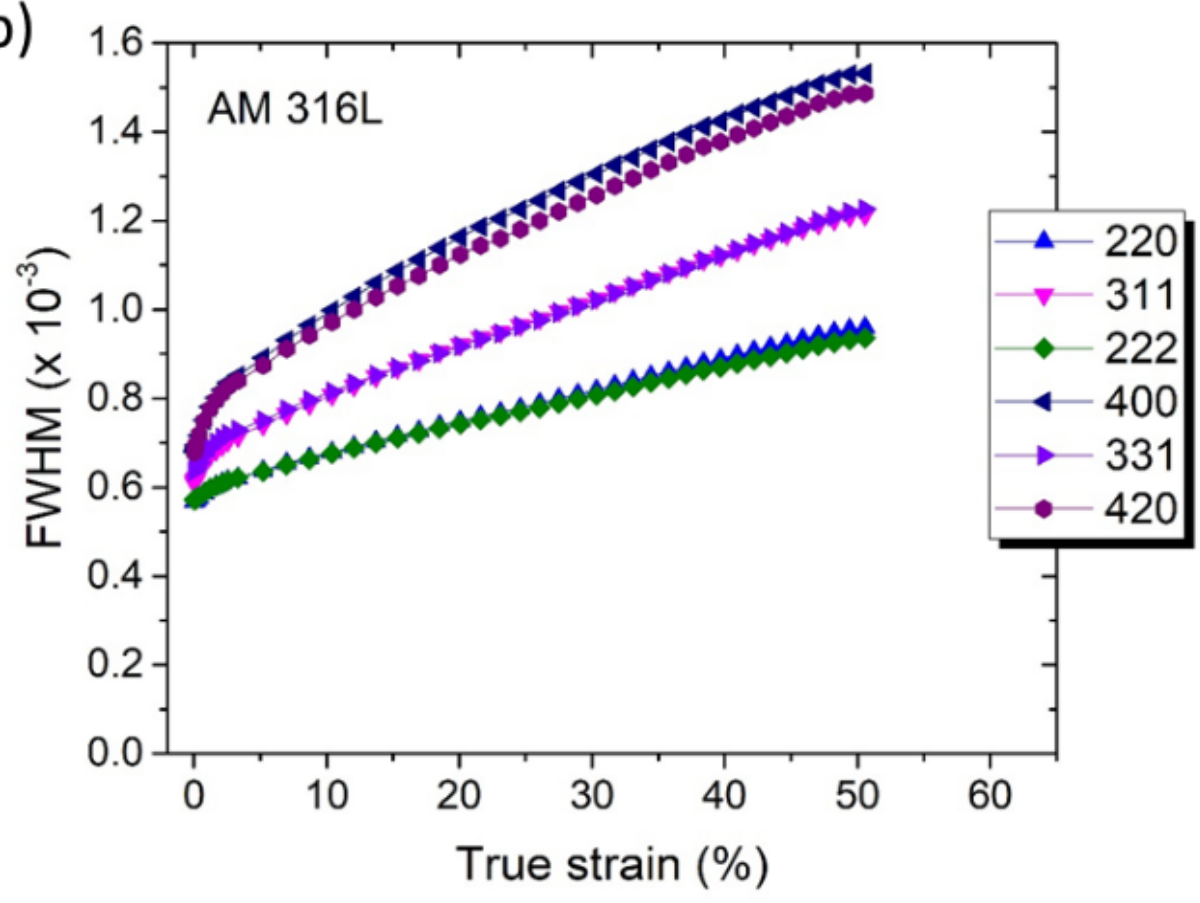

Figure 4-21. The lattice strain (a) and the FWHM (b) as a function of true strain for peaks 3-8 of the AM 316L sample. 
The x-ray radiographs taken from the gage center of AM316L (Figure 4-22) reveal the sample's internal porosity. The as-received sample had a high density of spherical pores with sizes up to $\sim 50 \mu \mathrm{m}$, together with a low density of larger, irregularly shaped pores. The initial porosity was $\sim 0.1 \%$. The radiographs at different strains show that the pores became elongated with increasing tensile deformation. As necking progressed, cracks initiated at a few large pores near the specimen edge. Further analysis of synchrotron high-energy x-ray diffraction and tomography/radiography is being conducted to understand the deformation mechanism in AM 316L SS.

Undeformed
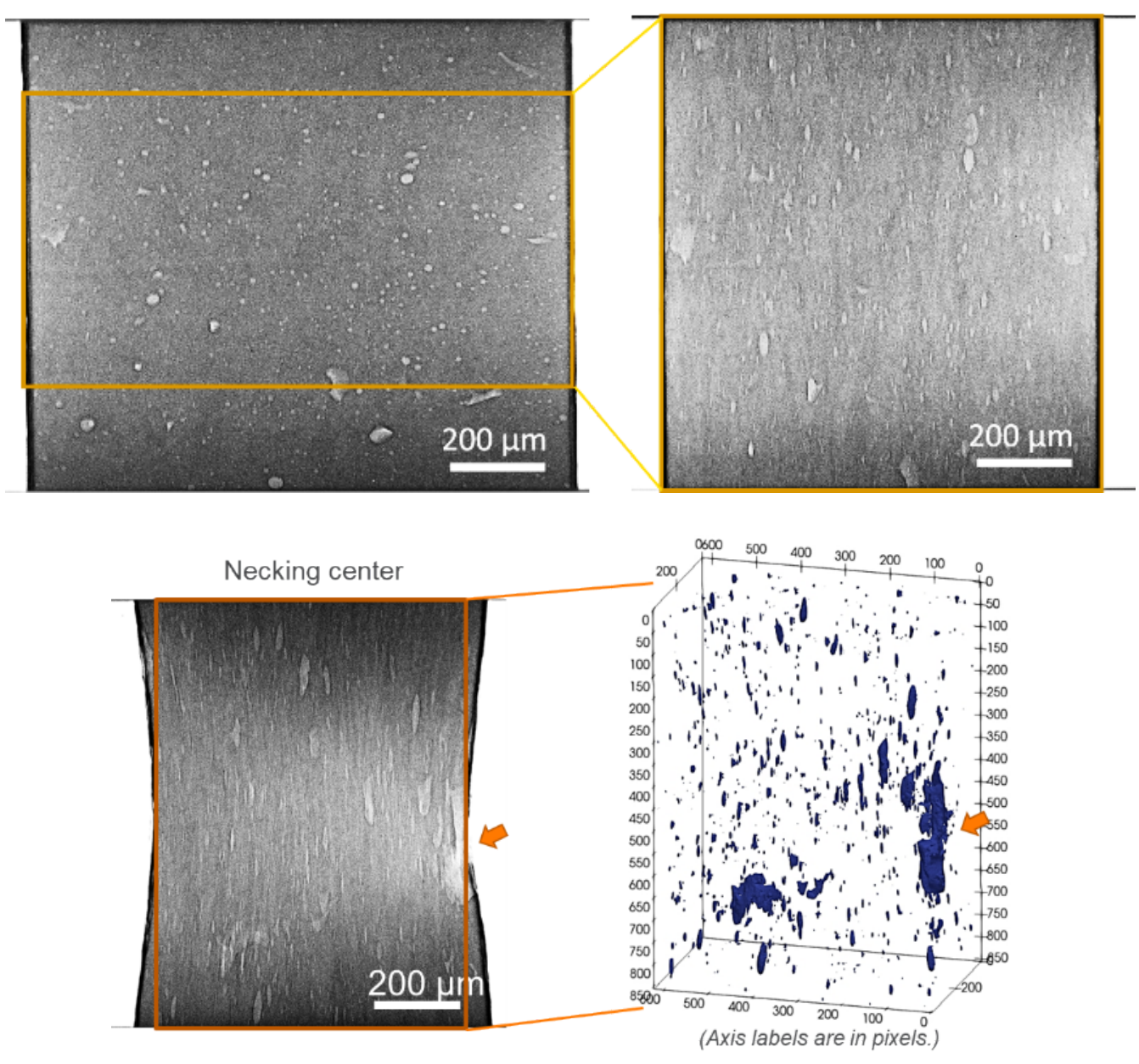

Figure 4-22. X-ray radiographs of the gage area of AM 316L showing the internal porosity at different deformation levels. 


\section{DEFORMATION AND FRACTURE PROCESSES}

\subsection{In-situ Tensile Testing in SEM}

The deformation and fracture behavior of AM 316L SSs was investigated using the electron backscatter diffraction (EBSD) technique of SEM, which allows crystallography at submicron scale and can be combined with a mechanical testing device. This section describes the results of the in-situ mechanical testing of the AM 316L steel in the as-built condition as well as in two annealed conditions. The deformation and fracture behaviors of AM 316L SSs were also compared with those of wrought $316 \mathrm{~L}$ steel. The tensile specimens used in this in-situ SEM testing were the SS-J2 design.

The in-situ mechanical testing was conducted using TESCAN MIRA 3 SEM with an advanced high-speed Oxford Symmetry EBSD detector (maximum pattern size of 1,288 × 1,024 pixels), as seen in Figure 5-1. All in-situ tests were run at an acceleration voltage of $20 \mathrm{kV}$ and at a nominal beam current of $\sim 3 \mathrm{nA}$. The SEM was equipped with an MZ.Sb K\&W (Kammrath and Weiss Tech.) miniature tensile frame with $5 \mathrm{kN}$ loading capacity. The EBSD settings (working distance, voltage, current, scanning rate or points per second, pattern binning, and microscope magnification) were kept as consistent as possible in all in-situ tensile experiments. In the in-situ tensile testing, specimens were loaded at a nominal strain rate of $10^{-3} \mathrm{~s}^{-1}$ (displacement rate of 5 $\mu \mathrm{m} / \mathrm{s}$ or $0.3 \mathrm{~mm} / \mathrm{min}$ ) at RT. EBSD data collected during the in-situ test were processed using EDAX OIM v.8.0 software. The crystal orientation data were imported from Oxford AZtec software with careful attention to the Euler angle change convention between these two software packages. EDAX OIM software was used to plot EBSD maps (inverse pole figure [IPF], image quality [IQ], phase) and to calculate the kernel average misorientation (KAM) and grain reference orientation distribution (GROD) parameters. The KAM parameter was selected as a typical kernelbased misorientation metric. According to its definition, the KAM is the average misorientation angle of a given point with all its neighbors. Here, KAM was calculated using only the nearest neighbors (1st order KAM), a maximum misorientation of $5^{\circ}$, and using only points in the perimeter.

To provide sufficient statistics for scanned area size and the number of grains within the scan, a region of interest (ROI) with initial dimensions of $300 \times 250 \mu \mathrm{m}$ was selected for each specimen and scanned with a step (pitch) of $0.5 \mu \mathrm{m}$ at a nominal $600 \times$ magnification using $8 \times 8$ binning. Features of interest (e.g., strain-induced twins) were also scanned at increased magnification levels (up to $2,000 \ldots 4,000 \times$ ) with a $125 \mathrm{~nm}$ step. To confirm the correct identification of observed features (e.g., twins, ferritic grains), multiple Kikuchi patterns were recorded and analyzed manually post-test. As is common practice, a misorientation angle of $5^{\circ}$ was selected to identify grains in the EBSD scans. Compromises were made regarding the dimension of ROI, EBSD resolution or step size, and the number of deformation steps so that the necessary data and statistics could be obtained in the time available at the SEM. 


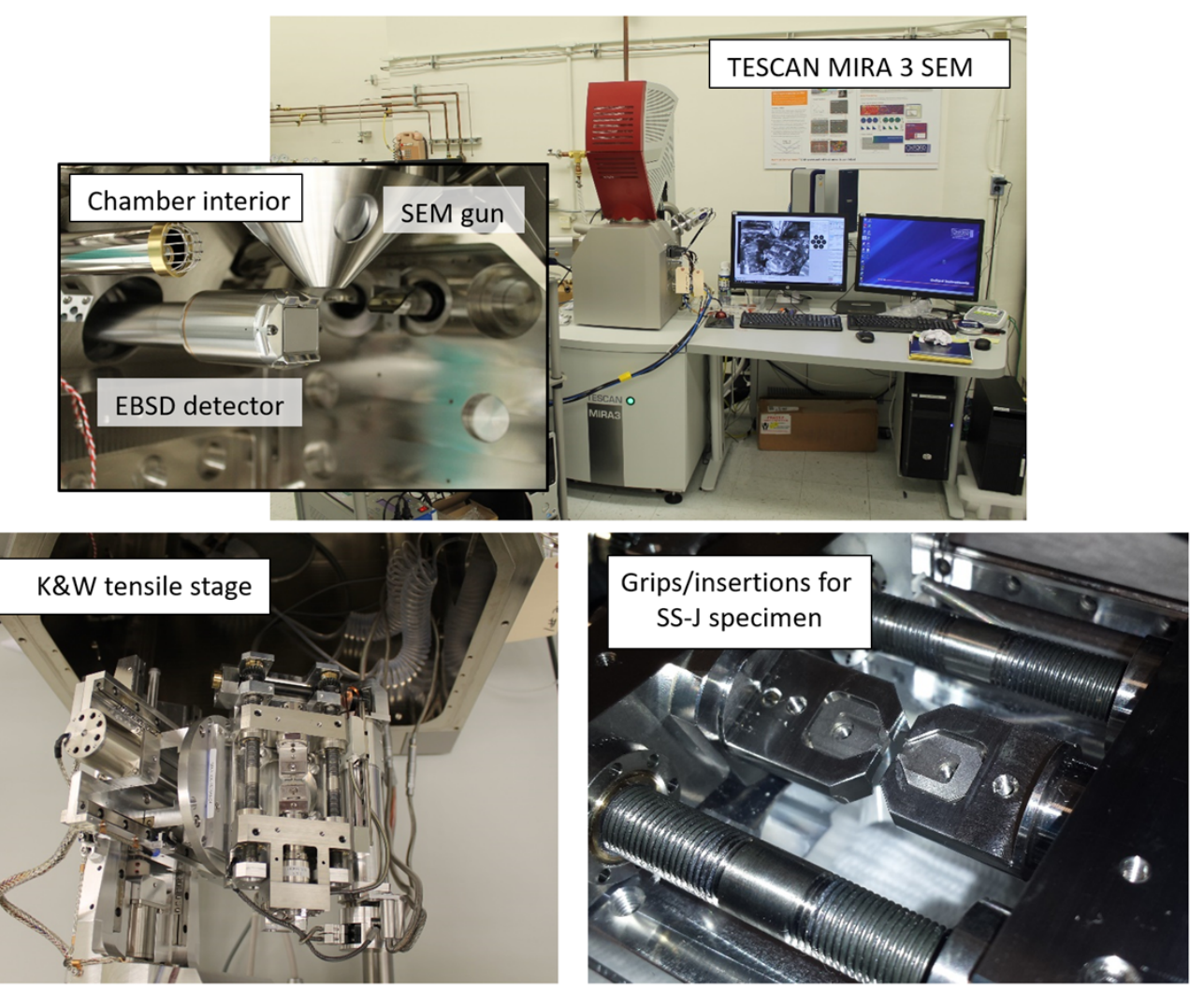

Figure 5-1. TESCAN MIRA3 SEM (top): the inset (top) shows an Oxford EBSD detector in working position; $K \& W$ tensile stage installed in the SEM chamber (bottom left) and master grip set for SS-J tensile specimen (bottom right).

After the tensile specimen is fractured, the broken halves are immediately put into fresh, contamination-free plastic membrane boxes. The specimens tested in situ were analyzed in the SEM (TESCAN MIRA 3) to investigate the fracture surface morphology. During fractography analysis, an acceleration voltage of $5 \mathrm{kV}$ and a working distance of $\sim 9.5-10 \mathrm{~mm}$ were employed. Additionally, a focused ion beam (FIB) device was used to produce samples for TEM analysis.

\subsection{Stress-Strain Behavior}

Figure 5-2 shows four tensile curves recorded for the AM-316L specimens in as-printed conditions. The red curve with small relaxation (force drop) segments corresponds to the record of an in-situ experiment conducted inside the SEM. The force-drop segments appeared when the mechanical test was interrupted to perform the EBSD scanning and SEM imaging of the surface. Three thin curves were from the ex-situ tests and are compared with the in-situ test curve. 


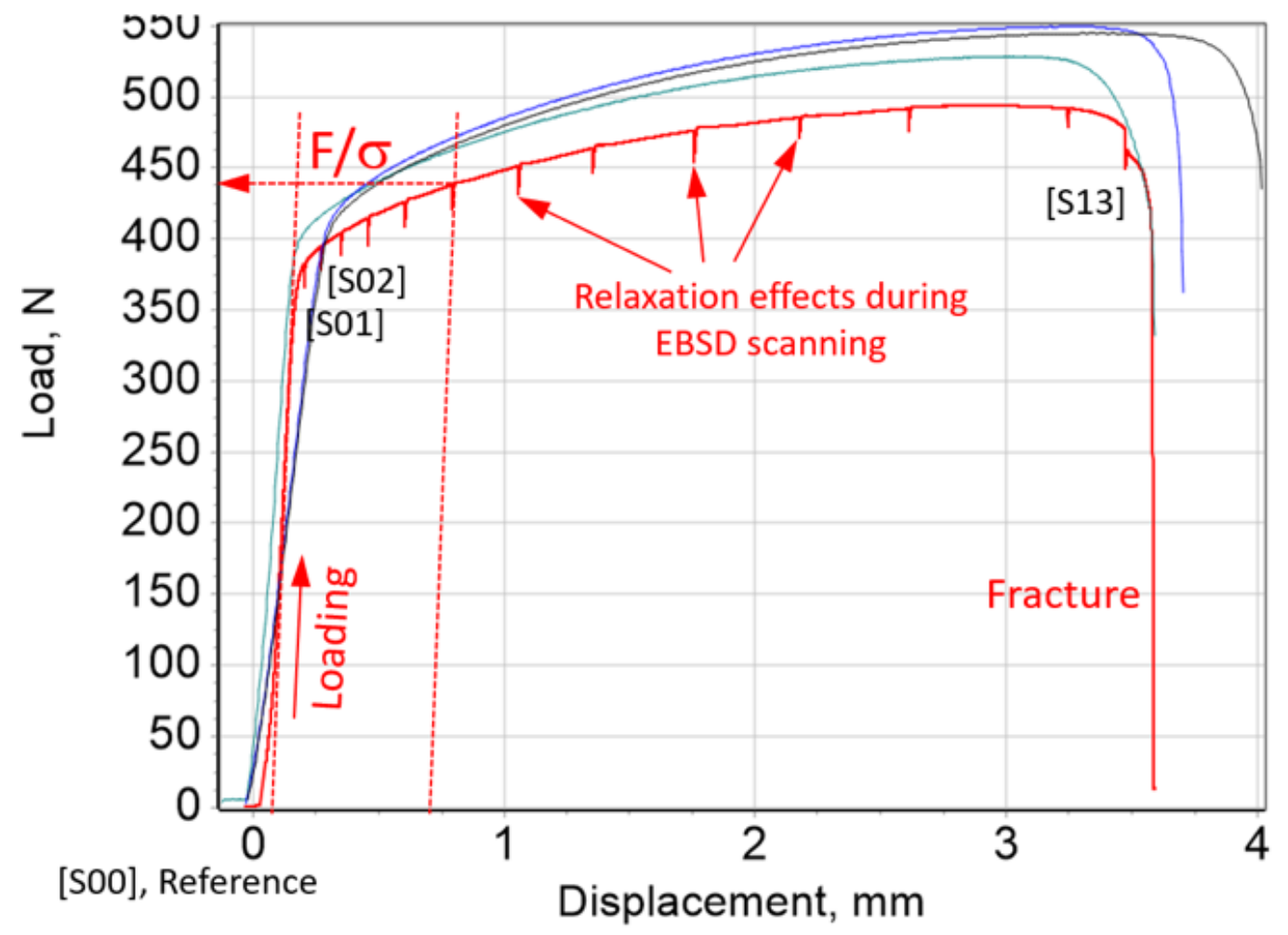

Figure 5-2. Tensile curves for the ex-situ (thin, smooth lines) and in-situ (thick red line with relaxation segments) tests. The step $\mathrm{S00}$ or reference step corresponds to zero stress and strain; the steps S01-S13 indicate deformation steps in the experiment.

Figure 5-3 compares the tensile stress-strain curves recorded for the AM 316L specimens in different conditions - as-built, stress-relieved $\left(650^{\circ} \mathrm{C} / 1 \mathrm{~h}\right)$, and solution-annealed $\left(1050{ }^{\circ} \mathrm{C} / 1 \mathrm{~h}\right)$ conditions - all of which are compared with the curve of WT $316 \mathrm{~L}$ steel. Table 5-1 lists the mechanical property parameters calculated from those tensile curves. It is observed that the AM $316 \mathrm{~L}$ in the as-built condition is the strongest in the low strain region, but it still has a high ductility. The comparison also shows that the post-built treatments reduced the strength level, and surprisingly, they led to some reduction in ductility. 


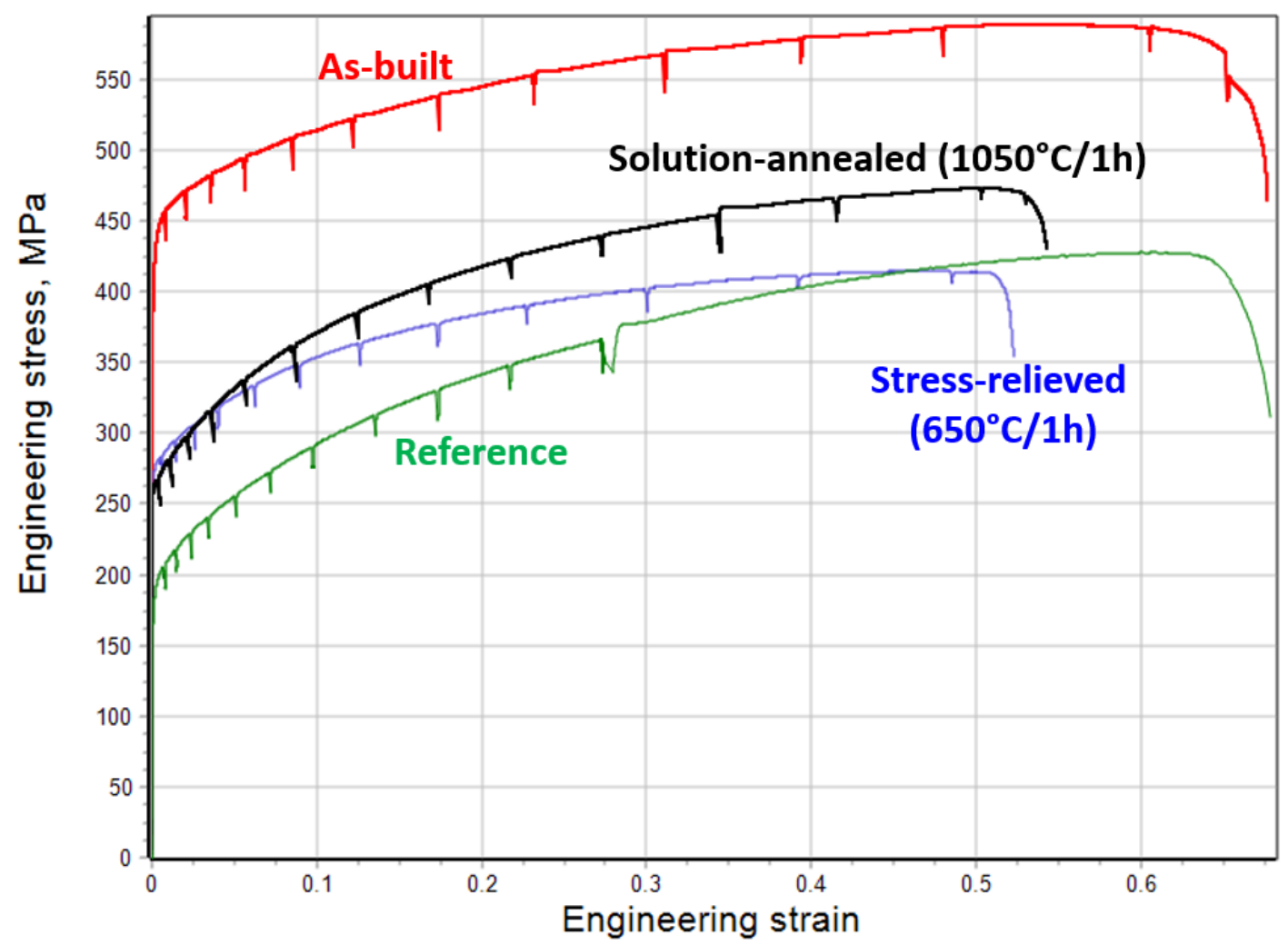

Figure 5-3. Engineering stress-strain curves for the AM 316L specimens in as-built, stress-relieved, and solution-annealed conditions, compared with that of the reference material (wrought 316L steel).

Table 5-1. Engineering mechanical properties of AM 316L SS.

\begin{tabular}{lcccc}
\hline $\begin{array}{l}\text { Processing condition of } \\
\text { 316L SS }\end{array}$ & YS (MPa) & UTS (MPa) & UE (\%) & TE (\%) \\
\hline As-built & 427.9 & 589.4 & 54.1 & 67.7 \\
$\begin{array}{l}\text { Stress-relieved at } 650{ }^{\circ} \mathrm{C} \\
\text { for 1 hour }\end{array}$ & 275.8 & 415.6 & 48.0 & 52.3 \\
$\begin{array}{l}\text { Solution-annealed at } \\
650{ }^{\circ} \mathrm{C} \text { for 1 hour }\end{array}$ & 265.2 & 474.0 & 50.0 & 54.3 \\
$\begin{array}{l}\text { Reference (wrought) } \\
\text { steel }\end{array}$ & 187.7 & 428.2 & 60.0 & 67.9 \\
\hline
\end{tabular}

\subsection{Initial Microstructure of AM 316L and WT 316L SSs}

This section provides a detailed discussion of the unique microstructures of AM 316L SS using the results from SEM and (S)TEM. Figure 5-4 shows the representative grain microstructure of the asprinted AM-material, which is distinctly different from the wrought annealed SSs. The AM 316L steel shows a relatively fine microstructure with mostly irregularly bent or crescent- shaped grains. 
Furthermore, the GROD maps show pronounced misorientation gradients in the grains, suggesting increased density of dislocations. The KAM map reveals low-angle in-grain boundaries.
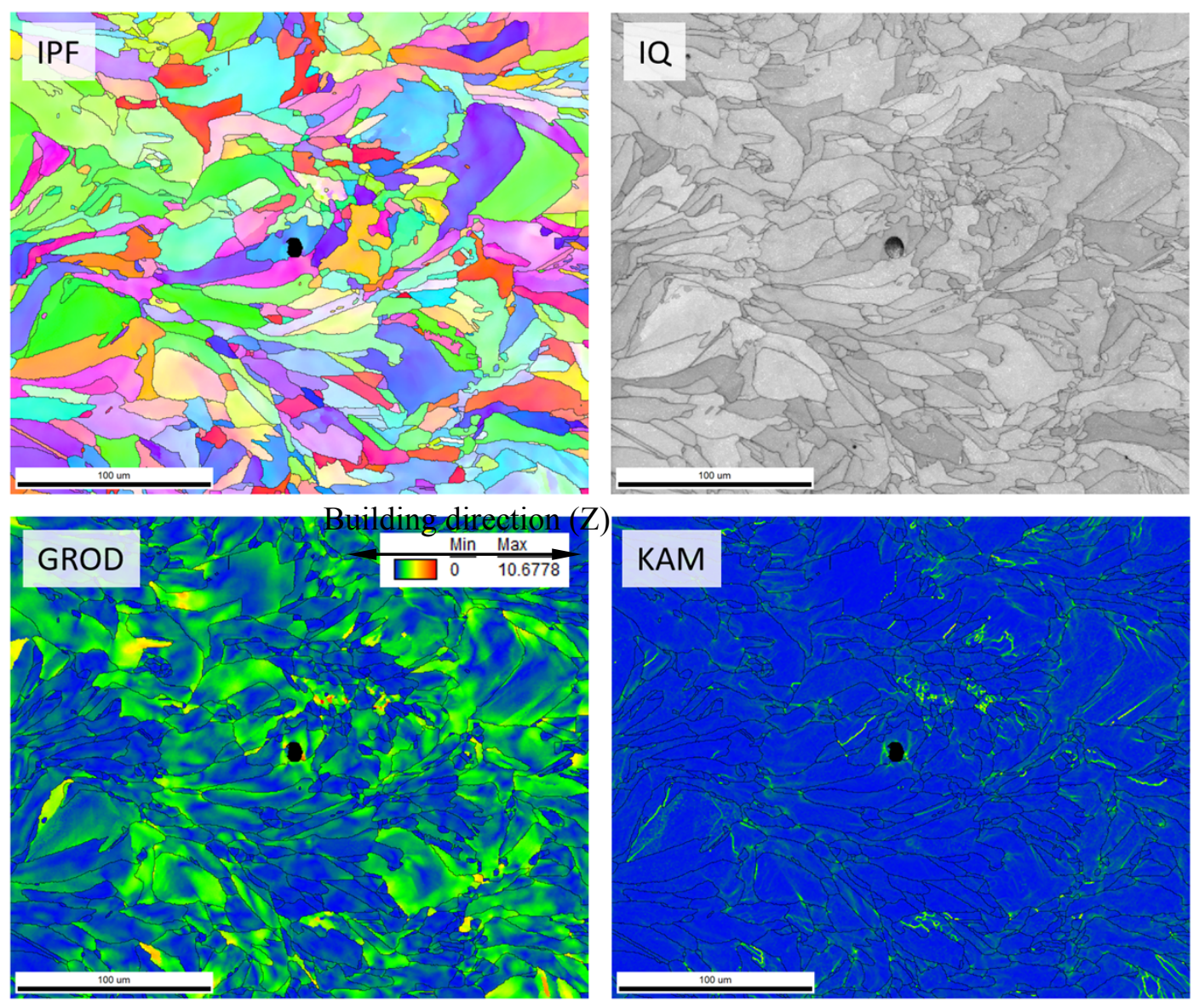

Figure 5-4. A representative grain structure in the as-built AM 316L steel shown in EBSD IPF, IQ, GROD, and KAM maps. This area is also an ROI for tracking during the in-situ test.

Figure 5-5 compares the grain structures of the AM 316L steel in different conditions, including as-built, stress-relieved $\left(650{ }^{\circ} \mathrm{C}\right.$ annealed), and solution-annealed $\left(1050{ }^{\circ} \mathrm{C}\right.$ annealed) conditions, which are also compared with the grain structure of wrought $316 \mathrm{~L}$ steel. For all conditions, the microstructures of the AM steels are different from those of the wrought steel. Grains in AM 316L are much smaller and elongated or bent; specific crescent-like grain clusters exist in the structure. These structures are most likely the remnants of the welding pools, many of which were partially remelted multiple times by subsequent laser beam passes. There are often relatively smaller grains or grain groups between the clusters of larger crescent-shaped grains. 

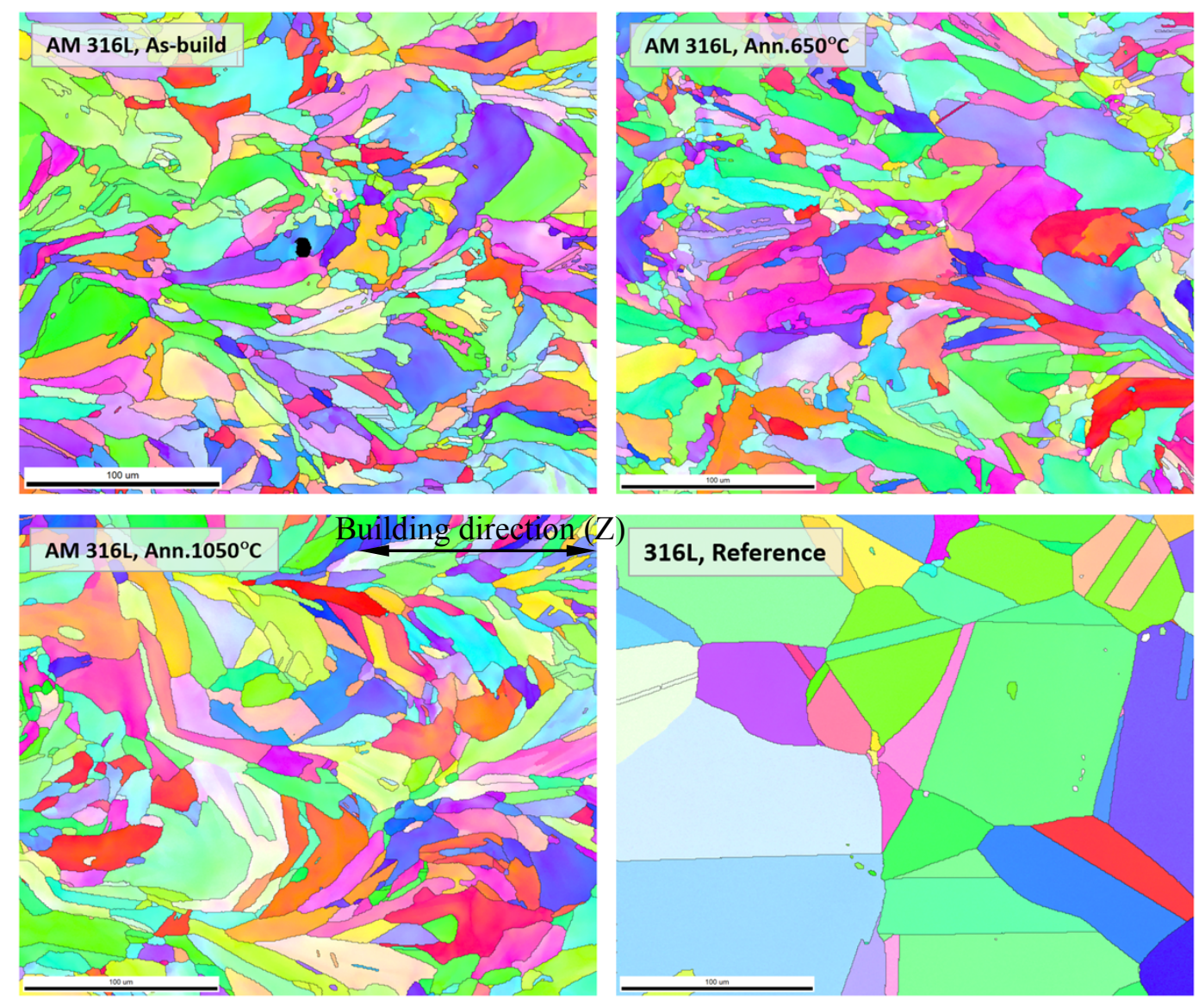

Figure 5-5. The microstructures (EBSD IPF maps) of AM-316L in different conditions. The building direction (Z) is horizontal. The EBSD IPF maps are colored relative to the building (horizontal) direction.

It is found that the $650{ }^{\circ} \mathrm{C}$ annealing (stress-relieving treatment) did not change grain morphology; grain size and shape appear to be close to the as-built material. In grain-color gradients are also still present in the structure, suggesting that very minor changes occurred in the in-grain dislocation structure. Meanwhile, solution annealing at $1,050{ }^{\circ} \mathrm{C}$ was performed with the objective to fully recrystallize the structure and produce annealed austenite with low dislocation density. Surprisingly, the high-temperature annealing did not cause any significant grain growth or pronounced change in the grain morphology. While some minor increase in the grain size occurred, full recrystallization did not occur. This suggests the presence of some microstructure factors preventing the recrystallization and stabilizing grain size. The resolution of EBSD $(\sim 100$ $\mathrm{nm}$ ) could not reveal any specific features leading to stabilized microstructure.

Grain shape in the AM 316L SS is very complex compared to the equiaxial grains in wrought steel. Common visualization approaches like metallography images after etching or even color EBSD IPF maps like those in Figure 5-4 and Figure 5-5 do not show this complexity. Several grains were extracted from the EBSD dataset and plotted separately in Figure 5-6. Such morphology usually does not appear in common wrought or cold-worked steel; nor does it appear 
in steel subjected to conventional welding. These complex shaped grains could be the result of multiple laser passes causing partial grain melting and fast solidification.

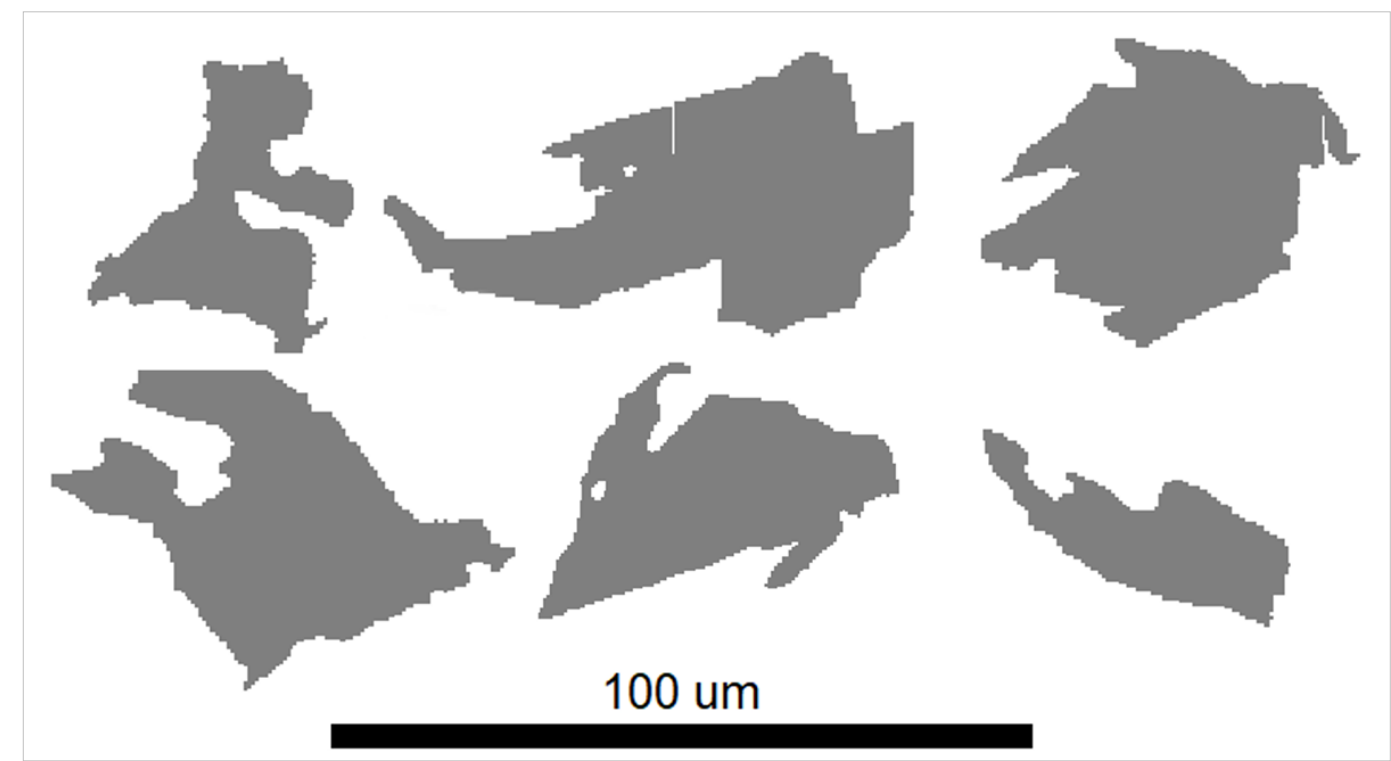

Figure 5-6. Grains extracted from the IPF map EBSD dataset for the as-built AM 316L steel (in Figure 5-4). To highlight grain shape only, one uniform in-grain color is used instead of a standard IPF color key.

Multiple welding passes may also generate significant thermal stresses and strains, leading to a complex combination of increased dislocation density and recrystallization. The in-grain structure is also complex, as shown in Figure 5-7. The presence of the in-grain low-angle boundaries and strong in-grain misorientation gradients can be seen in the KAM and GROD maps. These maps also suggest that there are diffused and distributed dislocation arrays, as well as elevated dislocation density when compared to the reference material.

The grain boundary network in the AM steel shown in the Figure 5-8 is of special interest due to a complex morphology of special grain boundaries ( $\Sigma 3$ or first-order twins). The annealing twins often appear as isolated "islands" in the parent austenitic grains, and the twin morphology is also complex, with multiple bends and dents. Although the total twin boundary fraction is comparable to the wrought steel $(\sim 40-45 \%)$, these twin boundaries in AM 316L appear to be often disconnected in the network of random high-angle boundaries (RHABs). These RHABs may be most vulnerable to corrosion or stress corrosion cracking in some environments; stress corrosion cracks will penetrate along RHAB and will be arrested once RHAB is followed by $\Sigma 3$. If an "RHAB walking exercise" is applied to the microstructure shown in Figure 5-8, one most likely will not be able to penetrate the structure moving along the RHAB. At some point, the "penetrator" (virtual crack tip) will have to stop at a $\Sigma 3$ or low-angle boundary. 

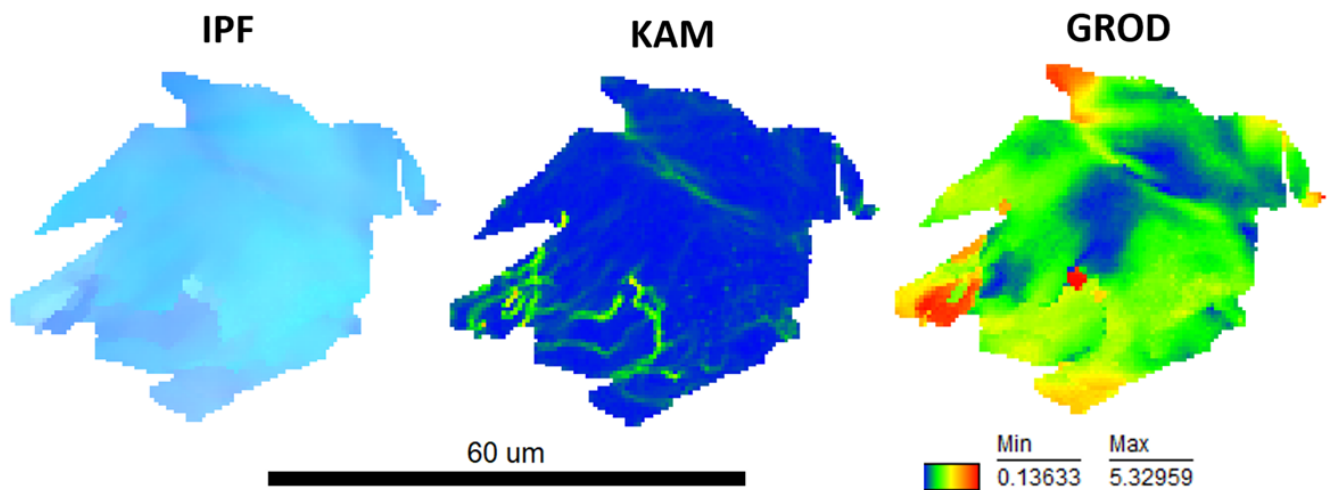

Figure 5-7. Detailed maps of a grain extracted from the EBSD dataset shown in Figure 5-4. The in-grain IPF color variations and the KAM and GROD maps suggest multiple in-grain low-angle boundaries $\left(\sim 1\right.$ to $\left.\sim 3^{\circ}\right)$ as a feature of concentrated dislocations.

In the AM process, multiple rapid heating-cooling cycles caused local plastic straining. It appears that this was effective for the formation of $\Sigma 3$ boundaries, thus breaking the RHAB network at some locations. The broken RHAB network may promise some improvement in the performance of the alloy in stress-corrosion environments, but more direct observation is needed.
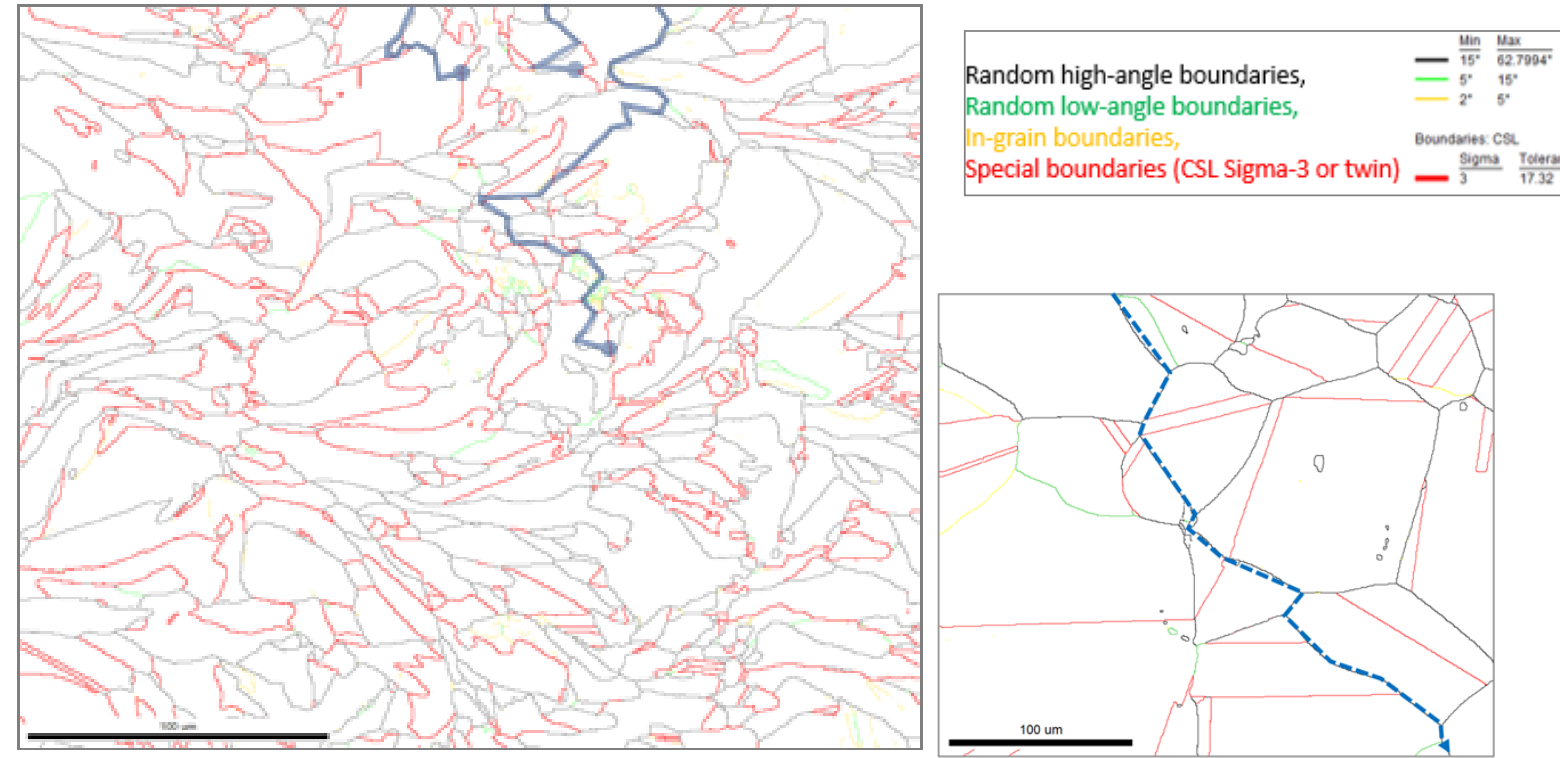

Figure 5-8. Grain boundary network in AM 316L in as-built condition. Black indicates RHABs, and green indicates random low-angle boundaries (RLABs). The red lines indicate twin $(\Sigma 3)$ grain boundaries. Other grain boundary types (e.g., $\Sigma 9$ or $\Sigma 27$ ) are considered as RHAB for simplicity. Blue lines starting from the top of the image illustrate the RHAB walking exercise. An inset at the right bottom shows the GB structure in wrought steel with the same color coding but at a different scale.

Additional characterization was carried out using STEM with EDS and transmission Kikuchi diffraction (TKD). These techniques were used to analyze the microstructural evolution of the AM-316L SS from the as-built condition, from thermal annealing, and after deformation. 
There are three primary effects as a result of the thermal treatment of the steel that affect the cellular structure, the oxide inclusion chemistry, and the ferrite content. It is well-established that AM of 316L SS produces a dislocation cellular structure during building $[13,18]$. This can be seen in Figure 5-9, where $\mathrm{Cr}$ is shown to segregate to the cell boundaries. Interestingly, the stressrelieving treatment at $650{ }^{\circ} \mathrm{C}$ does not appear to change the cell structure in any significant way; however, the solution annealing treatment at $1,050^{\circ} \mathrm{C}$ completely removes the cellular structure. Solution annealing appears to mostly homogenize the microstructure, except for the oxide inclusions, as discussed below.

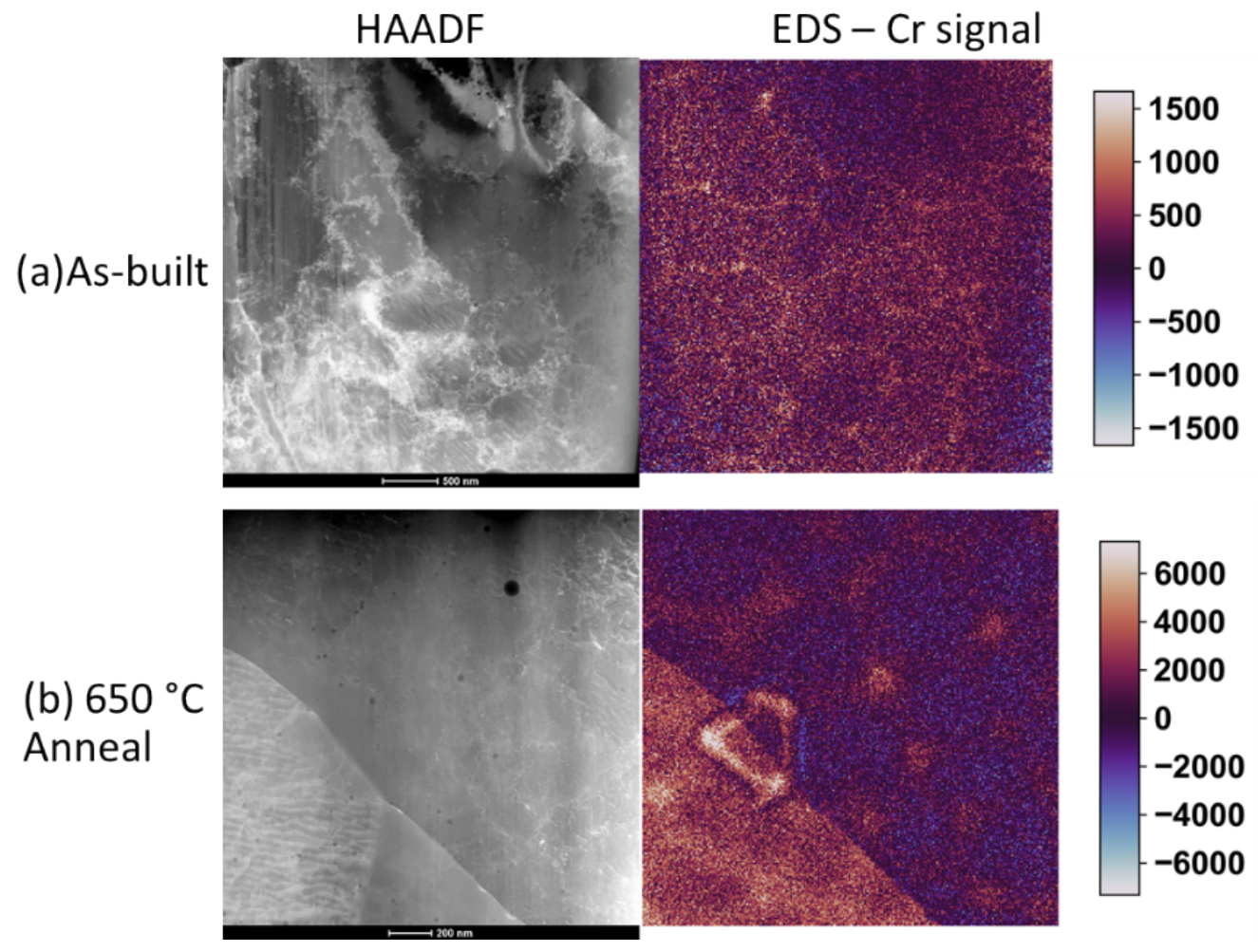

Figure 5-9. Cr segregation to dislocation cell structure walls in both (a) as-built and (b) stress-relieved conditions; solution annealing at $1,050{ }^{\circ} \mathrm{C}$ (not shown) removes cellular structure

Nanoscale oxide inclusions are found throughout the material. In Figure 5-10, Si-rich oxides decorate cell boundaries in both the as-built structure and the stress-relieved material. It is unknown at this time if these oxides formed first or if the cell boundaries formed first. If the oxide particles formed first, then this would show that these may act to pin cell boundaries. After solution annealing at $1,050{ }^{\circ} \mathrm{C}$, which removed the cell structure, the oxide inclusions have transformed from Si-rich oxides to Cr-rich oxides, and the Cr likely came from the cell boundaries. 
(a) As-built
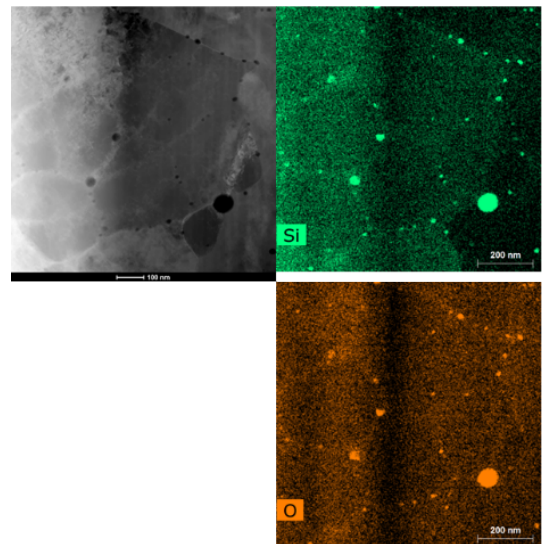

(b) $650^{\circ} \mathrm{C}$ Stress Relieved

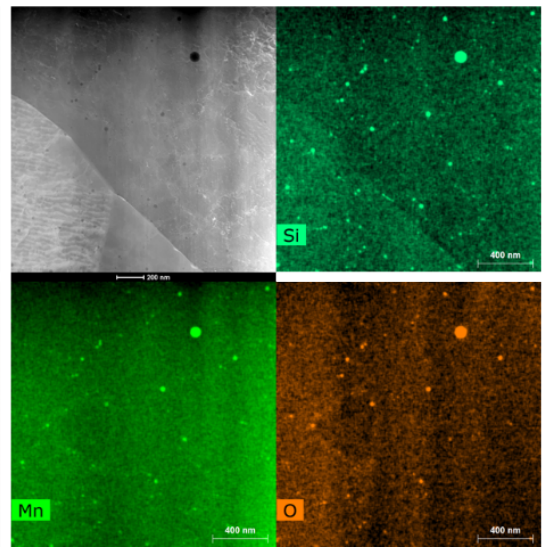

(c) $1050^{\circ} \mathrm{C}$ Solution Annealed

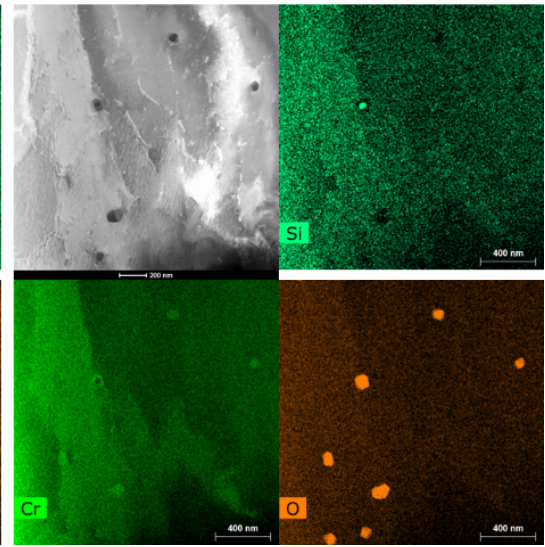

Figure 5-10. STEM-EDS maps showing nanoscale oxide inclusions in all conditions. In the (a) as-built and (b) stress-relieved conditions, $\mathrm{Si} / \mathrm{Mn}$-rich oxides decorate cell boundaries. (c) After solution annealing at $1,050{ }^{\circ} \mathrm{C}$, the oxides transform from Si-rich to $\mathrm{Cr}$-rich.

The AM was found by TKD to form some ferrite grains (Figure 5-11). This is likely retained ferrite from the localized melting that never transformed into austenite. From SEM studies, the amount of ferrite is likely quite small. It is also almost completely removed upon annealing at 650 ${ }^{\circ} \mathrm{C}$ and is removed entirely at $1,050{ }^{\circ} \mathrm{C}$.

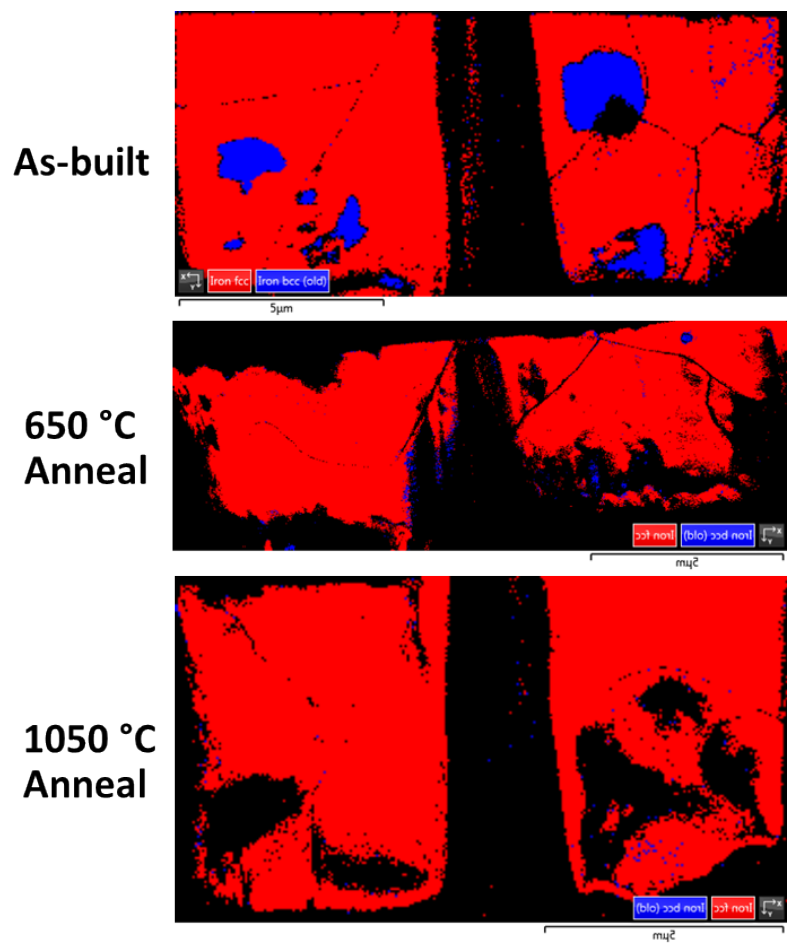

Figure 5-11. TKD analysis found grains of body-centered cubic ferrite in the as-built structure, but not in either of the annealed structures. 


\subsection{In-Situ Observation of Deformation Process}

This subsection discusses selected results of in-situ tensile testing to provide insights into key aspects of the deformation process. Figure 5-12 shows EBSD-IPF maps recorded at different steps during in-situ testing; each map is an array of color-coded points representing crystal orientation data. The maps provide information primarily on grain morphology and orientation with respect to tensile direction. Changes in colors reflect misorientation variations in the lattice, which in turn may be converted into the density of geometrically necessary dislocations.
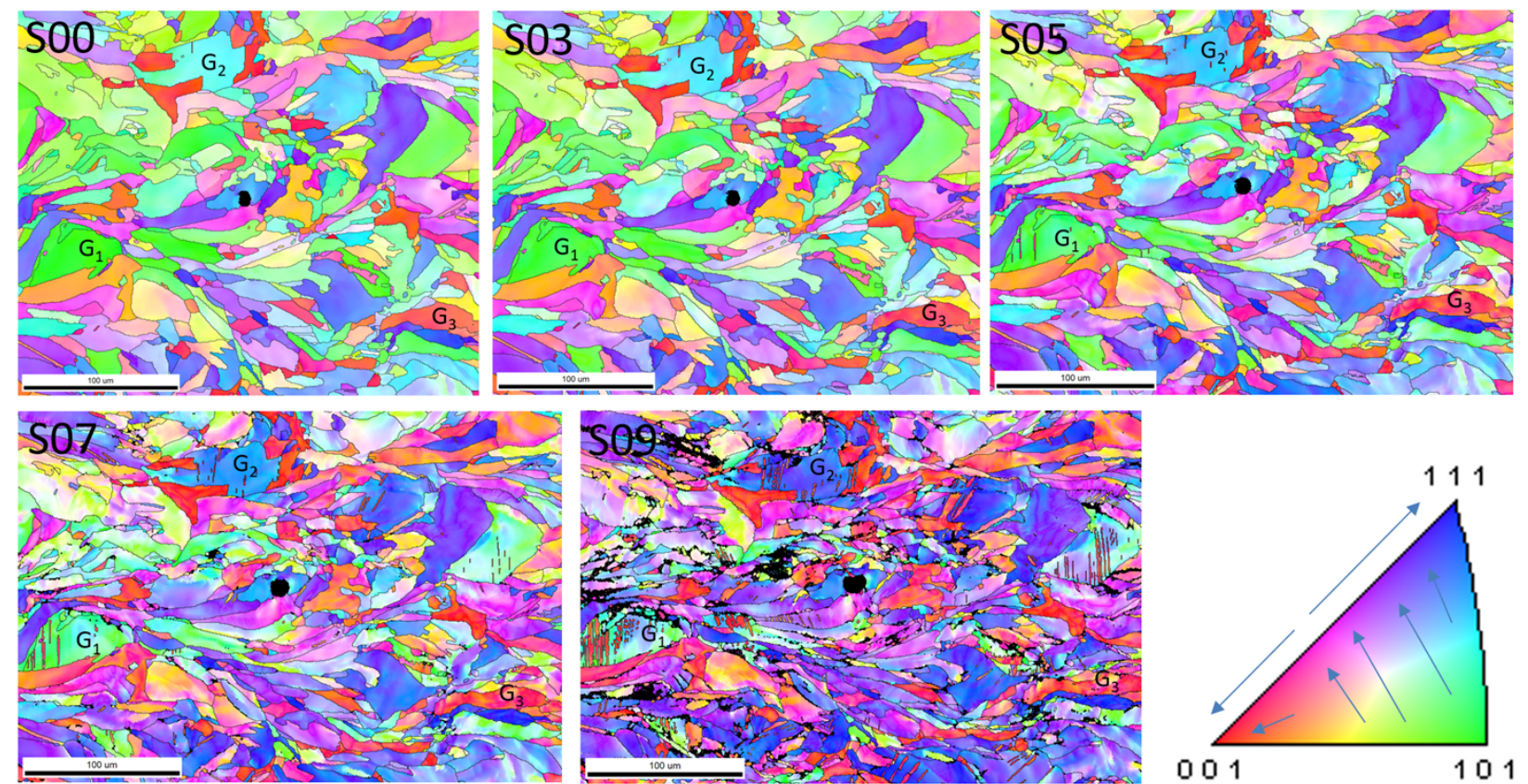

Figure 5-12. EBSD IPF maps recorded at different steps of the in-situ SEM-EBSD tests for the as-built AM 316L steel. The zero step (S00) corresponds to the structure shown in Figure 5-4, and the tensile curve for the test is given in Figure 5-2.

In Figure 5-12, the strain level increases with step number, and obvious strain-induced changes are observed. Color distribution in the IPF maps changes from a near-random distribution, which means that the material has little or no texture, to the dominating red and blue colors, indicating pronounced texture. During the tensile test, the lattice of each grain rotated towards specific orientations, reflecting the activity of different dislocation slip systems. Grains typically rotate towards the [001]-[111] line of the unit triangle, after which their orientations move towards the [001] or [111] corners of the unit triangle.

The grain $\mathrm{G}_{1}$ in Figure 5-12 ( green color) keeps its orientation at steps 01-04 - an interesting phenomenon - until some strain level is reached. After that it appears as light blue and then turns to partially blue. The grain $\mathrm{G}_{2}$ (light blue) will become darker blue at some point, reflecting lattice rotation. The grain $\mathrm{G}_{3}$ (red), being of stable 001-orientation, keeps its orientation for a long enough time until a high dislocation density is achieved. Interaction with neighboring grains leads to a minor secondary lattice rotation direction, which often differs from the general deformation trend in the surrounding area. In addition, needle-like objects appear in the structure at step 4 and in 
several grains at step 5, reflecting the activation of deformation twinning. Strain-induced twins are visible in grains $\mathrm{G}_{1}$ and $\mathrm{G}_{2}$.

Tracking a specific grain during deformation may provide a detailed insight into the structural change. Figure 5-13 displays a step-by-step deformation process in a selected grain in AM 316L steel. The grain has multiple in-grain low-angle boundaries that are visible in the KAM map. The GROD colored map reflects strong in-grain orientation variations of several degrees, suggesting significant dislocation densities. With the plastic strain (step) increases, the in-grain dislocation density grows, becoming visible as more and more pronounced in-grain boundaries and GROD value variations. Interestingly, the pre-existing in-grain boundaries maintain their position in the grain, although it is expected that these boundaries will migrate or even dissolve due to dislocation activities. Strain-induced twins also appear in the structure at step 7 and grow until their propagation is limited by the areas with increased KAM. Twins in AM 316L steel may propagate until they reach the in-grain low-angle boundaries. This would form relatively smaller straininduced twins $(10-15 \mu \mathrm{m})$ in AM 316L steel than in the wrought 316L steel, in which straininduced twins may grow throughout all the grain.

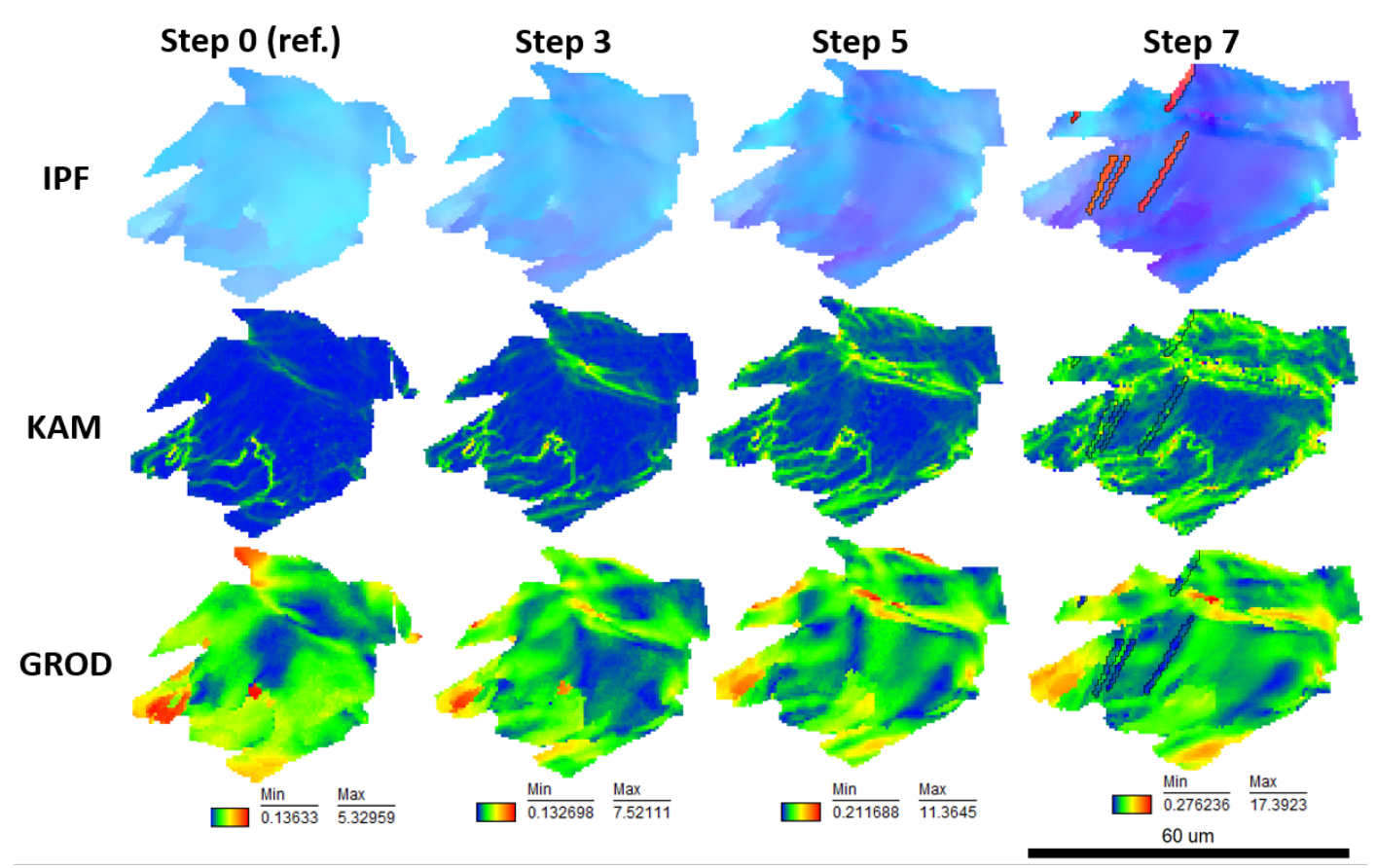

Figure 5-13. Evolution of in-grain structure during plastic deformation (grain shown here is chosen from the microstructure in Figures 5-4 and 5-12).

Another way to analyze the EBSD dataset(s) and the strain-induced changes is to calculate some metric of a parameter that reflects processes or phenomena of interest. The KAM parameter for the given point reflects local lattice curvature, and in turn local dislocation density. According to the literature, there is a direct linear correlation between KAM and dislocation density; however, the exact correlation slope (and offset) may vary from case to case, depending on the material composition and history. Note also that KAM considers only geometrically necessary dislocations (GNDs), whereas a stochastically stored dislocation population does not influence KAM. Figure 5- 
14 plots KAM as a function of plastic strain for the as-built AM 316L steel. Typically, KAM increases linearly with strain level and tends to saturate at a strain level of $\sim 0.3-0.35$. The AM steel shows several distinct stages. In the first stage, small strains show little or no increase in the average misorientation level. This means that there is little or no increase in the dislocation density (i.e., density of GND). Since the AM material has pre-existing dislocations, deformation at small strains could be connected to the movement/evolution of the existing GND population, as dislocation multiplication is limited. The second stage reflects a fast increase in the dislocation population, but the slope change (appearance of the third stage) is unexpected and usually does not appear in the wrought metallic polycrystals. The fast KAM growth at the second stage may be connected to the much smaller grain size in the AM material compared to wrought steel, and the appearance of the third stage may be connected (again, preliminary) to grain fragmentation and evolution of in-grain boundaries.

Twinning deformation in 316L SS is usually pronounced at RT and below. Figure 5-15 shows that a few thin, needle-like twins were formed in a parent grain, and no obvious stress localization source was observed. The parent grain orientation was close to 101. The twins are thin $(\sim 1 \mu \mathrm{m})$ and long $(10-20 \mu \mathrm{m})$, originating from a boundary or a manufacturing-induced pore in the structure. At this strain step, the plastic strain was $\sim 5.5 \%$, and the stress was $\sim 495 \mathrm{MPa}$. This strain level is much smaller than the twinning strain of the wrought material: the strain-induced twins typically appear at a strain level of 10-20\%, whereas the twinning stress levels appear close at a common range of $\sim 500-600 \mathrm{MPa}$ for austenitic SSs. Twins are expected to form in grains oriented close to the 111 corner of the unit triangle; some authors suggest that the 101-111 line represents the most favorable orientations for twinning.

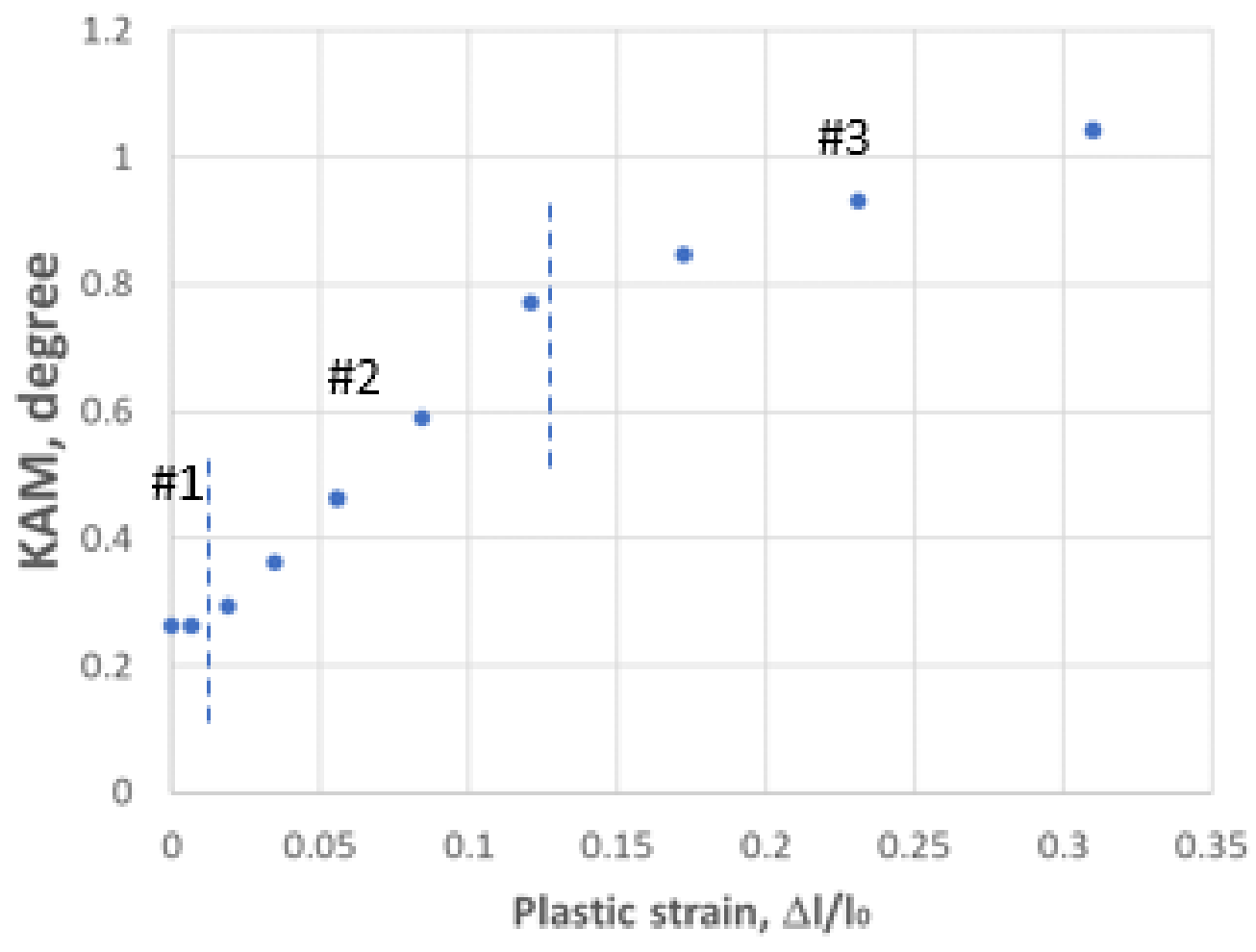

Figure 5-14. KAM vs. strain for the AM-316L in as-built condition. 

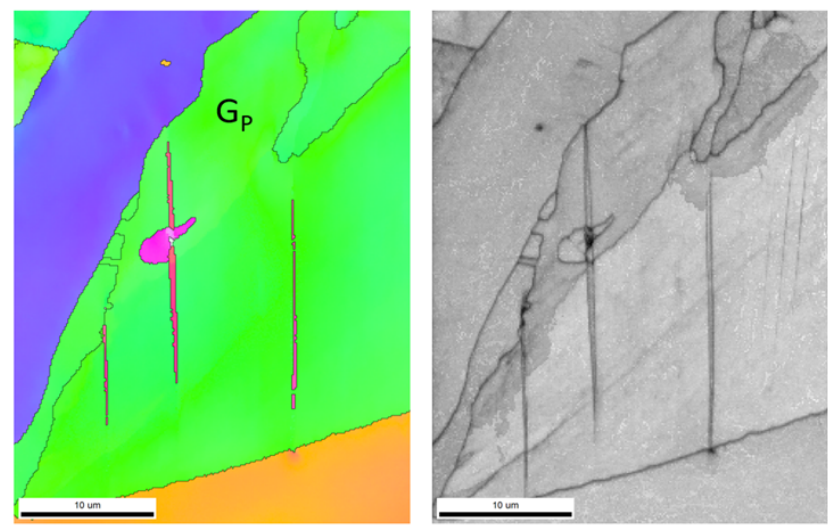

[010]

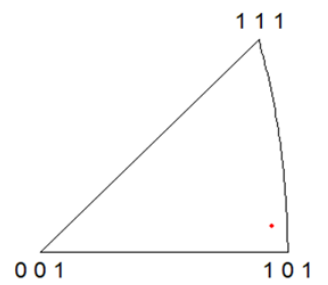

Figure 5-15. Fine needle-like twins in the as-built AM 316L steel (step 4). The inverse pole figure at the right shows the orientation of the parent grain with respect to the tensile axis.

The deformation mechanisms in higher resolution were also confirmed by observing the gauge length of fractured tensile test specimens of the as-built, stress-relieved, and solution-annealed AM 316L SS in STEM. As seen in Figure 5-16, the STEM bright-field (BF), low angle annular dark field (LAADF), and high angle annular dark-field (HAADF) images indicate that the primary deformation mechanisms are deformation twinning and dislocation tangling. The random curved line features indicate a dislocation tangling mechanism, whereas the thicker straight bands, more of which are seen in the solution-annealed sample, indicate a twinning mechanism. The deformation mechanisms do not appear to change much with annealing.

(a) As-built

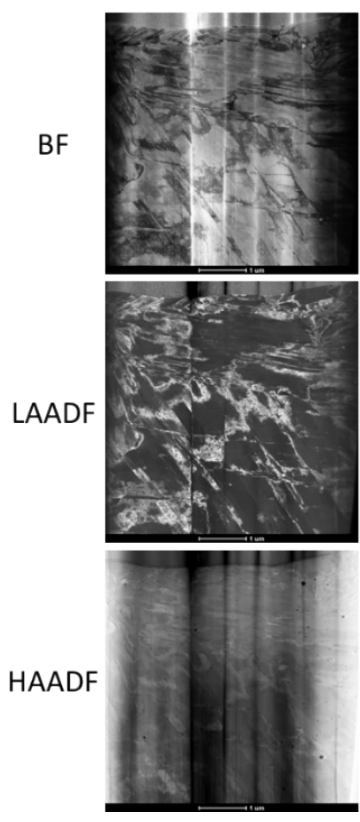

(b) $650^{\circ} \mathrm{C}$ Stress Relieved
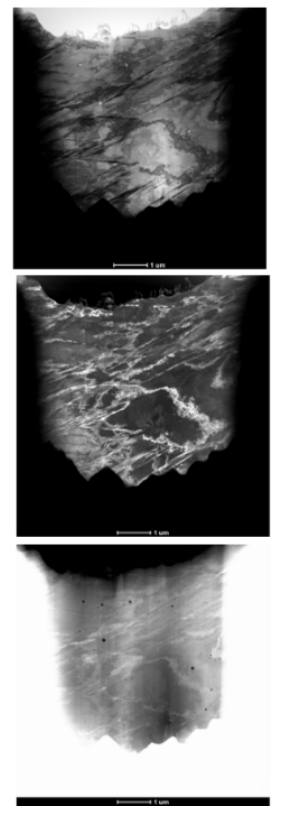

(c) $1050^{\circ} \mathrm{C}$ Solution Annealed
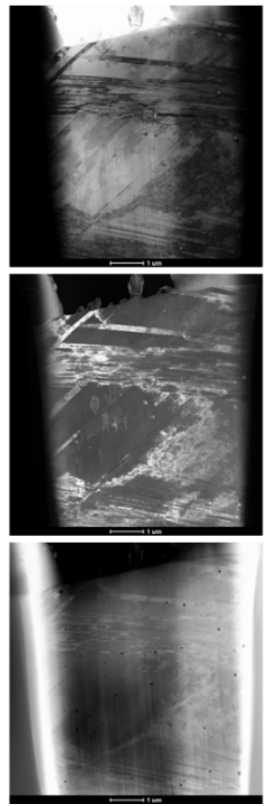

Figure 5-16. STEM BF, LAADF, and HAADF imaging of the structure of (a) as-built, (b) stress-relieved, and (c) solution-annealed AM 316L SSs. 


\subsection{Fracture Behavior of AM 316L}

Analysis of fracture mechanisms is of high importance for characterizing material performance. The appearance of brittle or cleavage spots and cracking may be an indication of reduced toughness. Figure 5-17 shows the general view of the AM 316L specimens' fracture surface compared to the reference specimen (wrought commercial steel). The AM material specimens show much smaller area reduction in contrast to the reference steel, which shows a very narrow, almost knife-like fracture line. Defects were more abundant at the fracture surfaces of the AM material, the multiple meso-level (tens of microns) pores, and even several macro-level $(\sim 0.1+$ $\mathrm{mm}$ ) objects (black arrows in Figure 5-17). Such large defects (pores or voids) might have been an important factor in specimen failure, causing fracture at smaller strain levels, compared to the reference material. Most likely, these defects evolved from pores or relatively large inclusions formed in the AM-material during manufacturing. The presence of defects of this scale - tens of microns to a fraction of a millimeter - may be a reason for the relatively lower ductility of the AM materials compared to the reference SS.
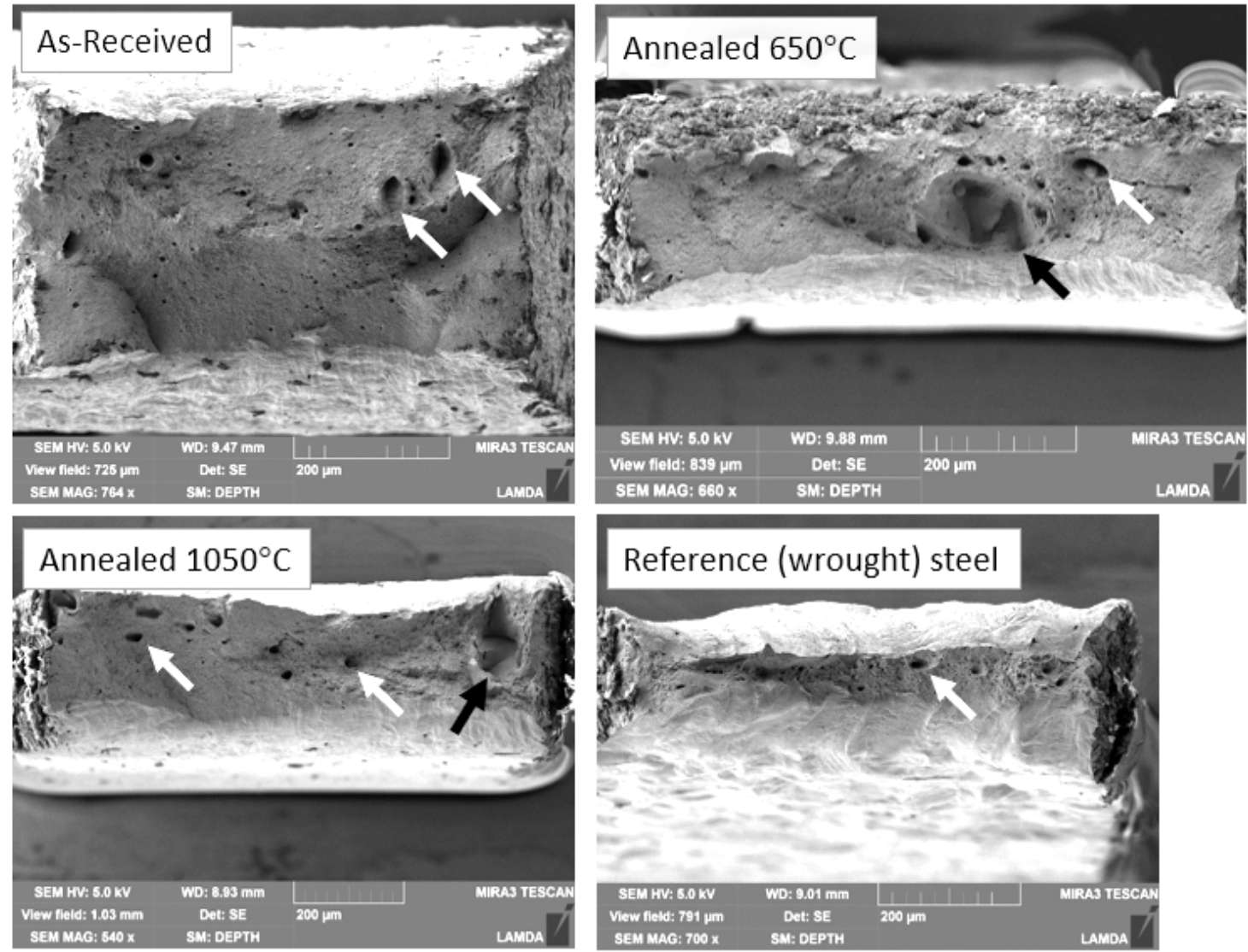

Figure 5-17. Fracture surfaces for the AM 316L specimens in different conditions. White arrows point to mesoscale defects $(\sim 20-40 \mu \mathrm{m})$, and black arrows point macroscale defects $(>\sim 0.1 \mathrm{~mm})$.

Figure 5-18 shows EDS maps for a fracture area spot with large pores. The enrichment in oxygen and silicon in the EDS maps and specific dark-gray objects in the SEM image suggest the presence of non-metallic inclusions, most likely $\mathrm{SiO}_{2}$. The presence of non-metallic inclusions was 
commonly associated with pores; often, Al-oxide traces also appeared in the data. Cracks formed around pores or other defects during tensile deformation may have been connected to the nonmetallic inclusions.

Mesoscale pores that are tens of micrometers in size also appear at the specimen's surface during deformation (Figure 5-19) starting at a strain level of approximately 15-20\%, and they tend to grow with strain increase. The number of visible defects increases with the plastic strain level, and individual defects tend to grow. In most cases, such defects were associated with non-metallic inclusions. Sometimes the connection between the pore and the non-metallic inclusion is obvious and easy to see; however, the defect often appears at the surface at some strain level, but the inclusion remains invisible, either hidden under the surface or masked by a high tilt angle.
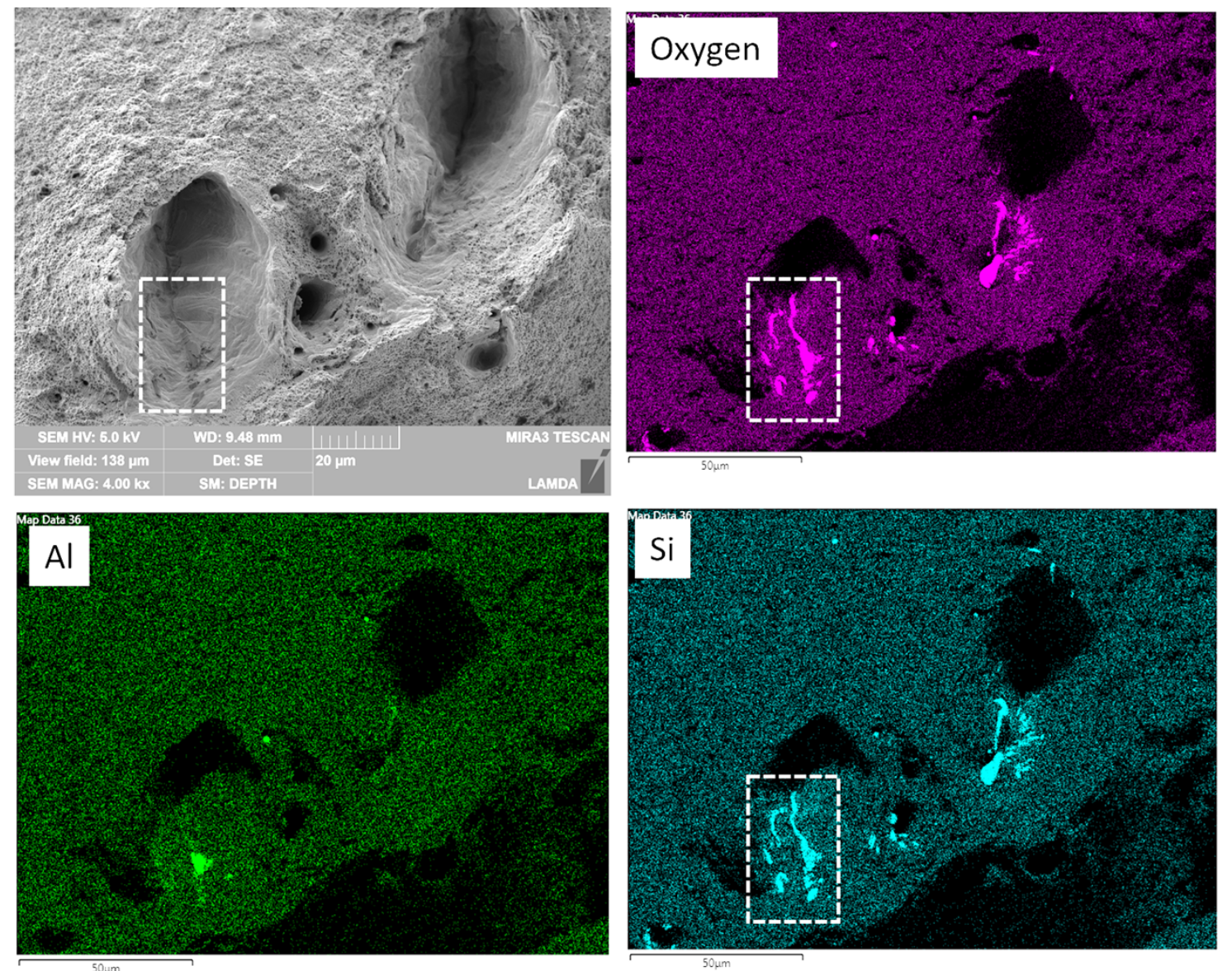

Figure 5-18. A fracture surface of as-built $A M$ 316L steel in which two mesoscale pores (see also Figure 5-17) are overlapped with EDS maps (oxygen, aluminum, and silicon). 


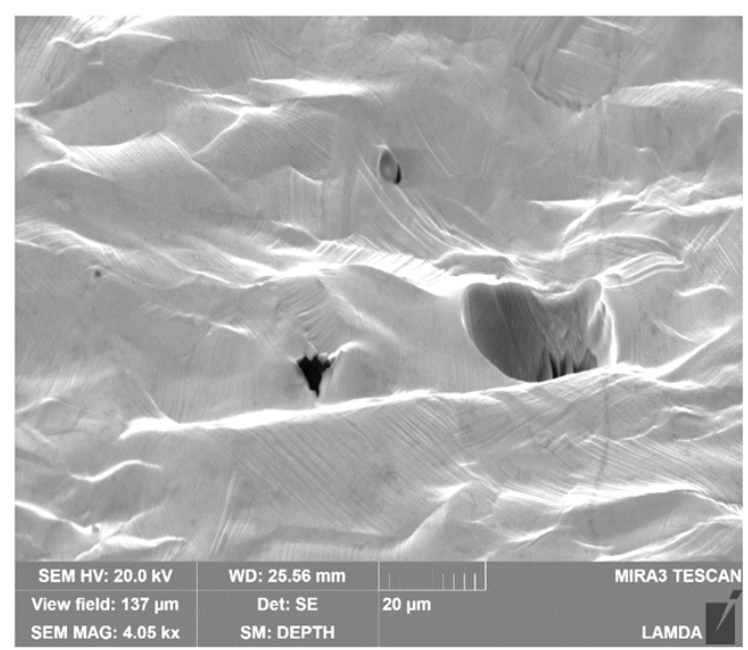

[S09] Microfracture events. Note the SEM-image is $70^{\circ}$-tilted.

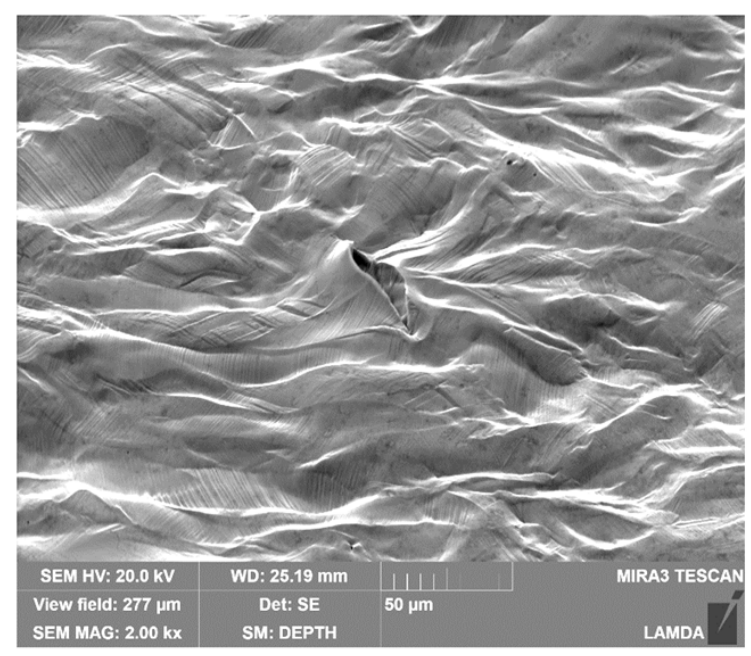

[S09] Delamination.

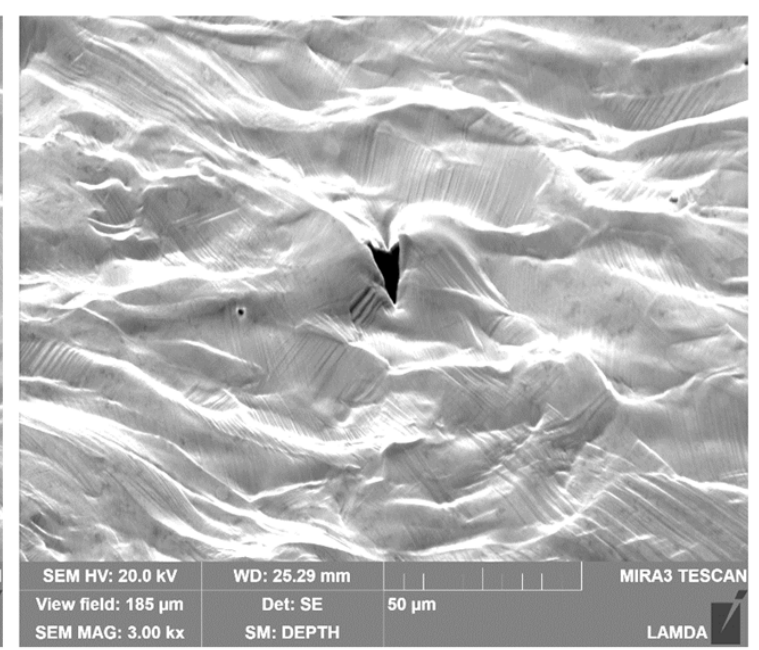

[S09] Opening microcrack (delamination?).

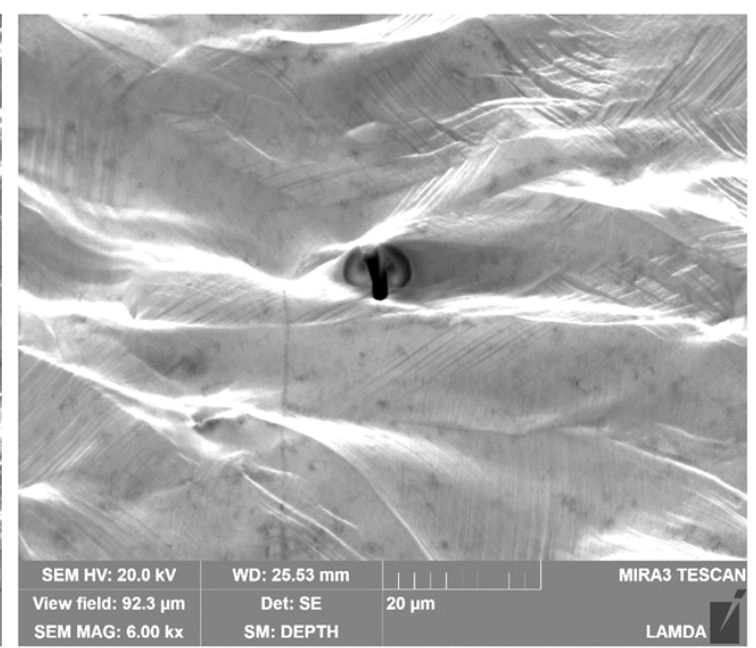

[S09] Cracked inclusion.

Figure 5-19. Mesoscale defects (pores and delaminations) at the surface of the as-printed AM 316L steel after deformation. A cracked non-metallic inclusion is visible in the bottom right image.

Once mesoscale defects appear, they tend to grow with plastic strain, as seen in Figure 5-20. As a rule, the growth mechanism is a ductile tearing and cracking into the surrounding material. Since 316L steel generally has relatively high fracture toughness, the mesoscale defects grow slowly without causing catastrophic failure.

Sometimes a large defect below the surface, invisible before the specimen is deformed, appears as the local cracking around it progresses, as shown in Figure 5-21. Such a crack usually grows with strain and becomes the main cause of specimen fracture. In Figure 5-21, the main cracking defect became clearly visible at Step 13 (S13) in the growing neck and increased in size with the increase of strain and further neck development. Post-test fractography (see the inset at the right and Figure 5-17) shows the defect size and morphology. In addition to the macro defect (Dm) at near final failure, multiple smaller voids/pores can be seen in the necked area. On the positive side, the fracture surfaces of AM $316 \mathrm{~L}$ and WT $316 \mathrm{~L}$ specimens confirmed that highly ductile fracture modes are common, regardless of a large variation in the final necking failure. 


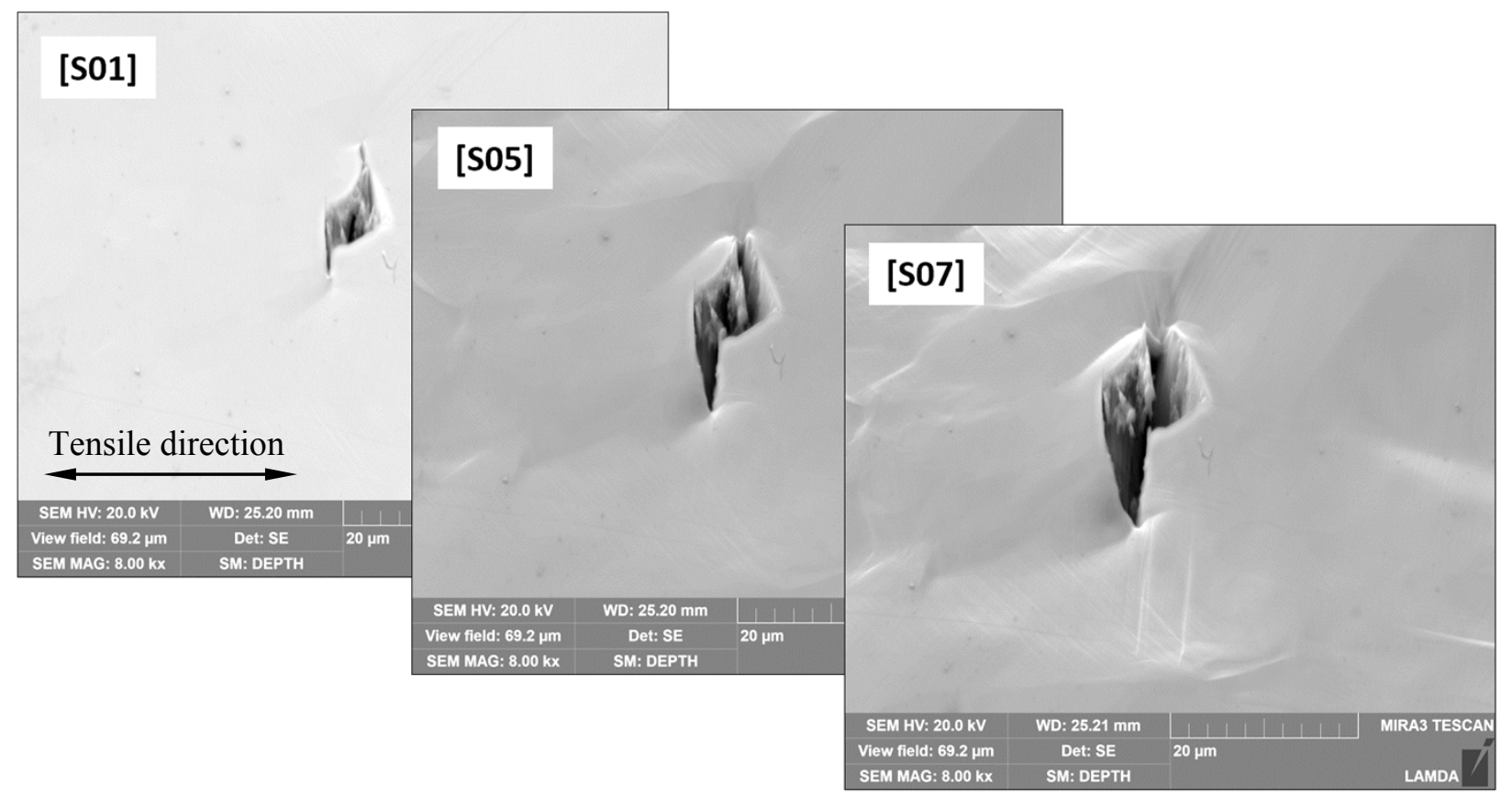

Figure 5-20. Evolution of a mesoscale pre-existing defect in AM-316L (stress-relieved at $650{ }^{\circ} \mathrm{C}$ ). The defect grows via a cracking mechanism of ductile tearing into surrounding material. 


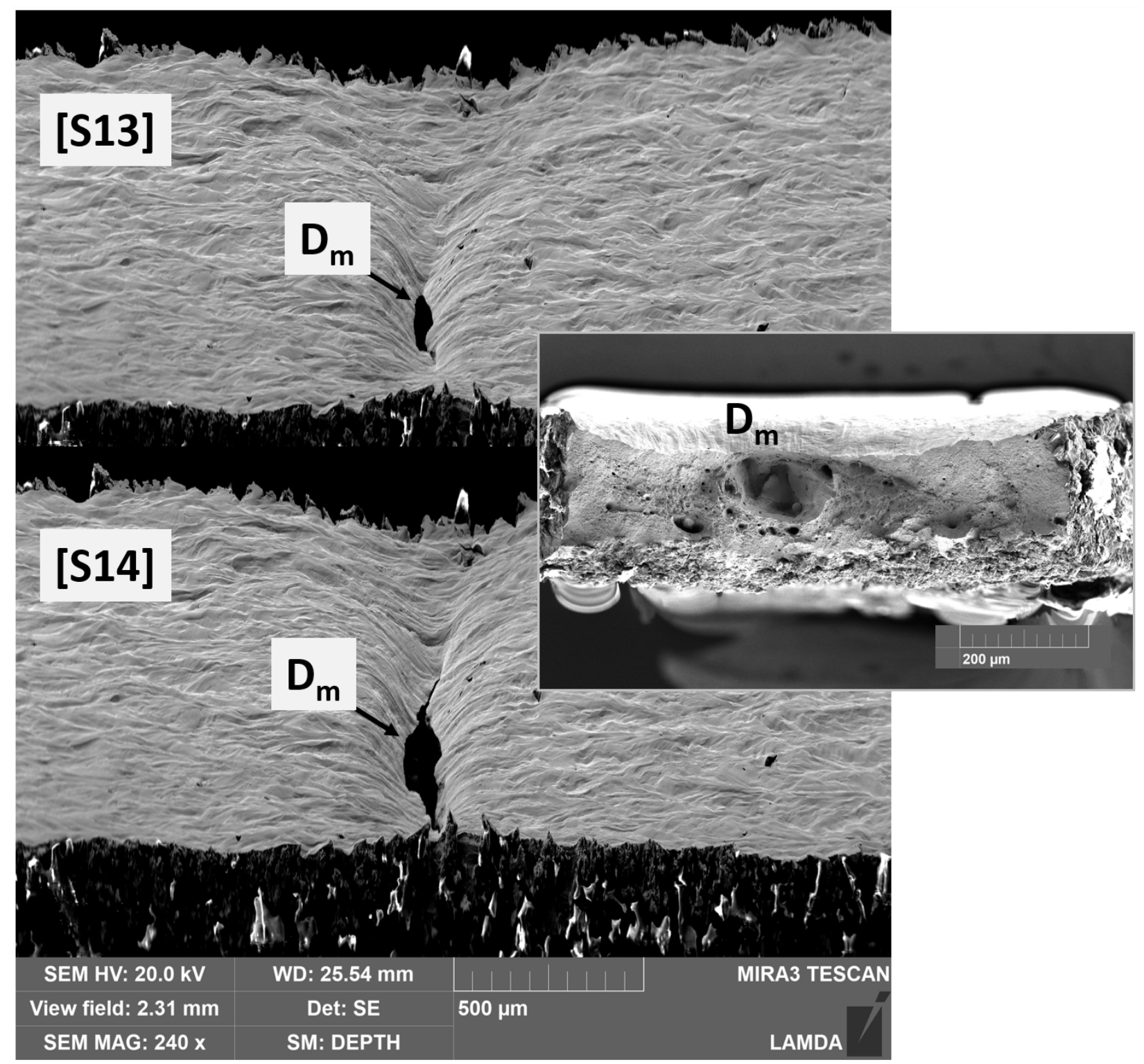

Figure 5-21. The appearance of a macro-defect, Dm (size $\sim 0.12-0.15 \mathrm{~mm})$ at the specimen surface during the in-situ testing of $A M 316 \mathrm{~L}$ steel annealed at $650{ }^{\circ} \mathrm{C}$.

Figure 5-22 shows the fracture surface for all tested conditions: the ductile fracture mechanism dominates in the testing of all four specimens; no brittle fracture spots or cleavage facets were observed. Interestingly, dimple size and height vary, depending on material conditions. The asprinted 316L specimen showed the smallest dimples, with very limited heights. There were insignificant changes after annealing at $650{ }^{\circ} \mathrm{C}$, but the solution annealing at $1,050{ }^{\circ} \mathrm{C}$ led to a significant increase in the dimple size. Even after annealing at such a high temperature, however, the overall dimple size for the AM 316L was much smaller compared to that in the reference steel. This suggests that full annealing or recrystallization with significant grain growth was not achieved. 

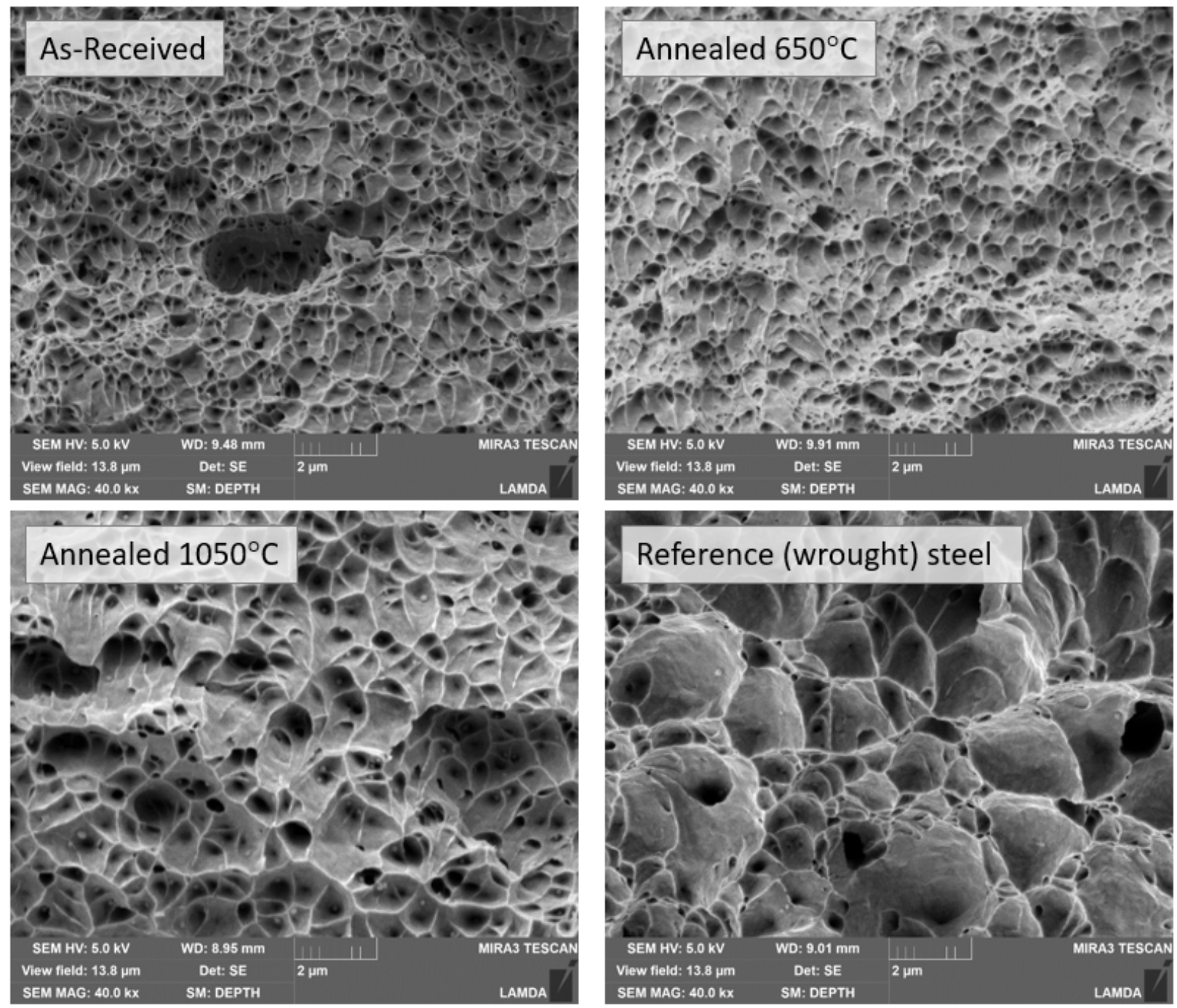

Figure 5-22. Fracture surfaces of 316L SSs at a high magnification. Only ductile dimples are observed for all conditions tested, but with different sizes and morphologies.

Analysis of dimples at very high magnification levels (Figure 5-23) shows the presence of very fine, round-shaped particles inside many dimples in the AM 316L specimens, regardless of heat treatment. Such particles are much rarer in the wrought steel. Most particles are $\sim 20-30 \mathrm{~nm}$ in size, lying at the edge of the SEM resolution. Several EDS scans were performed (see the inset in Figure 5-23) to evaluate the element composition of the observed objects. The particles did not show elements common for $316 \mathrm{~L}$ steel $(\mathrm{Fe}, \mathrm{Ni})$; they revealed weak traces of $\mathrm{Cr}$, and they demonstrated strong enrichment in oxygen and silicon, as they were most likely $\mathrm{SiO}_{2}$ particles.

It is believed that the silicon oxide or non-metallic inclusions are inherited from the steel powder used in the AM process. Melting and multiple re-meltings during manufacturing may lead to the strong fragmentation of the $\mathrm{SiO}_{2}$ impurity objects, as well, generating the small objects observed in the dimples. The density of such small particles seems to be high enough to pin grain boundaries, making recrystallization and grain growth more difficult. 

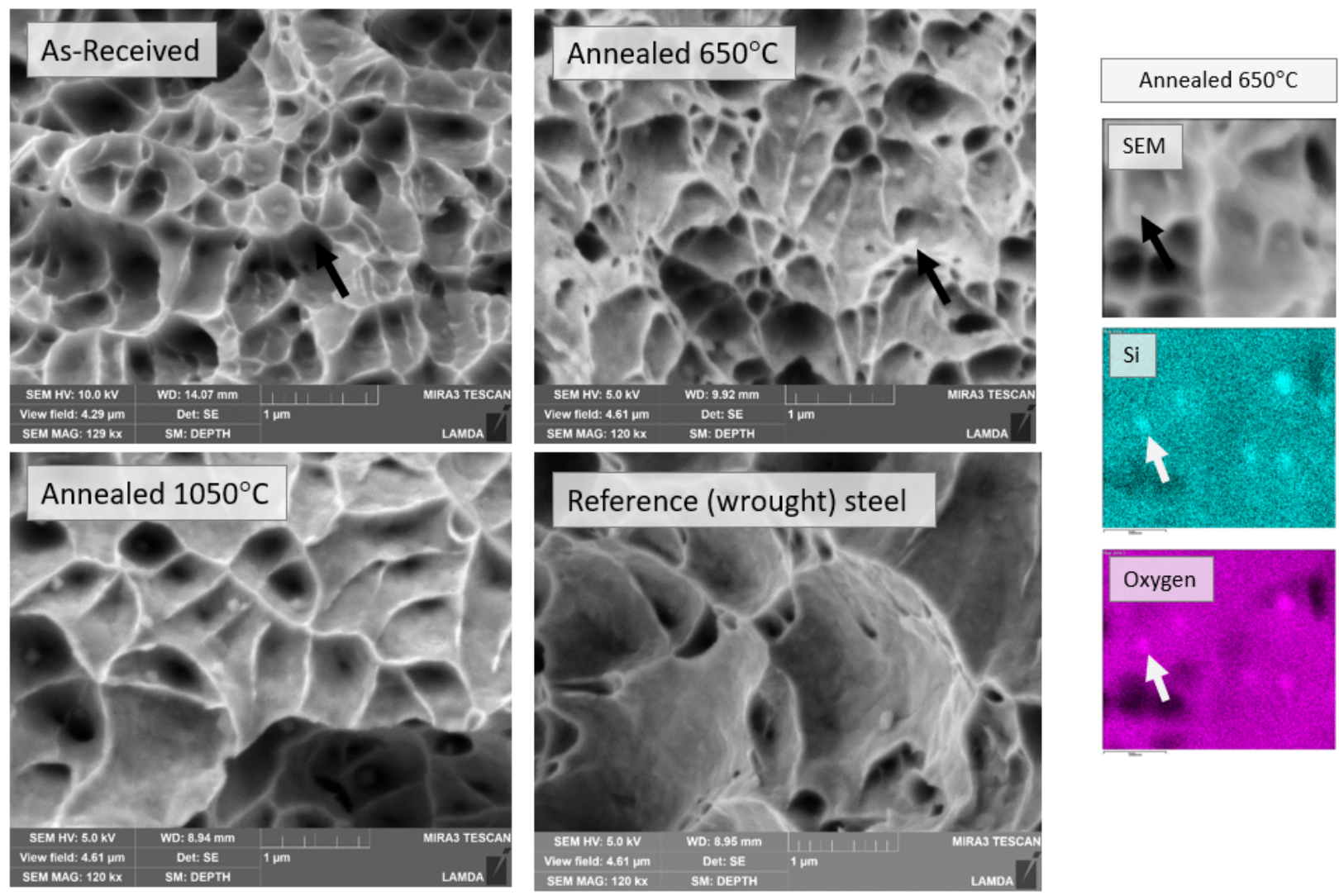

Figure 5-23. High magnification SEM images showing the presence of small, round-shaped particles (indicated by black arrows) inside the dimples. The reference steel has mostly clear, particle-free dimples, with only one fine object visible. 


\section{PROGRESSES IN ONGOING TASKS}

\subsection{HFIR Irradiation of AM 316L}

Neutron irradiation of six rabbit capsules are being carried out at HFIR to obtain the target displacement damage of $0.2,2$, and 8 dpa at 300 and $600^{\circ} \mathrm{C}$. All 316L specimens loaded in the first irradiation campaign for the TCR program are the SS-J2 specimens; their pre-irradiation data are reported in sections 3 and 5 in this document. Irradiation of the lowest dose has been completed, and post-irradiation evaluation is being prepared. Mechanical testing after neutron irradiation will be performed later in the fiscal year, and the results will be compared with the datasets presented in this report. Each capsule contains 32 SS-J2 tensile specimens-24 AM 316L specimens and 8 reference 316L specimens-as summarized in Table 6-1.

Table 6-1. SS-J2 tensile specimens being irradiated in ongoing irradiation experiment

\begin{tabular}{|c|c|c|c|}
\hline Capsule ID & $\begin{array}{c}\text { Irradiation temperature } \\
\qquad\left({ }^{\circ} \mathrm{C}\right)\end{array}$ & $\begin{array}{l}\text { Irradiation dose } \\
\text { (dpa) }\end{array}$ & Materials (\# of SS-J3 specimens) \\
\hline GTCR01 & 300 & 0.2 & $\begin{array}{l}\text { AM 316L as-built (8) } \\
\text { AM 316L stress-relieved (8) } \\
\text { AM 316L solution-annealed (8) } \\
\text { WT 316L (8) }\end{array}$ \\
\hline GTCR02 & 300 & 2 & $\begin{array}{l}\text { AM 316L as-built (8) } \\
\text { AM 316L stress-relieved (8) } \\
\text { AM 316L solution-annealed (8) } \\
\text { WT 316L (8) }\end{array}$ \\
\hline GTCR03 & 300 & 8 & $\begin{array}{l}\text { AM 316L as-built (8) } \\
\text { AM 316L stress-relieved (8) } \\
\text { AM 316L solution-annealed (8) } \\
\text { WT 316L (8) }\end{array}$ \\
\hline GTCR04 & 900 & 0.2 & $\begin{array}{l}\text { AM 316L as-built (8) } \\
\text { AM 316L stress-relieved (8) } \\
\text { AM 316L solution-annealed (8) } \\
\text { WT 316L (8) }\end{array}$ \\
\hline GTCR05 & 900 & 2 & $\begin{array}{l}\text { AM 316L as-built (8) } \\
\text { AM 316L stress-relieved (8) } \\
\text { AM 316L solution-annealed (8) } \\
\text { WT 316L (8) }\end{array}$ \\
\hline GTCR06 & 900 & 8 & $\begin{array}{l}\text { AM 316L as-built (8) } \\
\text { AM 316L stress-relieved (8) } \\
\text { AM 316L solution-annealed (8) } \\
\text { WT 316L (8) }\end{array}$ \\
\hline
\end{tabular}

In the pre-irradiation testing campaign, 54 SS-J2 specimens were tested in the temperature range of RT $-600{ }^{\circ} \mathrm{C}$, as reported in the Section 3. The $192 \mathrm{SS}-\mathrm{J} 2$ specimens listed in Table 6-1 will be tested in the same temperature range. If the dose rate allows, the same load frame in the LAMDA facility that was used for the baseline testing will be used for this post-irradiation testing. Otherwise, one test frame in the 3025E hot cell will be used. Some of these irradiated SS-J2 tensile specimens will also be used for microscopy and other property measurements. 


\subsection{Ion Irradiation Experiment}

Ion irradiation is underway at the Ion Beam Materials Laboratory at the University of Tennessee, Knoxville, to obtain information on microstructural evolution during irradiation to 2, 8 and 80 dpa at 300 and $600{ }^{\circ} \mathrm{C}$. AM 316L, WT 316L, and AM IN 718 specimens are irradiated with $5 \mathrm{MeV} \mathrm{Ni}$ in different materials conditions: AM 316L in as-built and stress-relieved conditions, WT 316L in standard condition, and AM IN718 in as-built condition. Microstructural characterization is being conducted on some of the specimens that have already been irradiated using SEM, TEM, and STEM. Note that this ion irradiation campaign also includes irradiation of 3D-printed $\mathrm{SiC}$ and chemical vapor deposition $\mathrm{SiC}$ materials.

\subsection{Small Ball Punch Testing of 316L and IN718 Alloys}

Small ball punch testing using thin, disc-shaped specimens is one of the most used miniature mechanical testing techniques. One of the merits of this testing technique is that it can generate a large amount of mechanical property data with a small spatial resolution if a thin printed sheet sample is used. This approach can also minimize machining cost. This task was proposed to efficiently produce mechanical properties data from 3D-printed metal sheets to provide feedback or working data to the manufacturing and/or digital platform tasks in the TCR program.

Five (5) sheet samples were prepared for this testing: two AM 316L sheets printed by laser 1 and laser 2 in the Concept Laser M2; two AM IN718 sheets in the as-built and precipitation-hardened conditions; WT 316L sheets for reference material data. For each material, 60-120 small punch data curves will be produced and analyzed. Figure 6-1 displays the second AM 316L sheet from which 102 tests have been performed.
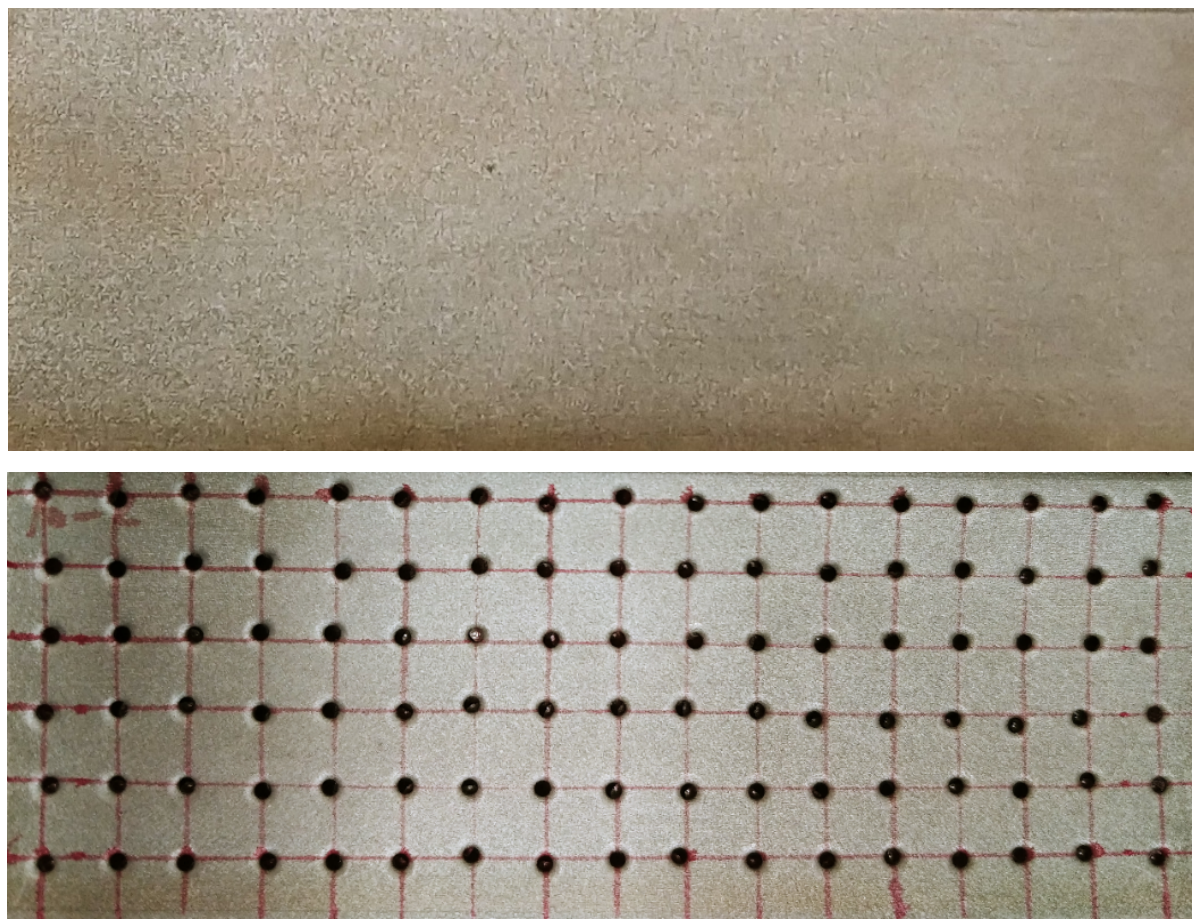

Figure 6-1. A thin AM 316L sheet $(0.5 \times 45 \times 120 \mathrm{~mm})$ before (top) and after (bottom) small ball punch testing. 


\subsection{Build of 316L by Wire-Arc Additive Manufacturing}

Wire-arc additive manufacturing (WAAM) using heat-resistant steel wire is considered as an alternative route for manufacturing relatively large reactor components. In this fiscal year, an attempt is being made to produce trial thick-wall blocks from commercial $316 \mathrm{~L}$ wire and to characterize them for basic properties. Trial blocks with an irregular L-shape with $\sim 1.5$ inch thick were printed with a commercial 316L SS wire which consisted of two different print patterns: one with a relatively short and continuously changing travel length, and the other with a longer, consistent travel length, as shown in Figure 6-2. Three blocks were printed at different peak current and travel speeds.

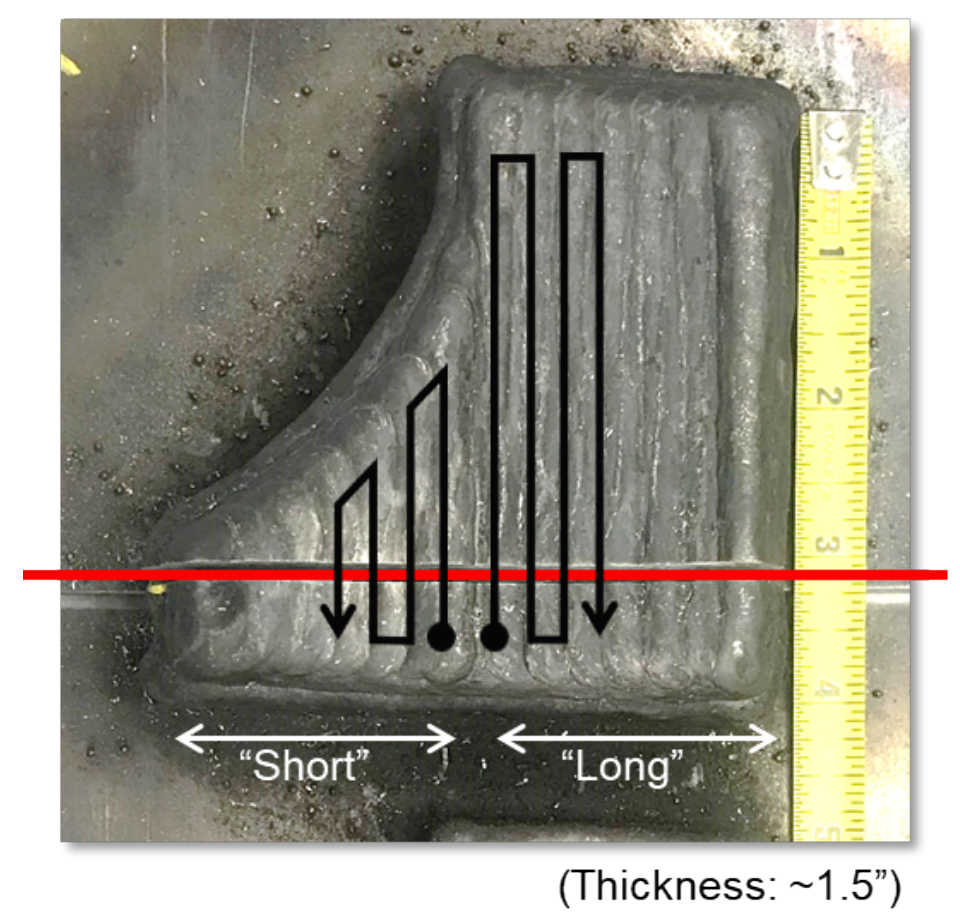

Figure 6-2. A trial L-shape block made of 316L SS. Black lines indicates printing paths, and the red line contains the locations for metallographic characterization.

Figure 6-3 illustrates the color contour maps of 2D hardness distribution in the cross sections of block 265 in Figure 6-3(a) and the Rapid X block in Figure 6-3(b). The hardness distribution is relatively homogeneous and is mostly in the range of $\pm 20-30$ Vickers number (HV) from bottom to top in each area, showing no strong correlation with the layered structure of the printed components. No significant difference was observed in the hardness between the short and long travel lengths, although a lot of HV data are missing in the long area in block 265. This is because the test could not be performed on the cracks during printing. The average HV of block 265 was $\sim 180 \mathrm{HV}$, whereas the average HV of the Rapid X block was $\sim 165 \mathrm{HV}$.

Because no phase transformation occurs in the 316L alloys, the cyclic heating-cooling process during printing would not strongly impact the hardness variation. Potential sources of the hardness variation would be the distribution of delta-ferrite, solidification of the cell structure, a trapped 
dislocation network, and inclusions. Rapid X block showed overall lower hardness than block 265 . This might be due to the higher annealing effect that occurred in the Rapid X block during printing. More annealing can promote dissolution of delta-ferrite and annihilation of the cell structure or dislocation network, which would monotonically decrease the hardness. Further microstructural characterization to correlate with the hardness distribution is currently in progress.

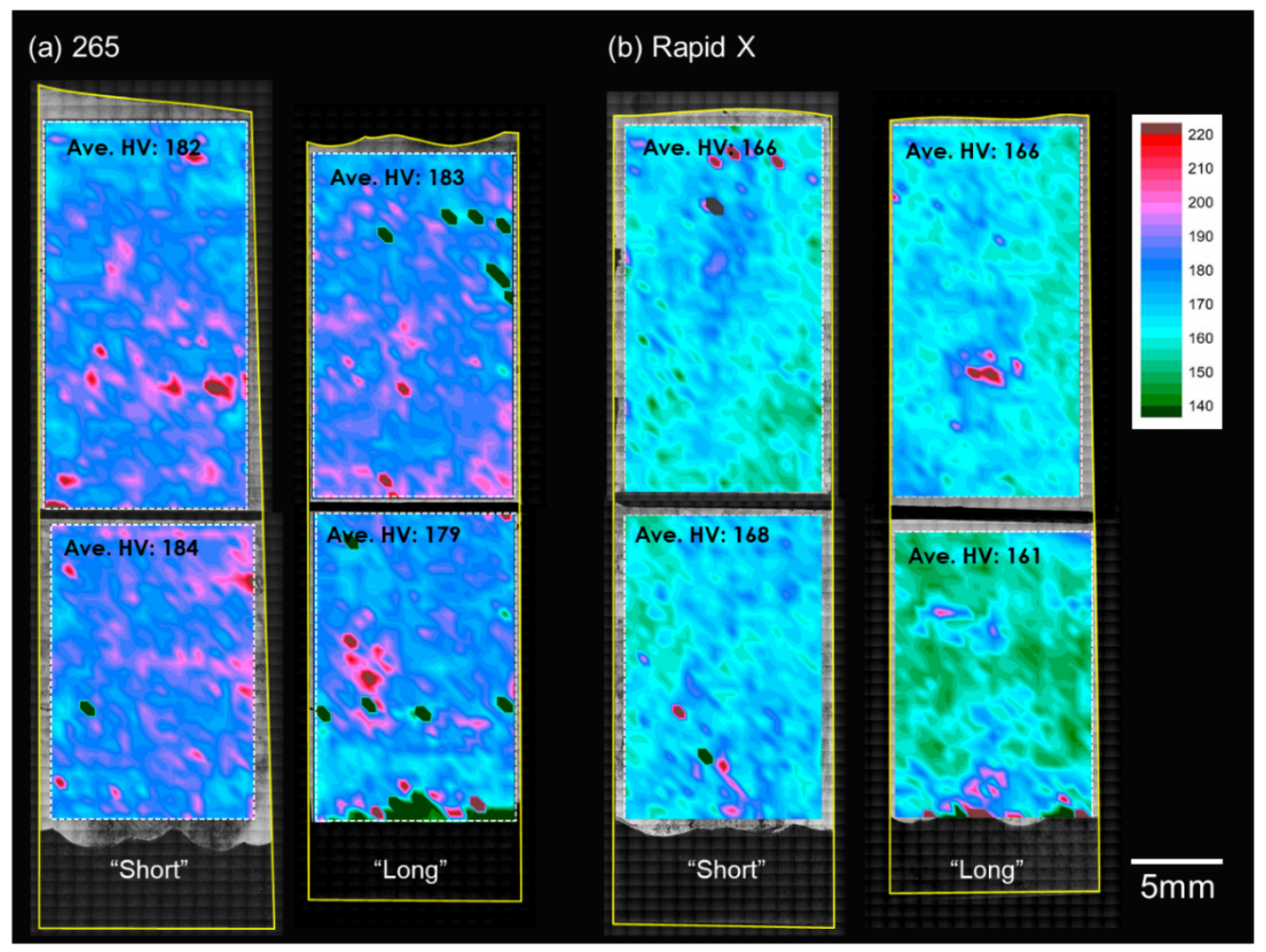

Figure 6-3. Color contour maps showing 2D hardness distribution in the cross sections of the as-printed 316L SS block with printing conditions of (a) block 265 and (b) the Rapid X block.

Room-temperature tensile properties of the as-printed 316L SS with Rapid X were evaluated by using miniature subsized dog-bone shaped SS-3 tensile specimens (gage section dimension: $0.76 \times$ $1.52 \times 7.62 \mathrm{~mm}$ ), machined along the built direction parallel to the tensile axis. Table 6-2 summarizes the tensile properties of as-printed 316L SS from the Rapid X block. There is no significant difference in the YSs and UTSs between the short and long travel lengths, and the values are very close to those in American Iron and Steel Institute (AISI) 316L annealed bar (205 and $515 \mathrm{MPa}$, respectively). TEs were 38 and $32 \%$ in the short and long sections, respectively, which is significantly lower than those in AISI $316 \mathrm{~L}(60 \%)$.

Table 6-2. RT tensile properties of as-printed 316L SS with Rapid X

\begin{tabular}{cccc}
\hline Sample & YS (MPa) & UTS (MPa) & TE (\%) \\
\hline Short & $239 \pm 5$ & $500 \pm 8$ & $38 \pm 3$ \\
Long & $219 \pm 10$ & $497 \pm 3$ & $32 \pm 4$ \\
\hline
\end{tabular}




\section{SUMMARY AND CONCLUSIONS}

Mechanical properties were evaluated for AM 316L SS in various material and testing conditions to construct a baseline mechanical property database. For the fiscal year, significant amounts of tensile properties data, as well as creep deformation and life data, were obtained for the AM $316 \mathrm{~L}$ SS in different post-build heat treatment conditions and for the WT 316L SS in reference condition. Microstructural evolution during deformation and fracture was also examined in detail using in-situ the SEM testing method and x-ray scattering and tomography techniques. The main observations and conclusions derived from the testing and examination tasks are summarized below.

Regardless of different post-build heat treatments, the strength and ductility of AM 316L SS were high enough to satisfy the standard requirements for the alloy (i.e., $205 \mathrm{MPa}$ for YS, $485 \mathrm{MPa}$ for UTS, and 35\% for TE at RT). In tensile properties, a significant effect of post-build heat treatment was measured in the low-strain region only, and its effect became much less in the later part of deformation. Both the strength and the ductility of the AM 316L and WT 316L SSs decreased with test temperature.

Thus far, creep testing has been performed at 550 and $650{ }^{\circ} \mathrm{C}$ in various stress conditions. Testing will be continued in a wider range of temperature and stress conditions to achieve a complete matrix for producing full range creep models. Microstructural characterization was also performed to assess the effect of the post-build heat treatment on the creep behavior of AM 316L SS. Due to the high-porosity and fine-grained microstructure, the creep deformation in AM 316L SSs occurred at a slightly higher rate when compared with the wrought $316 \mathrm{~L}$.

The in-situ deformation testing in SEM and in a high-energy $x$-ray device indicated that the characteristic features from AM, such as complex and fine grain morphology, dislocation network, pores and silicon oxides, evolve and exert various roles during deformation and fracture. It was obvious that the interaction of dislocation slips with pores and oxides resulted in accelerated cracking. Overall, however, their influence on mechanical performance was limited, as the excellent ductility of $316 \mathrm{~L} \mathrm{SS}$ helps avoid any premature fracture. 


\section{REFERENCES}

[1] K.G. Field, J. Simpson, M. N. Gussev, H. Wang, M. Li, X. Zhang, X. Chen, T. Koyanagi, K. Kane, A. Marquez Rossy, M. Balooch, and K.A. Terrani, Handbook of Advanced Manufactured Material Properties from TCR Structure Builds at ORNL - FY19, ORNL/TM-2019/1328, Oak Ridge National Laboratory, 2019. https://doi.org/M3CT19OR06090121.

[2] B. M. Morrow, T. J. Lienert, C. M. Knapp, J. O. Sutton, M. J. Brand, R. M. Pacheco, V. Livescu, J. S. Carpenter, and G. T. Gray, "Impact of Defects in Powder Feedstock Materials on Microstructure of 304L and 316L Stainless Steel Produced by Additive Manufacturing," Metall. Mater. Trans. A. 49 (2018) 3637-3650. https://doi.org/10.1007/s11661-018-4661-9.

[3] T. Ronneberg, C. M. Davies, and P. A. Hooper, "Revealing Relationships between Porosity, Microstructure and Mechanical Properties of Laser Powder Bed Fusion 316L Stainless Steel through Heat Treatment," Mater. Des. 189 (2020) 108481. https://doi.org/https://doi.org/10.1016/j.matdes.2020.108481.

[4] U. S. Bertoli, B .E. MacDonald, and J. M. Schoenung, "Stability of Cellular Microstructure in Laser Powder Bed Fusion of 316L Stainless Steel," Mater. Sci. Eng. A. 739 (2019) 109117. https://doi.org/https://doi.org/10.1016/j.msea.2018.10.051.

[5] A. J. Birnbaum, J. C. Steuben, E. J. Barrick, A. P. Iliopoulos, and J. G. Michopoulos, "Intrinsic Strain Aging, $\Sigma 3$ Boundaries, and Origins of Cellular Substructure in Additively Manufactured 316L, Addit. Manuf. 29 (2019) 100784. https://doi.org/https://doi.org/10.1016/j.addma.2019.100784.

[6] E. Garlea, H. Choo, C. C. Sluss, M. R. Koehler, R. L. Bridges, X. Xiao, Y. Ren, and B. H. Jared, "Variation of Elastic Mechanical Properties with Texture, Porosity, and Defect Characteristics in Laser Powder Bed Fusion 316L Stainless Steel," Mater. Sci. Eng. A. 763 (2019) 138032. https://doi.org/https://doi.org/10.1016/j.msea.2019.138032.

[7] T. Pinomaa, M. Lindroos, M. Walbrühl, N. Provatas, and A. Laukkanen, "The Significance of Spatial Length Scales and Solute Segregation in Strengthening Rapid Solidification Microstructures of 316L Stainless Steel," Acta Mater. 184 (2020) 1-16. https://doi.org/https://doi.org/10.1016/j.actamat.2019.10.044.

[8] D. Kong, X. Ni, C. Dong, L. Zhang, C. Man, X. Cheng, and X. Li, “Anisotropy in the Microstructure and Mechanical Property for the Bulk and Porous 316L Stainless Steel Fabricated via Selective Laser Melting," Mater. Lett. 235 (2019) 1-5. https://doi.org/https://doi.org/10.1016/j.matlet.2018.09.152.

[9] J. Lin, F. Chen, X. Tang, J. Liu, S. Shen, and G. Ge, "Radiation-Induced Swelling and Hardening of 316L Stainless Steel Fabricated by Selected Laser Melting," Vacuum. 174 (2020) 109183. https://doi.org/https://doi.org/10.1016/j.vacuum.2020.109183.

[10] M. Song, M. Wang, X. Lou, R. B. Rebak, and G. S. Was, "Radiation Damage and Irradiation-Assisted Stress Corrosion Cracking of Additively Manufactured 316L Stainless 
Steels," J. Nucl. Mater. 513 (2019) 33-44.

https://doi.org/https://doi.org/10.1016/j.jnucmat.2018.10.044.

[11] T. Kurzynowski, K. Gruber, W. Stopyra, B. Kuźnicka, and E. Chlebus, Correlation between Process Parameters, Microstructure and Properties of 316 L Stainless Steel Processed by Selective Laser Melting," Mater. Sci. Eng. A. 718 (2018) 64-73. https://doi.org/https://doi.org/10.1016/j.msea.2018.01.103.

[12] C. R. Brinkman, Elevated-Temperature Mechanical Properties of an Advanced Type 316 Stainless Steel, United States, Oak Ridge National Laboratory, ORNL/CP-101053, 1999, http://inis.iaea.org/search/search.aspx?orig_q=RN:32035007.

[13] S. Li, J. Hu, W.-Y. Chen, J. Yu, M. Li, and Y. Wang, "Evolution of Cellular Dislocation Structures and Defects in Additively Manufactured Austenitic Stainless Steel under Ion Irradiation," Scr. Mater. 178 (2020) 245-250. https://doi.org/https://doi.org/10.1016/j.scriptamat.2019.11.036.

[14] Y.M. Wang, T. Voisin, J.T. McKeown, J. Ye, N. P. Calta, Z. Li, Z. Zeng, Y. Zhang, W. Chen, T. T. Roehling, R. T. Ott, M. K. Santala, P. J. Depond, M. J. Matthews, A. V. Hamza, and T. Zhu, "Additively Manufactured Hierarchical Stainless Steels with High Strength and Ductility," Nat. Mater. 17 (2018) 63-71. https://doi.org/10.1038/nmat5021.

[15] Z. Sun, X. Tan, S. B. Tor, and C. K. Chua, "Simultaneously Enhanced Strength and Ductility for 3D-Printed Stainless Steel 316L by Selective Laser Melting, NPG Asia Mater. 10 (2018) 127-136. https://doi.org/10.1038/s41427-018-0018-5.

[16] X. Zhang, M. Li, J.-S. Park, P. Kenesei, J. Almer, C. Xu, and J. F. Stubbins, "In Situ HighEnergy X-ray Diffraction Study of Tensile Deformation of Neutron-Irradiated Polycrystalline Fe-9\%Cr alloy, Acta Mater. 126 (2017) 67-76. https://doi.org/https://doi.org/10.1016/j.actamat.2016.12.038.

[17] T. Ungár and A. Borbély, "The Effect of Dislocation Contrast on X-ray Line Broadening: A New Approach to Line Profile Analysis, Appl. Phys. Lett. 69 (1996) 3173-3175. https://doi.org/10.1063/1.117951.

[18] Y. Zhong, L. Liu, S. Wikman, D. Cui, and Z. Shen, "Intragranular Cellular Segregation Network Structure Strengthening 316L Stainless Steel Prepared by Selective Laser Melting," J. Nucl. Mater. 470 (2016) 170-178. https://doi.org/https://doi.org/10.1016/j.jnucmat.2015.12.034. 